\title{
EFEITO DO GESSO E DE FERTILIZANTES NITROGENADOS NA PRODUÇÃO E UTILIZAÇÃO DE MACRONUTRIENTES PELO MILHO "SAFRINHA"
}

\author{
RAFFAELLA ROSSETTO \\ Engenheiro Agrônomo
}

Orientador: Prof. Dr. TAKASHI MURAOKA

\begin{abstract}
Tese apresentada à Escola Superior de Agricultura "Luiz de Queiroz", da Universidade de São Paulo, para obtenção do título de Doutor em Agronomia, Área de Concentração: Solos e Nutrição de Plantas.
\end{abstract}

P I R A C I C A B A

Estado de São Paulo - Brasil

Maio - 1995 


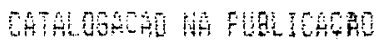

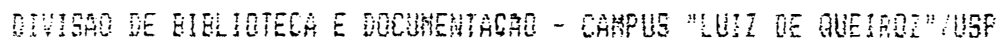

Foscetto. Ratfenlly

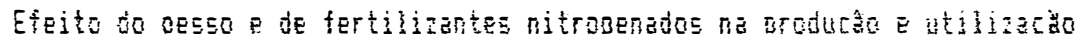

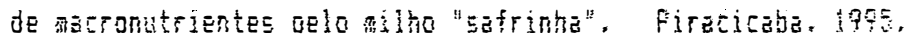

15is. Hus.

Tese - Eapio

Gibljuorofiz.

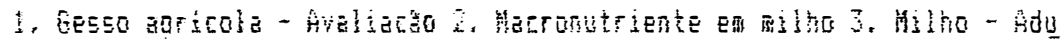

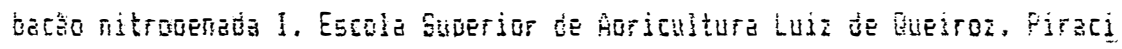
cầ 


\title{
EFEITO DO GESSO E DE FERTILIZANTES NITROGENADOS NA PRODUÇÃO E UTILIZAÇÃO DE MACRONUTRIENTES PELO MILHO "SAFRINHA"
}

\author{
Raffaella Rossetto
}

Aprovada em: 28/06/1995

Comissão Julgadora:

Prof. Dr. Takashi Muraoka

Prof. Dr. Jorge de Castro Kiehl

Prof. Dr. José Orlando Filho

Prof. Dr. Antonio Enedi Boaretto

Dr. Rivail S. Lourenço

CENA/USP
ESALQ/USP
UFSCar
CENA/USP
EMBRAPA/CNPF

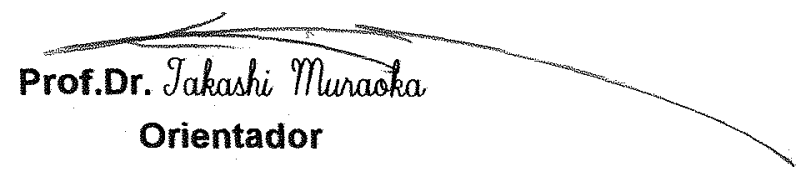


Milho...

Punhado plantado nos quintais.

Talhões fechados pelas roças,

Entremeado nas lavouras.

Em qualquer parte da Terra

um homem estará sempre plantando, recriando a Vida.

Recomeçando o Mundo.

Cora Coralina

Ao guido

$$
\text { Dérgio, }
$$

nossas famílias e a todas as pessoas

que acreditam que a vida pode ser feita de coisas simples, como o amor, o trabalho, a amizade, lealdade........ 


\section{Agradecimentos}

Este trabalho foi realizado com a presteza e colaboração de várias pessoas. A elas todo o meu reconhecimento. Em especial, agradeço à:

- Dr. Takashi Muraoka, pela confiança, amizade e orientação, demonstrados não apenas durante a execução deste trabalho, mas em todo o período de convivência na Seção de Fertilidade do Solo do CENA;

- Ao Professor Dr. Geraldo Victorino de França, em nome do Depto. de Ciências do Solo-ESALQ, pela gentileza e aceitação a todos os meus pedidos;

- Aos professores e amigos Dr. Antonio Enedi Boaretto e Maria Emilia Mattiazzo-Prezotto pelo incentivo, exemplo e por estarem sempre dispostos a colaborar;

- Aos amigos João Odemir Salvador, Gilberto de Assis Ribeiro e Newton Paulo de Souza Falcão, pela ajuda nas fases mais dificeis de instalação do experimento e coleta de amostras de solo e pela convivência sempre alegre e produtiva;

- A IAEA que através do suporte financeiro a esta pesquisa e do Curso de Treinamento em Técnicas Nucleares, muito contribuiu para minha formação profissional;

- Às instituições Usina Costa Pinto S/A e ESALQ-Fazenda Areão pelo apoio na instalação do experimento no campo;

- À Marileuza A. Bassi Elias, Sandra T. Pereira dos Santos e Henriqueta M. Gimenez Fernandes, pelo grande auxílio nas análises químicas e todos os procedimentos de laboratório;

- À Dra. Sonia M. de Stefano Piedade pela orientação nas análises estatísticas;

- Aos amigos Maria Aparecida Callegaro e Izael Fortunato Jr., pela ajuda na digitação dos dados e elaboração do texto final e pela paciência com as inúmeras correções das falhas;

- À Marilia Ribeiro Garcia Henyei pela normatização da bibliografia citada;

- Às Instituições Centro de Energia Nuclear na Agricultura CENA-USP; Instituto Agronômico de Campinas-IAC e Estação Experimental de Piracicaba-IAC, por facilitar sobremaneira minhas atividades durante o curso de Pós-graduação;

- Ao Sérgio de Oliveira Moraes e toda a nossa familia, pelo apoio constante. 
Í N D I C E

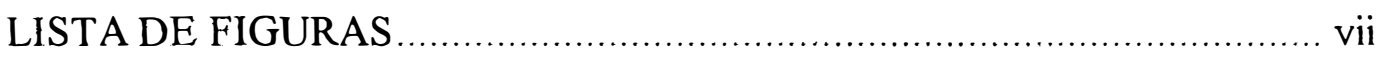

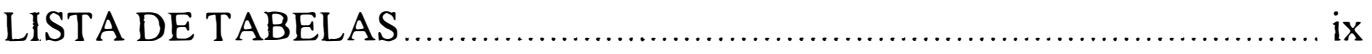

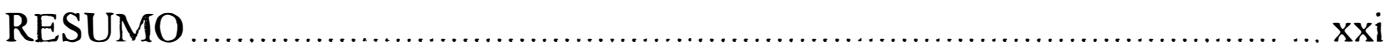

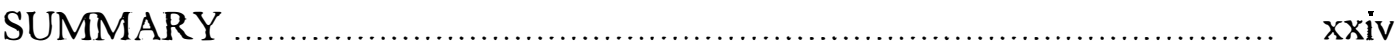

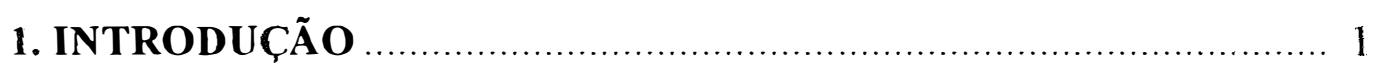

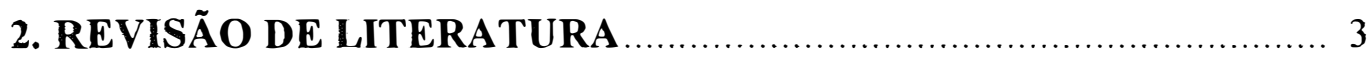

2.1. O Gesso Agrícola ....................................................................... 3

2.2. O Gesso Agrícola e a Melhoria do Ambiente Radicular ...................... 5

2.3. O Gesso e o Movimento de Íons no Solo ........................................ 9

2.4. Produção de Milho no Brasil e Importância de Milho Safrinha ........... 12

2.5. Absorção e Utilização do Nitrogênio pelo Milho................................. 13

2.6. Gesso, Sistema Radicular do Milho e Utilização de Nitrogênio .......... 17 


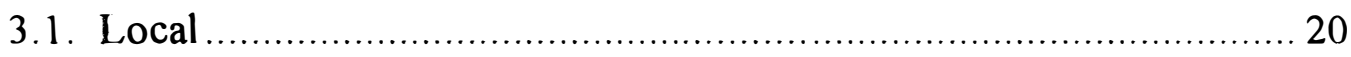

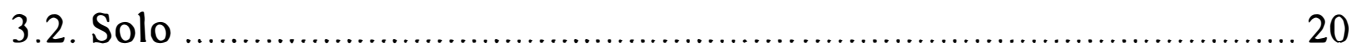

3.3. Área e Delineamento Experimental ................................................ 23

3.4.Instalação e Condução do Experimento ……………......................... 25

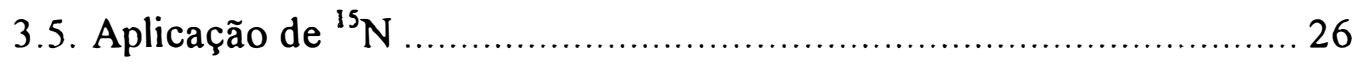

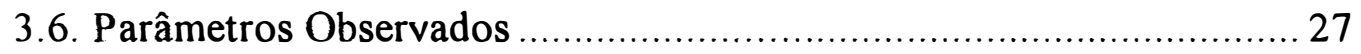

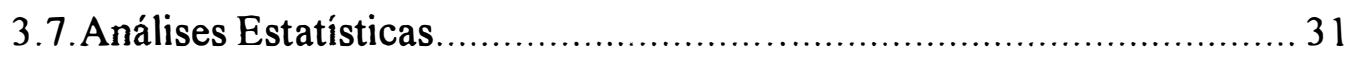

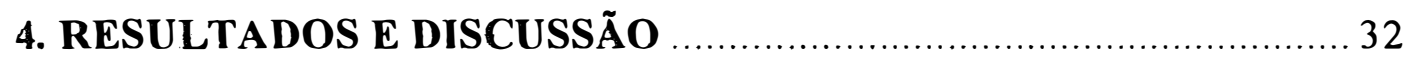

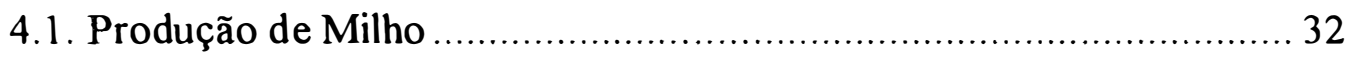

4.2. Teores de Macronutrientes na Matéria Seca de Folhas + Colmos ....... 41

4.3. Quantidades Acumuladas de Macronutrientes na Matéria Seca de

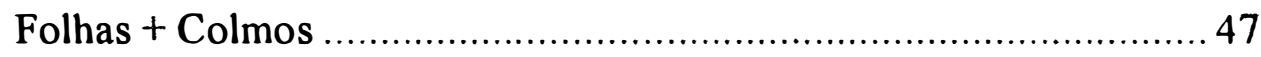

4.4. Teores e Conteúdos de Macronutrientes nos Grãos de Milho ............. 53

4.5. Conteúdo de Nutrientes nas Folhas, Colmos e Grãos .......................... 60

4.6. Efeitos da Aplicação do Gesso e Fertilizantes Nitrogenados no Solo.. 67 
4.6.1. Macronutrientes no Solo 67

4.6.2.Parâmetros de Acidez e Retenção de Cátions ......................... 81

4.7. Eficiência de Utilização do Nitrogênio . 95

5. CONCLUSÕES 102

6. LITERATURA CITADA 104 


\section{LISTA DE FIGURAS}

\section{Figura}

Página

1 Balanço hídrico da cultura de milho "safrinha"em Piracicaba (SP) no período de 5 de março a 3 de setembro de 1993.

2 Produção estimada de grãos de milho $(\mathrm{kg} / \mathrm{ha})$ para os diversos tratamentos estudados. 40

3 Médias dos teores de N, P, K, Ca, Mg e S obtidos na parte aérea das plantas de milho (folhas + colmos), considerando as fontes nitrogenadas independente das doses, na presença ou ausência de gesso.

4 Médias dos acúmulos de $\mathrm{N}, \mathrm{P}, \mathrm{K}, \mathrm{Ca}, \mathrm{Mg}$ e $\mathrm{S}$ obtidos na parte aérea das plantas de milho (folhas + colmos), considerando as fontes nitrogenadas independente das doses, na presença ou ausência de gesso.

5 Médias dos acúmulos de $\mathrm{N}, \mathrm{P}, \mathrm{K}, \mathrm{Ca}, \mathrm{Mg}$ e $\mathrm{S}$ obtidos na parte aérea das plantas de milho (folhas + colmos + grãos), considerando as fontes nitrogenadas independente das doses, na presença ou ausência de gesso. 
6 Curvas de regressão entre os parâmetros $\mathrm{N}$ absorvido pelo milho e produção de grãos 66

7 Médias dos teores de $\mathrm{N}(\mathrm{mg} / \mathrm{kg}$ solo) obtidos nas três profundidades analisadas, como efeito do gesso, independente das fontes e doses de nitrogênio estudadas.

8 Médias dos teores de $\mathrm{P}$ e S-SO ${ }_{4}^{-2}\left(\mathrm{mg} / \mathrm{dm}^{3}\right.$ solo) obtidos nas três profundidades analisadas, como efeito do gesso, independente das fontes e doses de nitrogênio estudadas.

9 Médias dos teores de $\mathrm{K}, \mathrm{Ca}$ e $\mathrm{Mg}\left(\mathrm{mmol}_{\mathrm{c}} / \mathrm{dm}^{3}\right.$ solo) obtidos nas três profundidades analisadas, como efeito do gesso, independente das fontes e doses de nitrogênio estudadas.

10 Médias da saturação da CTC em alumínio ( $\mathrm{m} \%)$ obtidas nas tres profundidades analisadas, como efeito do gesso, independente das fontes e doses de nitrogênio estudadas 86

11 Percentagem dos fertilizantes nitrato de cálcio e sulfato de amônio que foram utilizados pelas plantas de milho e permaneceram no solo ao final do experimento. 


\section{LISTA DE TABELAS}

Tabela

Página

1 Análise química do Latossolo Vermelho-escuro, textura argilosa, onde foi instalado o experimento

2 Composição granulométrica e densidade aparente do solo utilizado no experimento

3 Tratamentos estudados no experimento e suas respectivas siglas

4 Valores médios de número de espigas, massa seca de espigas, massa seca de grãos, massa seca de folhas + colmos $\left(\mathrm{kg}\right.$. parcela $\left.^{-1}\right)$ e produção relativa, obtidos para os diversos tratamentos.

5 Médias de massa seca de folhas + colmos e grãos, (kg. parcela $^{-1}$ ) obtidas nas parcelas de milho, considerando os tratamentos com ou sem gesso, independente das fontes e doses de nitrogênio.

6 Médias de massa seca de folhas + colmos e grãos, (kg.parcela ${ }^{-1}$ ) obtidas nas parcelas de milho, considerando as fontes nitrogenadas, independente das doses de nitrogênio e da aplicação de gesso. 
7 Médias de massa seca de folhas + colmos e grãos, (kg.parcela ${ }^{-1}$ ) obtidas nas parcelas de milho em função das doses de nitrogênio, independente das fontes e da aplicação de gesso.

8 Valores do Teste $\mathrm{F}$ a $5 \%$ de probabilidade para as interações entre gesso, fonte de nitrogênio e dose de nitrogênio para os parâmetros massa seca de folhas + colmos e grãos.

9 Médias dos teores de macronutrientes na parte aérea das plantas de milho (g.kg matéria seca ${ }^{-1}$ ), obtidas nos diversos tratamentos.

10 Médias dos teores de macronutrientes ( $\mathrm{g} . \mathrm{kg}$ de matéria seca $^{-1}$ ), na parte aérea das plantas de milho, considerando o efeito do gesso, independente das fontes e doses de nitrogênio aplicadas.

11 Médias dos teores de macronutrientes (g.kg matéria $\operatorname{seca}^{-1}$ ), na parte aérea das plantas de milho, independente da aplicação de gesso e das doses de nitrogênio aplicadas. 44

12 Médias dos teores de macronutrientes (g.kg matéria seca $^{-1}$ ), na parte aérea das plantas de milho, independente da aplicação de gesso e das doses de nitrogênio aplicadas. 
13 Valores de teste $\mathrm{F}$ a $5 \%$ ou a $1 \%$ de probabilidade para as interações entre gesso, fonte de nitrogênio e dose de nitrogênio, para os teores de $\mathrm{N}, \mathrm{P}, \mathrm{K}, \mathrm{Ca}, \mathrm{Mg}$ e $\mathrm{S}$ na matéria seca da parte aérea do milho.

14 Médias dos conteúdos de macronutrientes (g . kg matéria seca de folhas + colmos $^{-1}$ ), acumulados pelas plantas de milho nos diversos tratamentos.

15 Médias dos conteúdos de macronutrientes (g.kg total de matéria seca de folhas $+\operatorname{colmos}^{-1}$ ), acumulados pelas plantas de milho nas parcelas, considerando os tratamentos com ou sem gesso, independente das fontes e doses de nitrogênio.

16 Médias dos conteúdos de macronutrientes (g.kg total de matéria seca de folhas $+\operatorname{colmos}^{-1}$ ), acumulados pelas plantas de milho nas parcelas, em função das fontes nitrogenadas, independente das doses de $\mathrm{N}$ e da aplicação de gesso.

17 Médias dos conteúdos de macronutrientes (g.kg total de matéria seca de folhas $+\operatorname{colmos}^{-1}$ ), acumulados pelas plantas de milho nas parcelas, em função das doses de nitrogênio, independente das fontes e da aplicação de gesso. 50 
18 Valores do teste $\mathrm{F}$ a $5 \%$ de probabilidade para as interações entre gesso, fonte de nitrogênio e dose de nitrogênio, para os conteúdos de macronutrientes nas folhas + colmos de milho.

19 Médias dos teores de macronutrientes nos grãos de milho (g.kg matéria seca de grãos $^{-1}$ ), obtidas nos diversos tratamentos

20 Médias dos acúmulos de macronutrientes nos grãos de milho (g.kg de grãos total da parcela $^{-1}$ ), obtidas nos diversos tratamentos.

21 Médias dos conteúdos de macronutrientes nos grãos de milho (g.kg de grãos total da parcela ${ }^{-1}$ ), considerando os tratamentos com ou sem gesso, independente das fontes e doses de nitrogênio aplicadas. 56

22 Médias dos conteúdos de macronutrientes nos grãos de milho (g.kg de grãos total da parcela ${ }^{-1}$ ), considerando as fontes nitrogenadas, independente das doses de $\mathrm{N}$ e da aplicação de gesso.

23 Médias dos conteúdos de macronutrientes nos grãos de milho (g.kg de grãos total da parcela ${ }^{-1}$ ), considerando as doses de nitrogênio, independente das fontes nitrogenadas e da aplicação de gesso. 
24 Valores de teste $\mathrm{F}$ a $5 \%$ de probabilidade para as interações entre gesso, fonte de nitrogênio e dose de nitrogênio, para os conteúdos de $\mathrm{N}, \mathrm{P}, \mathrm{K}, \mathrm{Ca}, \mathrm{Mg}$ e $\mathrm{S}$ nos grãos de milho.

25 Médias dos conteúdos de macronutrientes (g/parcela), acumulados pelas plantas de milho (folhas+colmos+grãos), nos diversos tratamentos 62

26 Médias dos conteúdos de macronutrientes (g/parcela), acumulados pelas plantas de milho (folhas+colmos+grãos), considerando os tratamentos com ou sem gesso, independente das fontes e doses de nitrogênio

27 Médias dos conteúdos de macronutrientes (g/parcela), acumulados pelas plantas de milho (folhas+colmos+grãos), em função das fontes nitrogenadas, independente das doses de $\mathrm{N}$ e da aplicação de gesso

28 Médias dos conteúdos de macronutrientes (g/parcela), acumulados pelas plantas de milho (folhas+colmos+grãos), em função das doses de nitrogênio, independente das fontes e da aplicação de gesso.

29 Valores do teste $\mathrm{F}$ a $5 \%$ de probabilidade para as interações entre gesso, fonte de nitrogênio e dose de nitrogênio, para conteúdos de macronutrientes, acumulados pelas plantas de milho(folhas+colmos + grãos). 
30 Médias dos teores de macronutrientes obtidos para os diversos tratamentos em amostras de solo retiradas da profundidade $0-30 \mathrm{~cm}$ 68

31 Médias dos teores de macronutrientes obtidos em amostras de solo retiradas da profundidade de 0-30 cm, considerando a aplicação de gesso, independente das doses ou fontes de nitrogênio

32 Médias dos teores de macronutrientes obtidos em amostras de solo retiradas da profundidade de $0-30 \mathrm{~cm}$, considerando as fontes de $\mathrm{N}$, independente das doses de $\mathrm{N}$ ou da aplicação de gesso.

33 Médias dos teores de macronutrientes obtidos em amostras de solo retiradas da profundidade de 0-30 cm, considerando as doses de $\mathrm{N}$, independente das fontes de nitrogênio e da aplicação de gesso.

34 Valores do teste $\mathrm{F}$ a 5 ou $1 \%$ de probabilidade para as interações entre gesso, fonte e dose de nitrogênio para os teores de macronutrientes em amostras de solo retiradas da camada de 0-30 $\mathrm{cm}$ de profundidade 71

35 Médias dos teores de macronutrientes obtidos para os diversos tratamentos em amostras de solo retiradas da profundidade de $30-60 \mathrm{~cm}$. 
36 Médias dos teores de macronutrientes obtidos em amostras de solo retiradas da profundidade de $30-60 \mathrm{~cm}$, considerando a aplicação de gesso, independente das doses ou fontes de nitrogênio.

37 Médias dos teores de macronutrientes obtidos em amostras de solo retiradas da profundidade de $30-60 \mathrm{~cm}$, considerando as fontes de $\mathrm{N}$, independente das doses de $\mathrm{N}$ ou da aplicação de gesso

Médias dos teores de macronutrientes obtidos em amostras de solo retiradas da profundidade de $30-60 \mathrm{~cm}$, considerando as doses de $\mathrm{N}$, independente das fontes de nitrogênio e da aplicação de gesso

39 Valores do teste $\mathrm{F}$ a 5 ou $1 \%$ de probabilidade para as interações entre gesso, fonte de nitrogênio para os teores de macronutrientes em amostras de solo retiradas da camada de $30-60 \mathrm{~cm}$ de profundidade

40 Médias dos teores de macronutrientes obtidos para os diversos tratamentos em amostras de solo retiradas da profundidade de $60-90 \mathrm{~cm}$ 78

41 Médias dos teores de macronutrientes obtidos em amostras de solo retiradas da profundidade de $60-90 \mathrm{~cm}$, considerando a aplicação de gesso, independente das doses ou fontes de nitrogênio 
42 Médias dos teores de macronutrientes obtidos em amostras de solo retiradas da profundidade de $60-90 \mathrm{~cm}$, considerando as fontes de $\mathrm{N}$, independente das doses de $\mathrm{N}$ ou da aplicação de gesso.

43 Médias dos teores de macronutrientes obtidos em amostras de solo retiradas da profundidade de $60-90 \mathrm{~cm}$, considerando as doses de $\mathrm{N}$, independente das fontes de nitrogênio e da aplicação de gesso.

44 Valores do teste $\mathrm{F}$ a 5 ou $1 \%$ de probabilidade para as interações entre gesso, fonte e dose de nitrogênio para os teores de macronutrientes em amostras de solo retiradas da camada de $60-90 \mathrm{~cm}$ de profundidade.

45 Médias dos valores de $\mathrm{pH}, \mathrm{H}^{+}, \mathrm{Al}^{+3}$, soma de bases (S); capacidade de troca catiônica $(\mathrm{T})$, saturação em bases $(\mathrm{V})$ e saturação em alumínio (m) para os diversos tratamentos, em amostras de solo, retiradas da profundidade de 0-30 $\mathrm{cm}$.

46 Médias dos valores de $\mathrm{pH} ; \mathrm{H}^{+} ; \mathrm{Al}^{+3}$; soma de bases (S); capacidade de troca catiônica $(\mathrm{T})$; saturação em bases $(\mathrm{V})$ e saturação em $\mathrm{Al}^{+3}$, obtidos em amostras de solo retiradas da profundidade $0-30 \mathrm{~cm}$, considerando a aplicação de gesso, independente das doses ou fontes de nitrogênio. 
47 Médias dos valores de $\mathrm{pH} ; \mathrm{H}^{+} ; \mathrm{Al}^{+3}$; soma de bases (S); capacidade de troca catiônica $(\mathrm{T})$; saturação em bases (V) e saturação em alumínio (m), obtidos em amostras de solo retiradas da profundidade de $0-30 \mathrm{~cm}$, considerando as fontes de $\mathrm{N}$, independente das doses de $\mathrm{N}$ ou da aplicação de gesso

$48 \quad$ Médias dos valores de $\mathrm{pH} ; \mathrm{H}^{+} ; \mathrm{Al}^{+3}$; soma de bases (S); capacidade de troca catiônica (T); saturação em bases (V) e saturação em alumínio (m), em amostras de solo retiradas da profundidade de 0-30 $\mathrm{cm}$, considerando as doses de $\mathrm{N}$, independente das fontes de nitrogênio e da aplicação de gesso.

49 Valores do teste $\mathrm{F}$ a 5 ou $1 \%$ de probabilidade para as interações entre gesso, fonte e dose de nitrogênio para os parâmetros: valores de $\mathrm{pH} ; \mathrm{H}^{+} ; \mathrm{Al}^{+3}$; soma de bases $(\mathrm{S})$; capacidade de troca catiônica (T); saturação em bases (V) e saturação em alumínio (m); em amostras de solo retiradas da camada de $0-30 \mathrm{~cm}$ de profundidade.

50 Médias dos valores de $\mathrm{pH}, \mathrm{H}^{+}, \mathrm{Al}^{+3}$, soma de bases (S); capacidade de troca catiônica (T), saturação em bases (V) e saturação em alumínio $(\mathrm{m})$ para os diversos tratamentos, em amostras de solo, retiradas da profundidade de 30 $60 \mathrm{~cm}$. 
51 Médias dos valores de $\mathrm{pH} ; \mathrm{H}^{+} ; \mathrm{Al}^{+3}$; soma de bases (S); capacidade de troca catiônica (T); saturação em bases (V) e saturação em Al, obtidos em amostras de solo retiradas da profundidade $30-60 \mathrm{~cm}$, considerando a aplicação de gesso, independente das doses ou fontes de nitrogênio.

52 Médias dos valores de $\mathrm{pH} ; \mathrm{H}^{+} ; \mathrm{Al}^{+3}$; soma de bases (S); capacidade de troca catiônica $(\mathrm{T})$; saturação em bases (V) e saturação em alumínio $(\mathrm{m})$, obtidos em amostras de solo retiradas da profundidade de $30-60 \mathrm{~cm}$, considerando as fontes de $\mathrm{N}$, independente das doses de $\mathrm{N}$ ou da aplicação de gesso

53 Médias dos valores de $\mathrm{pH} ; \mathrm{H}^{+} ; \mathrm{Al}^{+3}$; soma de bases (S); capacidade de troca catiônica $(\mathrm{T})$; saturação em bases (V) e saturação em alumínio (m), em amostras de solo retiradas da profundidade de $30-60 \mathrm{~cm}$, considerando as doses de $\mathrm{N}$, independente das fontes de nitrogênio e da aplicação de gesso.

$54 \quad$ Valores do teste $F$ a 5 ou $1 \%$ de probabilidade para as interações entre gesso, fonte e dose de nitrogênio para os parâmetros: valores de $\mathrm{pH} ; \mathrm{H}^{+} ; \mathrm{Al}^{+3}$; soma de bases (S); capacidade de troca catiônica (T); saturação em bases (V) e saturação em alumínio (m); em amostras de solo retiradas da camada de $30-60 \mathrm{~cm}$ de profundidade. 
55 Médias dos valores de $\mathrm{pH}, \mathrm{H}^{+}, \mathrm{Al}^{+3}$, soma de bases (S); capacidade de troca catiônica (T), saturação em bases (V) e saturação em alumínio $(\mathrm{m})$ para os diversos tratamentos, em amostras de solo, retiradas da profundidade de 60$90 \mathrm{~cm}$.

$56 \quad$ Médias dos valores de $\mathrm{pH} ; \mathrm{H}^{+} ; \mathrm{Al}^{+3}$; soma de bases (S); capacidade de troca catiônica (T); saturação em bases (V) e saturação em $\mathrm{Al}$, obtidos em amostras de solo retiradas da profundidade $60-90 \mathrm{~cm}$, considerando a aplicação de gesso, independente das doses ou fontes de nitrogênio

57 Médias dos valores de $\mathrm{pH} ; \mathrm{H}^{+} ; \mathrm{Al}^{+3}$; soma de bases (S); capacidade de troca catiônica $(\mathrm{T})$; saturação em bases (V) e saturação em alumínio $(\mathrm{m})$, obtidos em amostras de solo retiradas da profundidade de $60-90 \mathrm{~cm}$, considerando as fontes de $\mathrm{N}$, independente das doses de $\mathrm{N}$ ou da aplicação de gesso. 93

58 Médias dos valores de $\mathrm{pH} ; \mathrm{H}^{+} ; \mathrm{Al}^{+3}$; soma de bases (S); capacidade de troca catiônica $(\mathrm{T})$; saturação em bases (V) e saturação em alumínio (m), em amostras de solo retiradas da profundidade de $60-90 \mathrm{~cm}$, considerando as doses de $\mathrm{N}$, independente das fontes de nitrogênio e da aplicação de gesso. 
59 Valores do teste $\mathrm{F}$ a 5 ou $1 \%$ de probabilidade para as interações entre gesso, fonte e dose de nitrogênio para os parâmetros: valores de $\mathrm{pH} ; \mathrm{H}^{+} ; \mathrm{Al}^{+3}$; soma de bases (S); capacidade de troca catiônica (T); saturação em bases (V) e saturação em alumínio (m); em amostras de solo retiradas da camada de $60-90 \mathrm{~cm}$ de profundidade

60 Médias dos valores de nitrogênio na planta proveniente do fertilizante-NPPF $\quad\left(\%\right.$ e g.parcela $\left.{ }^{-1}\right)$ e eficiência de utilização do fertilizante nitrogenado-EUF (\%), para os tratamentos onde foi aplicado ${ }^{15} \mathrm{~N}$.

61 Médias dos valores de nitrogênio na planta proveniente do fertilizante-NPPF $\quad\left(\%\right.$ e g.parcela $\left.{ }^{-1}\right)$ e eficiência de utilização do fertilizante nitrogenado (\%), considerando o efeito do gesso independente das fontes de nitrogênio, para os tratamentos onde foi aplicado ${ }^{15} \mathrm{~N}$.

62 Médias dos valores de nitrogênio no solo proveniente do fertilizante-NSPF $\quad(\%$ e $\mathrm{mg} / \mathrm{kg}$ solo $)$ e percentagem do fertilizante aplicado que permaneceu nas camadas de 030; 30-60 e 60-90 $\mathrm{cm}$ de profundidade, para os tratamentos onde foi aplicado ${ }^{15} \mathrm{~N}$. 99

Médias dos valores de nitrogênio no solo proveniente do fertilizante-NSPF ( $\%$ e mg.kg solo ${ }^{-1}$ ) e percentagem do fertilizante aplicado que permaneceu nas camadas de 0-30; 30-60 e 60-90 $\mathrm{cm}$ de profundidade, considerando o efeito do gesso, independente das fontes de nitrogênio, para os tratamentos onde foi aplicado ${ }^{15} \mathrm{~N}$ 100 


\title{
EFEITO DO GESSO E DE FERTILIZANTES NITROGENADOS NA PRODUÇÃO E UTILIZAÇÃO DE MACRONUTRIENTES PELO MILHO "SAFRINHA".
}

\author{
Autora: RAFFAELLA ROSSETTO \\ Orientador: PROF. DR. TAKASHI MURAOKA
}

\section{RESUMO}

Com o objetivo de avaliar o efeito do gesso na produção, na absorção de macronutrientes e na eficiência de utilização de fertilizantes nitrogenados pelo milho "safrinha"( milho produzido na entressafra rotineira), além de acompanhar as modificações ocorridas nas propriedades químicas do solo, instalou-se um experimento em Latossolo Vermelho-escuro, argiloso, no município de Piracicaba, SP, em esquema de blocos ao acaso com 18 tratamentos e 4 repetições. O esquema para a instalação dos tratamentos foi um fatorial de fontes nitrogenadas (nitrato de cálcio; nitrato de magnésio;sulfato de amônio; mistura granulada de uréia+sulfato de amônio na proporção de 80 : 20\%; doses de nitrogênio ( 60 e $120 \mathrm{kgN} \cdot \mathrm{ha}^{-1}$ ) e da aplicação ou não de 2,5 t.ha ${ }^{-1}$ de gesso. Foram adicionados 2 tratamentos: testemunha e testemunha + gesso. Nos tratamentos nitrato de cálcio e sulfato de amônio na dose $\left(60 \mathrm{~kg} \mathrm{~N} \cdot \mathrm{ha}^{-1}\right)$ demarcouse uma subparcela central, onde foram aplicados os fertilizantes contendo ${ }^{15} \mathrm{~N}$. 
Após o ciclo completo, as parcelas foram colhidas e a massa colmos+folhas e de grãos foram avaliadas. Os teores de macronutrientes absorvidos e ${ }^{15} \mathrm{~N}$ foram analisados na matéria seca. Em cada parcela, ao final do experimento, foram retiradas amostras de solo a 3 profundidades $(0-30 ; 30-60$ e $60-90 \mathrm{~cm})$. Foram avaliados: $\mathrm{pH} ; \mathrm{H} \mathrm{e} \mathrm{Al} ; \mathrm{N}$ total $; \mathrm{P} ; \mathrm{S}^{-S}{ }_{4}^{-2} ; \mathrm{K} ; \mathrm{Ca}$ e $\mathrm{Mg}$ trocáveis e ${ }^{15} \mathrm{~N}$. Foram calculados: soma de bases (S), CTC, saturação em bases (V\%), saturação em alumínio $(\mathrm{m} \%)$. Obteve-se os valores de nitrogênio na planta e no solo proveniente do fertilizante e a eficiência de utilização do fertilizante nitrogenado.

Os resultados permitiram concluir que:

A adubação nitrogenada e a aplicação de gesso aumentaram a produção de grãos de milho safrinha. O gesso foi responsável por aumentos de $14 \%$, sendo que aliado à utilização de fertilizante nitrogenado, o aumento foi de $57 \%$. Os fertilizantes nitrato de cálcio e sulfato de amônio foram as fontes nitrogenadas mais eficientes entre as estudadas, no aumento da produção de milho. A dosagem de $120 \mathrm{~kg}$ N.ha ${ }^{-1}$ promoveu aumentos de produção de $13,7 \%$ em relação à dose de $60 \mathrm{kgN}$.ha ${ }^{-1}$.

A aplicação de gesso, independentemente das fontes nitrogenadas e das

doses de $\mathrm{N}$, promoveu maiores acúmulos de $\mathrm{N}, \mathrm{P}, \mathrm{Ca}, \mathrm{Mg}$ e $\mathrm{S}$ nas plantas de milho (folhas+colmos +grãos), da ordem de 15, 24, 17, 19 e 25\%.

$\mathrm{O}$ gesso aumentou os teores de $\mathrm{Ca}$ e $\mathrm{SO}_{4}^{-2}$ do solo até $90 \mathrm{~cm}$ de profundidade. Promoveu aporte de P e K para a camada de $30-60 \mathrm{~cm}$ e de Mg para a camada de $60-90 \mathrm{~cm}$. A soma de bases e a CTC do solo foram aumentadas em todas as 
profundidades estudadas como resultado do efeito do gesso. A saturação da CTC por bases foi aumentada nas profundidades de $30 \mathrm{a} 90 \mathrm{~cm}$.

O teor de $\mathrm{Al}$ não foi alterado, mas a saturação da CTC por alumínio foi diminuída consideralvelmente até $60 \mathrm{~cm}$ de profundidade. A aplicação de gesso melhorou a eficiência de utilização dos fertilizantes nitrato de cálcio e sulfato de amônio de 24,4 e 35,6\% (sem aplicação de gesso) para 45 e 41,6\% (com aplicação de gesso), respectivamente. 


\section{EFFECT OF GYPSUM AND NITROGEN FERTILIZER ON YIELD AND MACRONUTRIENTS UTILIZATION OF "SAFRINHA" CORN CROP}

Author: RAFFAELLA ROSSETTO Adviser: PROF. DR. TAKASHI MURAOKA

\section{SUMMARY}

The objective of this study was to evaluate the effect of gypsum on yield, macronutrients uptake and nitrogen fertilizers utilization efficiency by "safrinha" corn crop, and on the soil chemical properties. The experiment, with 18 treatments and four replicates, in randomized block design, was conducted in Piracicaba, SP in a clayey dark red latosol. The treatments scheme was a factorial of four nitrogen sources (calcium nitrate; magnesium nitrate, ammonium sulfate; urea + ammonium sulfate, in $80: 20 \%$ proportion in the fertilizer grain); two nitrogen rates (60 and $\left.120 \mathrm{~kg} \cdot \mathrm{ha}^{-1}\right)$; and two gypsum rates: zero and 2.5 t. ha ${ }^{-1}$.

Two additional treatments were included: control and control + gypsum. In the treatments were calcium nitrate and ammonium sulfate, were applied at the rate of $60 \mathrm{~kg} \mathrm{~N} \cdot \mathrm{ha}^{-1}$, a central subplot was used for ${ }^{15} \mathrm{~N}$ labeled fertilizer application. 
At the end of the growth cycle, stalks, leaves and grain yields were evaluated. The contents of macronutrients in the dry matter were determined.

At the end of experimental period, soil samples were taken in each plot, from 3 depths $(0-30 ; 30-60$ and $60-90 \mathrm{~cm})$, and subjected to determination of: $\mathrm{pH}$; $\mathrm{H}+\mathrm{Al} ; \mathrm{N} ; \mathrm{P} ;{\mathrm{S}-\mathrm{SO}_{4}}^{-2} ; \mathrm{K} ; \mathrm{Ca}$ and $\mathrm{Mg}$. Sum of bases (S); CEC; base saturation (V\%) and Al saturation $(\mathrm{m} \%)$ were calculated. Nitrogen in the plant derived from fertilizer and fertilizer nitrogen use efficiency values were obtained from the ${ }^{15} \mathrm{~N}$ data.

The nitrogen fertilizers and gypsum application increased the corn grain yield. The gypsum was responsible for $14 \%$ increase, but when combined with nitrogen fertilizers, the increase was $57 \%$. The calcium nitrate and ammonium sulfate were the most efficient nitrogen sources in increasing corn yield. The application of 120 $\mathrm{kg} \mathrm{N} \cdot \mathrm{ha}^{-1}$ promoted an increase of $13.7 \%$ in the yield over the $60 \mathrm{~kg} \mathrm{~N} . \mathrm{ha}^{-1}$ rate.

The gypsum application, irrespectively to the sources and rate of nitrogen, resulted in higher $\mathrm{N}, \mathrm{P}, \mathrm{Ca}, \mathrm{Mg}$ and $\mathrm{S}$ content of corn plants (leaves + stalks + grains), in the order of $15,24,17,19$ and $25 \%$.

Gypsum increased the $\mathrm{Ca}$ and $\mathrm{SO}_{4}^{-2}$ content of the soil up to the depht of $90 \mathrm{~cm}$. It promoted the leaching of $\mathrm{P}$ and $\mathrm{K}$ to the depht of $30-60 \mathrm{~cm}$ and of $\mathrm{Mg}$ to the depht of $60-90 \mathrm{~cm}$. The sum of bases and the CEC of the soil were increased in all the depths studied as an effect of gypsum. The base saturation was increased in 30 and $90 \mathrm{~cm}$ depth. 
The soil $\mathrm{Al}$ content was not altered, but the $\mathrm{Al}$ saturation was considerably reduced up to the $30-60 \mathrm{~cm}$ depth. The application of gypsum increased the efficiency of utilization of calcium nitrate and ammonium sulfate from 24.4 and $35.6 \%$ (without gypsum application) to 45 and $41.6 \%$ (with gypsum application), respectively. 


\section{INTRODUÇÃO}

A utilização de gesso agrícola na agricultura é um tema atual e de grande interesse para todos os países que possuem indústrias de fertilizantes fosfatados, onde quantidades desse subproduto se acumulam em grandes proporções.

Recentemente, o tema "gesso na agricultura" foi objetivo de uma extensa revisão de literatura por ALCORDO \& RECHEIGL (1993), onde fica evidente o interesse e o envolvimento de muitos pesquisadores em diversos países. No Brasil, o interesse pelo tema também é relevante devido à predominância de solos ácidos e de baixa fertilidade.

Os solos ácidos apresentam, de maneira geral, baixa concentração de bases, especialmente $\mathrm{Ca}$ e $\mathrm{Mg}$ e elevados teores de $\mathrm{Al}$ e $\mathrm{Mn}$ em relação às necessidades nutricionais das plantas. A prática agrícola mais recomendada para a melhoria da fertilidade desses solos é a aplicação de materiais corretivos, principalmente os calcários. Entretanto, a solubilização desses materiais é lenta e sendo incorporados superficialmente, pouco atuam em camadas de solo subjacentes, limitando o efeito corretivo a profundidades próximas da aplicação. 
A melhoria da fertilidade em subsuperficie pode ser conseguida com aplicação de gesso, pois esta fonte é mais solúvel que os calcários e também apresenta o ânion sulfato, que forma complexos químicos com cátions cuja percolação para subsuperficie fica facilitada. Aumentando os teores de cálcio e reduzindo o efeito tóxico do alumínio das camadas mais profundas, há um aprofundamento do sistema radicular das plantas que passam a explorar maior volume de solo com consequente maior utilização de água e nutrientes.

Geralmente as culturas apresentam baixa eficiência de utilização de fertilizantes nitrogenados. Segundo dados da IAEA (1976), raramente a eficiência ultrapassa a $60 \%$. Vários fatores concorrem para alterar as perdas do $\mathrm{N}$ nos solos, e práticas que visem aumentar a eficiência de utilização do $\mathrm{N}$ são altamente desejáveis. Alguns experimentos tem mostrado que o gesso aumenta a utilização do nitrogênio pelas plantas, entretanto, existem poucos estudos sobre esse assunto.

O objetivo deste trabalho foi avaliar o efeito do gesso na produção, na absorção de macronutrientes e na eficiência de utilização de fertilizantes nitrogenados pela cultura do milho, além de acompanhar as modificações ocorridas em algumas propriedades químicas do solo. 


\section{REVISÃO DE LITERATURA}

\subsection{O Gesso Agrícola}

O gesso a ser utilizado na agricultura pode ser proveniente de minas naturais ou de subprodutos industriais. Na natureza o gesso ocorre principalmente na forma dihidratada $\left(\mathrm{CaSO}_{4} \cdot 2 \mathrm{H}_{2} \mathrm{O}\right)$. Outras formas como a: hemihidratada $\left(\mathrm{CaSO}_{4}, 1 / 2 \mathrm{H}_{2} \mathrm{O}\right)$ e a anidra $\left(\mathrm{CaSO}_{4}\right)$, também podem ocorrer (Doner \& Lynn, $1989^{1}$, citados por SUMNER, 1992).

No Brasil, a maioria das indústrias de fertilizantes utilizam a reação do ácido sulfúrico com a rocha fosfática para a obtenção do ácido fosfórico, o qual é posteriormente separado do sulfato de cálcio dihidratado formado na reação. A indústria de fertilizantes fosfatados acumula quatro a cinco toneladas de gesso por tonelada de $\mathrm{P}_{2} \mathrm{O}_{5}$ de ácido fosfórico produzido (PAOLINELLI et al., 1985). Para as rochas brasileiras pode-se considerar 4,2 toneladas de gesso por tonelada de $\mathrm{P}_{2} \mathrm{O}_{5}$ produzida, $\mathrm{o}$ que representava ao final de 1991 uma reserva de 29 milhões de toneladas de gesso nas seis fábricas de ácido fosfórico do Brasil (BARTL \& ALBUQUERQUE, 1992). 
Anualmente são produzidos 3,6 milhões de toneladas de gesso no Brasil apenas como subproduto da indústria de fertilizantes fosfatados (PAOLINELLI et al., 1985).

Além do Brasil, outros países como Austrália, Canadá, Japão, Índia e Holanda apresentam problemas com acúmulo de grandes quantidades do subproduto gesso. Estima-se que o acúmulo mundial desse subproduto seja de 135 milhões de toneladas anuais. Desse total, apenas $4 \%$ são utilizados na agricultura (ALCORDO \& RECHEIGL, 1993).

O subproduto gesso apresenta uma série de impurezas que provém da rocha fosfática. Uma análise típica, segundo PAOLINELLI et al. (1985), aponta: resíduo insolúvel $=3,2 \%$; óxidos do terceiro grupo $\mathrm{R}_{2} \mathrm{O}_{3}=0,59 \% ; \mathrm{CaO}=30,90 \% ; \mathrm{S}=17,70 \%$; $\mathrm{P}_{2} \mathrm{O}_{5}=0,67 \% ; \mathrm{F}=0,23 \%$ e umidade $=15,5 \%$. O sulfato de cálcio puro é um sal neutro cuja solubilidade em água é de $0,241 \mathrm{~g} / \mathrm{L}$. O gesso agrícola, entretanto, é ácido, e seu pH em água pode variar entre 2 a 5, principalmente devido às impurezas (Nifong, $1988^{1}$, citado por ALCORDO \& RECHEIGL, 1993). As impurezas limitam seu uso na construção civil e na indústria química, mas não impedem seu emprego na agricultura.

$\mathrm{Na}$ agricultura, o gesso pode ser utilizado em diversas práticas já consagradas pela pesquisa, como correção de solos sódicos, redução da salinidade dos solos, redução nas perdas de $\mathrm{N}$ durante a compostagem de estercos, e fornecimento de de Ca e S para as culturas (Malavolta,1992). Outras utilizações ainda em estudo científico, dizem respeito à agregação de partículas e melhoria do ambiente radicular da subsuperficie do solo (SOUSA et al., 1992).

${ }^{1}$ NIFONG, G.D. Environmental aspects of phosphogypsum (mimeogr.). Florida Institute of Phosphate Research, Bartow, Florida, 1988. 


\subsection{O Gesso Agrícola e a Melhoria do Ambiente Radicular}

Os trabalhos de SUMNER (1970) e REEVE \& SUMNER (1972), foram pioneiros em observar que o gesso poderia melhorar o ambiente radicular em subsuperficie. O trabalho de REEVE \& SUMNER (1972) foi realizado em colunas de solo contendo $100 \mathrm{~g}$ de terra de superficie aplicada sobre $100 \mathrm{~g}$ de terra de subsuperfície de um Oxisolo da África do Sul. Os autores concluíram haver diminuição no teor de alumínio solúvel na terra de subsuperfície em função do gesso aplicado na superficie. A aplicação de 22 t.ha $^{-1}$ de gesso reduziu o $\mathrm{Al}^{+3}$ de $2,4 \mathrm{meq} / 100 \mathrm{~g}$ para $1,4 \mathrm{meq} / 100 \mathrm{~g}$ e aumentou o teor de Ca trocável de 0,7 para $2,5 \mathrm{meq} / 100 \mathrm{~g}$ de solo.

A diminuição no teor de alumínio trocável foi motivo de dúvidas e grandes debates, motivando uma série de trabalhos científicos posteriores. RAIJ (1989), por exemplo, questiona o método de determinação do alumínio nesse trabalho, por ter sido um método indireto. Vários autores observaram diminuição do teor de $\mathrm{Al}^{+3} \mathrm{em}$ função da aplicação de gesso, a exemplo de SUMNER et al. (1986); FARINA \& CHANNON (1988) e SMITH \& CRAVO (1992). No trabalho de ALVES (1984), o teor de alumínio passou de 0,56 meq. $100 \mathrm{~cm}^{-3}$ de $\mathrm{Al}$ para 0,$3 ; 0,2$; e 0,2 meq $\mathrm{Al}^{+3} / 100$ $\mathrm{cm}^{3}$ respectivamente para as doses de 1,2 e $4 \mathrm{t}$ gesso.ha. ${ }^{-1}$. PAVAN et al.(1984) também observaram redução de $1,6 \mathrm{meq} \mathrm{Al}^{+3} / 100 \mathrm{~g}$ para $0,6 \mathrm{meq} \mathrm{Al}^{+3} / 100 \mathrm{~g}$ nos $10 \mathrm{~cm}$ iniciais da coluna de solo e de 1,9 para 1,5 meq $\mathrm{Al}^{+3} / 100 \mathrm{~g}$ para a camada de $80-100 \mathrm{~cm}$ de profundidade. 
Alguns autores não observaram alterações no teor de $\mathrm{Al}^{+3}$ em função da aplicação de gesso, mas apenas diminuição na saturação em alumínio , a exemplo de BLACK \& CAMERON (1984); ERNANI (1986) e MARIA et al. (1993).

No Brasil, RITCHEY et al. (1980) foram os primeiros a observar que o efeito do gesso contido no superfosfato simples teria sido responsável por um maior crescimento radicular de plantas de milho, que lhe conferiam maior resistência à seca. Análises de solo mostraram que esse tratamento apresentava também mais cálcio, menos alumínio e consequente menor saturação em alumínio. Entretanto, houve uma redução significativa da acidez, indicada por valores mais altos de $\mathrm{pH}$ na subsuperficie. O efeito do gesso em alterar o $\mathrm{pH}$ de solos seria uma segunda questão polêmica a provocar dúvidas, uma vez que o gesso, um sal neutro em sua forma pura, não deveria modificar a reação do solo.

Um trabalho realizado por ADAMS \& LUND em 1966 passou a fazer parte das discussões sobre uso de gesso no solo. Nesse trabalho, os autores cultivaram algodão em vasos subdivididos, onde na parte inferior foi colocada terra de subsolo, ou solução nutritiva. Na solução nutritiva variaram-se os teores de sulfato de cálcio e alumínio. $\mathrm{O}$ aumento na concentração de $\mathrm{CaSO}_{4}$ ocasionou diminuição da toxidez de alumínio. Como o teor ou a saturação de alumínio trocável representavam toxidez em alguns solos e não em outros, sugeriram utilizar a atividade do alumínio como parâmetro para avaliar a toxidez.

Os estudos sobre práticas agrícolas e modificação da atividade do íon $\mathrm{Al}^{+3}$ passaram a ter grande interesse. Ocorre que, após a dissolução do gesso, o sulfato 
pode permanecer na solução do solo como ânion livre ou formar complexos solúveis com ácidos duros $\left(\mathrm{Al}^{+3}, \mathrm{Ca}^{+2}, \mathrm{Mg}^{+2}\right)$ através de ligações iônicas. A distribuição das espécies iônicas depende principalmente do $\mathrm{pH}$ e da força iônica da solução (PAVAN \& VOLKWEISS, 1986). Segundo LINDSAY et al. (1959), toda vez que o pH decresce de 0,1 unidade, a atividade do $\mathrm{Al}^{+3}$ aumenta de duas a três vezes.

Com o desenvolvimento de programas de computador específicos para a determinação das espécies químicas na solução, a exemplo do GEOCHEM desenvolvido por SPOSITO \& MATTIGOD (1980), diversos autores procuraram avaliar as espécies químicas formadas no solo após a aplicação do gesso, como por exemplo os trabalhos de PAVAN \& BINGHAM (1982) e PAVAN et al. (1982) e (1984). No trabalho de PAVAN \& BINGHAM (1982), comprovou-se que a formação de complexos do sulfato com o alumínio, diminuiu a atividade do íon $\mathrm{Al}^{+3}$ que é a espécie mais tóxica às raízes. Houve grande aumento na concentração da espécie $\mathrm{AlSO}_{4}{ }^{+}$, que foi pouco absorvida pelas raizes de café. A redução da toxidez de alumínio através da formação de complexos com $\mathrm{SO}_{4}^{-2}$ também foi comprovada para a soja por ALVA et al. (1991)

\section{Conforme comentaram PAVAN \& VOLKWEISS (1986), as} associações químicas do sulfato com metais revelam que determinada percentagem dos cátions solúveis em um sistema contendo gesso, está presente em formas neutras ou com menor valência, o que aumenta sua mobilidade no perfil de solos. CAMERON et al. (1986) mostraram que não é somente o sulfato contido no gesso agrícola que diminui a atividade do alumínio, quando observaram que o íon fluoreto $\left(F^{-}\right)$também forma 
complexos de alta estabilidade e diminui a atividade desse íon. A neutralização da acidez do subsolo, que poderia explicar as dúvidas representadas pela diminuição do teor de $\mathrm{Al}^{+3}$ e elevação do pH do solo, poderia ser obtida, segundo RAIJ (1989), de três maneiras: aplicação de doses grandes de calcário na camada arável, aplicação superficial de gesso e absorção pelas plantas de nitrato do subsolo. No caso da aplicação de gesso, elevação de pH poderia ocorrer em solos ricos em óxidos de ferro e alumínio devido à reação de troca de ligantes ou adsorção específica do sulfato, segundo a reação:

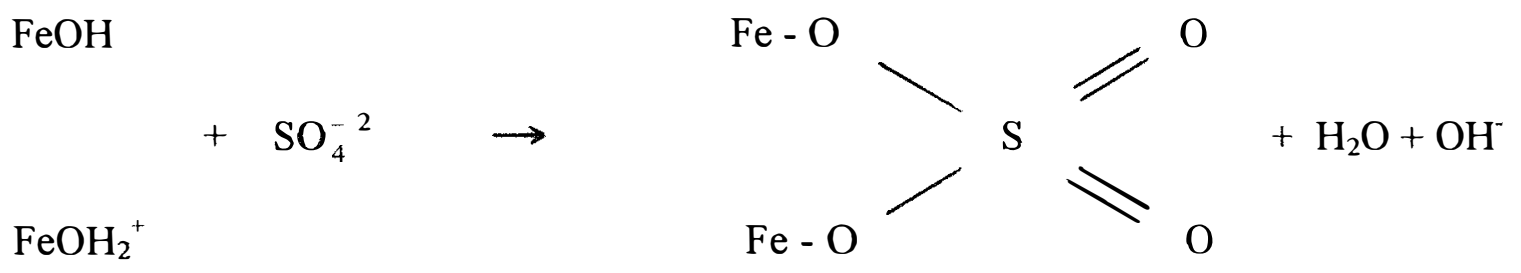

Nessa reação, uma hidroxila é liberada e neutralizaria o alumínio. Este processo foi proposto por REEVE \& SUMNER em 1972, chamado de auto-calagem. Até hoje é o mecanismo aceito para explicar a elevação do $\mathrm{pH}$ do solo em função da aplicação do gesso. Entretanto, este processo só ocorre em solos com teores elevados de óxidos de ferro e alumínio e é um processo reversível (RAIJ, 1988).

São contraditórias na literatura as observações quanto às variações no pH do solo, obtidas em ensaios com aplicação de gesso. Alguns autores obtiveram 
elevação do pH em função da aplicação de gesso, a exemplo de RAIJ et al. (1988) e RITCHEY et al. (1980). Outros não observaram alterações, como MARIA et al. (1993); SUMNER et al. (1986); OATES \& CALDWELL (1985); PAVAN et al. (1984) e ROSOLEM \& MACHADO (1984) em Latossolo Roxo. Existem também trabalhos onde o gesso diminuiu o pH do solo, como ALVA et al. (1990); MATHEWS \& JOOST (1990) e ROSOLEM \& MACHADO (1984) em Latossolo Vermelho-escuro.

Outro processo onde ocorre adsorção de sulfato envolve a precipitação de minerais, como a reação de formação da alunita. Neste caso, íons $\mathrm{Al}^{+3}$ desaparecem, mas surgem íons $\mathrm{H}^{+}$, que podem redissolver os minerais que contém o alumínio. (ADAMS \& RAWAJFIH, 1977).

Um fato de consenso é que o cálcio ou a ausência de alumínio exercem efeito benéfico ao crescimento das raízes. O aprofundamento do sistema radicular pode conduzir à vantagens como maior aproveitamento de água e nutrientes, reciclagem de nutrientes de camadas do subsolo e maior produtividade.

\subsection{O Gesso e o Movimento de Íons no Solo}

A neutralização ou a diminuição da valência dos íons através da formação de complexos são os principais mecanismos químicos que facilitam a movimentação de íons em solos.

Após a dissolução do gesso, o sulfato movimenta-se em profundidade carreando cátions como o $\mathrm{Ca}^{+2}, \mathrm{o} \mathrm{Mg}^{+2}$ e o $\mathrm{K}^{+}$. Este efeito pode ser indesejado quando 
promove perdas de cátions para camadas situadas fora do alcance das raízes, significando perdas de nutrientes para as culturas.

Algumas características dos solos influem na lixiviação de íons, como o $\mathrm{pH}$, e o teor e mineralogia da argila. A intensidade de chuva e a própria dosagem do gesso também promovem a lixiviação desses cátions (SOUSA et al., 1992).

As cargas elétricas do solo tem efeito marcante na lixiviação de íons. CAMARGO \& RAIJ (1989) estudaram a lixiviação de $\mathrm{Ca}^{+2}{\text { e } \mathrm{SO}_{4}^{-2}}^{-}$num solo onde ocorreram alterações de $\mathrm{pH}$ e concluiram que o $\mathrm{Ca}$ é mais retido a valores de $\mathrm{pH}$ mais altos, ocorrendo o contrário com o $\mathrm{SO}_{4}^{-2}$.

Em estudo realizado em colunas de terra, SOUSA \& RITCHEY (1986) aplicaram três sais: carbonato de cálcio, cloreto de cálcio e sulfato de cálcio. Após a percolação de $1200 \mathrm{~mm}$ de água, observaram que o ânion influi decisivamente na descida do cálcio pelo perfil do solo. O carbonato de cálcio, cujo ânion reage formando $\mathrm{CO}_{2}$ que se dissipa, praticamente não promoveu o movimento do cálcio. O cloreto percolou facilmente no solo e o sulfato atingiu praticamente $70 \mathrm{~cm}$ de profundidade.

DURING \& COOPER (1974) observaram que o sulfato movia-se 1 cm para cada $3 \mathrm{~cm}$ de água percolada na camada superior de um solo com alta capacidade de retenção de sulfato. Abaixo da camada superficial, o movimento foi mais lento, não se observando a presença de sulfato abaixo de $45 \mathrm{~cm}$ de profundidade.

A lixiviação de $\mathrm{K}^{+}$e $\mathrm{Mg}^{+2}$ após a aplicação de gesso foi constatada por REEVE \& SUMNER (1972) e RITCHEY et al. (1980), entre outros. Quanto ao K ${ }^{+}$, 
sabe-se que sua percolação depende dos teores de $\mathrm{Ca}^{+2}$ e $\mathrm{Mg}^{+2}$ nos solos, sendo que RAIJ \& CAMARGO (1973) constataram que a melhor relação entre cátions lixiviados e cátions trocáveis foi obtida quando se utilizou a expressão $\mathrm{K}(\mathrm{Ca}+\mathrm{Mg})$. RAIJ (1988), explica que esta relação significa que as perdas de K serão menores para menores teores de $\mathrm{K}$ trocável e maiores teores de $\mathrm{Ca}+\mathrm{Mg}$ trocáveis. Então, a calagem e a adição de gesso, ao elevarem os teores de $\mathrm{Ca}$ e $\mathrm{Mg}$ no solo, contribuiriam para perdas menores de K. Entretanto, este não é um fato que tem sido verificado na experimentaçao com o uso de gesso.

A camada superficial de muitos solos cultivados apresenta predomínio de cargas negativas, provenientes da presença de matéria orgânica como consequência da aplicação de corretivos de acidez que elevam o pH. A presença de ânions fosfato na superficie, retidos preferencialmente ao sulfato, torna ainda mais desfavorável a adsorção de sulfatos na superficie dos solos.

Segundo RAIJ (1988), subsolos ácidos devem apresentar considerável retenção de sulfato, o que retardaria a lixiviação desse ânion pela água de percolação. A lixiviação de gesso apresenta ainda um limite imposto pela solubilidade do sal,cujas soluções apresentam uma concentração máxima de 0,014 M. Para uma camada de solo de $20 \mathrm{~cm}$ de profundidade e $30 \%$ de retenção máxima de água, poderiam ser colocados $0,8 \mathrm{meq} / 100 \mathrm{~cm}^{3}$ de terra, ou seja, 1,6 t de gesso. $\mathrm{ha}^{-1}$.

Em experimento realizado em colunas de solo, MARIA et al. (1993), observaram que a aplicação de gesso e de calcário + gesso promoveram maiores perdas de $\mathrm{Ca}^{+2}, \mathrm{Mg}^{+2}, \mathrm{~K}^{+}$e $\mathrm{Al}^{+3}$ na solução percolada. 
Com o objetivo de avaliar a lixiviação de bases ${\mathrm{e} \mathrm{SO}_{4}^{-2}}^{-2}$ alterações nos teores de $\mathrm{Al}^{+3}$, BIANCHI et al (1991) conduziram experimento em solo Podzólico Vermelho-escuro, onde aplicaram várias doses de gesso até 8 t.ha ${ }^{-1}$. Os autores observaram que após 6 meses da aplicação o teor de $\mathrm{Ca}^{+2}$ tinha aumentado nas 3 camadas de solo estudadas $\left(0-15,15-30\right.$ e $30-45 \mathrm{~cm}$ de profundidade). $\mathrm{O} \mathrm{Mg}^{+2}$ deslocou-se em profundidade e $\mathrm{O} \mathrm{SO}_{4}^{-2}$ também teve concentração aumentada em profundidade. Não

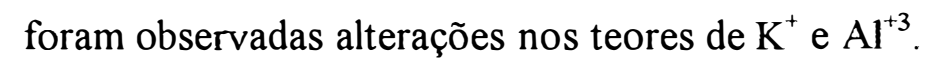

A lixiviação de $\mathrm{Mg}^{+2}$ e $\mathrm{K}^{+}$para camadas fora do alcance das raízes também foi observada por QUAGGIO et al. (1982) e PAVAN et al (1984) e é considerada um dos principais problemas da aplicação de gesso, principalmente em doses elevadas.

\subsection{Produção de Milho no Brasil e Importância do Milho "Safrinha"}

Segundo dados do IBGE-1993, a produção de milho no Brasil ocupou 13,58 milhões de hectares em 1991, sendo que a produção foi maior que 23 milhões de toneladas. O rendimento médio é bastante baixo, por volta de $1.808 \mathrm{~kg}^{-\mathrm{ha}^{-1}}$. O milho, no estado de São Paulo, ocupa uma área de 1,45 milhões de hectares, com produtividade de $2.811 \mathrm{~kg} \cdot \mathrm{ha}^{-1}$.

O milho produzido na entressafra, conhecido como milho "safrinha", ocupou mais de um milhão de hectares em 1993, respondendo por quase $8 \%$ da produção nacional de milho (CRUZ et al., 1994). É uma prática que vem crescendo no estado de 
São Paulo devido às vantagens de promover a colheita na entressafra do produto aproveitando melhor preço, além do uso mais intensivo da terra e de meios de produção. O milho safrinha apresenta desvantagens de queda na produtividade, devidas a déficits hídricos ou geadas. Para não promover competição intensa por água, o número de plantas por hectare da plantação deve ser mais baixo. A média de produtividade obtida em ensaios de competição de 25 híbridos ou variedades foi de $3.232 \mathrm{~kg}$. ha ${ }^{-1}$ no trabalho de CRUZ et al. (1994).

\subsection{Absorção e Utilização do Nitrogênio pelo Milho}

O milho, assim como a maioria das plantas, pode utilizar o nitrogênio tanto na forma de $\mathrm{NO}_{3}{ }^{-}$como de $\mathrm{NH}_{4}{ }^{+}$. O nitrato é frequentemente a forma mais absorvida e move-se até às raízes por fluxo de massa e difusão.

A absorção de nitrato é ativa e favorecida por condições de baixo $\mathrm{pH}$. $\mathrm{O}$ nitrato deve ser reduzido dentro da planta antes de ser incorporado às proteínas, num processo que consome energia (duas moléculas de $\mathrm{NADPH}^{+}$para cada molécula de $\mathrm{NO}_{3}{ }^{-}$ a ser reduzida).

A absorção do íon $\mathrm{NH}_{4}{ }^{+}$promove economia energética na planta, uma vez que não necessita ser reduzido. A absorção é máxima quando o pH do solo é próximo da neutralidade, diminuindo quando há aumento na acidez do solo. Se o íon amônio for absorvido diretamente pela planta, ocorre a liberação de $\mathrm{H}^{+}$, contribuindo 
para a acidificação do solo na rizosfera. A absorção de nitrato, por sua vez eleva o pH da rizosfera através da excreção de íons $\mathrm{HCO}_{3}{ }^{-}$pelas raízes afim de manter o balanço de cargas elétricas (TISDALE et al., 1985).

RAIJ (1989) relata que essas observações foram identificadas por PIERRE em $1928^{1}$ ao verificar que os efeitos da acidificação dos adubos nitrogenados eram menores que os esperados em solos cultivados com plantas. Esclarece ainda que, para a maior parte das plantas há maior absorção de ânions, representada por $\mathrm{NO}_{3}{ }^{-}, \mathrm{Cl}^{-}$ $\mathrm{H}_{2} \mathrm{PO}_{4}^{-}$e $\mathrm{SO}_{4}^{-2}$, do que de cátions como, $\mathrm{NH}_{4}, \mathrm{Na}^{+}, \mathrm{Ca}^{+2}, \mathrm{Mg}^{+2}$ e K . O desbalanço de cargas é compensado pela excreção de $\mathrm{HCO}_{3}{ }^{-}$, que poderia elevar o $\mathrm{pH}$ da rizosfera.

Após a absorção, o nitrogênio é incorporado a aminoácidos ainda nas raízes, que serão posteriormente utilizados nas diversas reações metabólicas da planta.

Trabalhos em soluções nutritivas tem mostrado que o $\mathrm{N}$ fornecido como $\mathrm{NH}_{4}{ }^{+}$promove um efeito no crescimento do milho maior do que quando se fornece apenas o $\mathrm{N}$ como $\mathrm{NO}_{3}^{-}$(OLSEN et al., 1991). Ao aplicar os fertilizantes ao solo, entretanto, estes estão sujeitos à reações com microrganismos, água, e com as partículas do solo. Os processos de nitrificação da amônia podem ser muito rápidos.

Várias fontes de nitrogênio podem ser utilizadas pelo milho com igual eficiência. A FAO (1980) avalia, com base em resultados de oito experimentos com milho em diversos locais do mundo, que tanto o sulfato de amônio como a uréia ou o nitrato de amônio podem ser fontes eficientes para o fornecimento de nitrogênio, sendo 
que variações na eficiência dependem das reações dos fertilizantes nos solos e das condições de aplicação.

Os diversos híbridos e variedades requerem quantidades diferentes de nitrogênio, de acordo com seu potencial de produtividade. Segundo SAYRE (1948), em estudos de marcha de absorção de $\mathrm{N}$ pelo milho, na época da colheita a distribuição de $\mathrm{N}$ na planta foi: $0,9 \mathrm{~g}$ no colmo; $1,18 \mathrm{~g}$ nas folhas, $0,30 \mathrm{~g}$ nas brácteas; $0,29 \mathrm{~g}$ no sabugo $\mathrm{e}$ $3,45 \mathrm{~g}$ nos grãos, num total de $6,12 \mathrm{~g} \mathrm{~N}$ na planta toda. No trabalho de marcha de absorção do nitrogênio em milho realizado por HANWAY (1963), do total de N absorvido, $65 \%$ estavam nos grãos; $18 \%$ nas folhas; $10 \%$ nos colmos; $3,5 \%$ nas brácteas e $3,5 \%$ no sabugo.

Segundo BARBER \& OLSON (1968), cada tonelada de grãos contém $12,77 \mathrm{~kg} \mathrm{~N}$, sendo que somando com os restos culturais, a extração chega a $18,88 \mathrm{~kg}$. Essa extração corresponde a $67,6 \%$ de $\mathrm{N}$ nos grãos e $32,4 \% \mathrm{~N}$ nos restos culturais. Para uma tonelada de grãos de milho são extraídos ainda no total de grãos e restos culturais, 3,87 kg de P; 19,45 kg de K; 4,02 kg de Ca; 4,33 kg de Mg; 2,10 kg de S; 0,25 kg de $\mathrm{Zn}$.

Quanto à eficiência de utilização do nitrogênio, avaliada pelo isótopo ${ }^{15} \mathrm{~N}$, a IAEA (1976), avaliando resultados obtidos em muitos experimentos sob os mais diversos sistemas agrícolas, com condições geográficas e climáticas diversas, conclui que raramente uma cultura aproveita mais que $60 \%$ do nitrogênio aplicado como fertilizante. NEPTUNE \& CAMPANELLI (1980) estudaram o efeito de épocas e modos de 
aplicação de sulfato de amônio- ${ }^{15} \mathrm{~N}$ e interações com fósforo na cultura do milho. A maior eficiência de utilização do fertilizante ocorrida no tratamento onde o $N\left(80 \mathrm{~kg} \cdot \mathrm{ha}^{-1}\right)$ foi aplicado antes da semeadura e o P na faixa da semeadura, foi de $17 \%$.

No experimento de REICHARDT et al. (1979), entretanto, cujo objetivo foi estudar a dinâmica do $\mathrm{N}$ num solo cultivado com milho, os autores obtiveram $89,1 \%$ de eficiência de utilização do $\mathrm{N}$ fornecido como sulfato de amônio na dose de 80 $\mathrm{kg} \mathrm{N} \cdot \mathrm{ha}^{-1}$. Cerca de $63 \%$ do $\mathrm{N}$ do fertilizante foram para os grãos e $26,1 \%$ ficaram na palha. Do total de nitrogênio absorvido pelos grãos, $41 \%$ vieram do fertilizante, sendo que na palha esse valor foi de $42,7 \%$. Nesse experimento, apenas $4,8 \%$ do fertilizante foram perdidos por lixiviação abaixo de $120 \mathrm{~cm}$ de profundidade.

Avaliando o balanço de nitrogênio na cultura do milho à qual se aplicaram $60 \mathrm{~kg} \mathrm{~N} \cdot \mathrm{ha}^{-1}$ como uréia- ${ }^{15} \mathrm{~N}$, COELHO et al. (1991) obtiveram eficiência de utilização do fertilizante de $56 \%$. Na camada de solo de $0-90 \mathrm{~cm}$ de profundidade, permaneceram $23 \%$ do $\mathrm{N}$ do fertilizante, sendo que $15 \%$ foram perdidos do sistema. Os autores observaram também que praticamente não há variação isotópica do $N$ nas diversas partes da planta, concluindo que não há necessidade de separar as diversas partes da planta, com economia no número de análises. Os autores citam ainda que essas observações também estão relatadas na literatura para trigo, feijão e arroz e são devidas à alta mobilidade dos compostos nitrogenados na planta.

Em experimento realizado para estudar a resposta do milho a diferentes doses de $\mathrm{N}$ em dois locais do Canadá, LIANG \& MACKENZIE (1994), verificaram que a eficiência de utilização do nitrato de amônio- ${ }^{15} \mathrm{~N}$, aplicado na dosagem de $170 \mathrm{~kg}$ 
N.ha ${ }^{-1}$, foi de 22 e $30 \%$ nos dois locais em estudo. Quando se utilizou a dose maior de $400 \mathrm{~kg} \mathrm{~N} \mathrm{ha}^{-1}$, a eficiência de utilização variou entre 9 e $22 \%$ para os dois locais. Nos anos subseqüentes houve aumento na eficiência de utilização do fertilizante, uma vez que os restos de cultura permaneceram no local do experimento. Os autores concluem que a eficiência de utilização do nitrogênio avaliada pelo método do ${ }^{15} \mathrm{~N}$ varia com o ano, com o local, com a dose de $\mathrm{N}$ aplicada, e é altamente dependente da produtividade da cultura.

Independentemente da utilização ou não da metodologia isotópica, a eficiência da utilização da adubação nitrogenada para o milho na região tropical é geralmente baixa, situando-se ao redor de 50\%, segundo SANTOS et al. (1983).

\subsection{Gesso, Sistema Radicular do Milho e Utilização de Nitrogênio}

A aplicação de gesso tem contribuído sensivelmente para o melhor desenvolvimento do sistema radicular em solos com restrições químicas. No experimento descrito em SOUSA \& RITCHEY (1986), a aplicação de 6 t/ha de gesso promoveu melhor distribuição das raízes de milho até $75 \mathrm{~cm}$ de profundidade. Na profundidade de 45 a $75 \mathrm{~cm}$ foram encontradas $29 \%$ das raízes no tratamento com 6 toneladas. ha $^{-1}$ de gesso, contra apenas $2 \%$ das raízes no tratamento sem gesso. Salienta-se que esse milho foi cultivado no período seco em um Latossolo Vermelho-escuro argiloso. Estudou-se também o fator irrigação, sendo que alguns tratamentos ficaram submetidos a 25 dias de déficit hídrico. Utilizou-se como fonte de $\mathrm{N}$ o sulfato de amônio. Parte dos ganhos de produtividade foram explicados pela melhor utilização de água, uma vez que a aplicação 
de duas toneladas. ha $^{-1}$ de gesso promoveu utilização de água até $100 \mathrm{~cm}$ de profundidade contra utilização de água até $60 \mathrm{~cm}$ no tratamento sem gesso. Mesmo sem o déficit hídrico, ainda ocorreram diferenças entre os tratamentos com diversas doses de gesso. Houve maior eficiência de absorção dos seguintes nutrientes: N, P, K, Ca, Cu, Fe, Mn e Zn. Em amostragem de solo feita 74 dias após a emergência das plantas, havia acúmulo de $48 \mathrm{~kg}$ de $\mathrm{N}-\mathrm{NO}_{3}{ }^{-} \cdot \mathrm{ha}^{-1}$ a mais no solo até a profundidade de $60-75 \mathrm{~cm}$ no tratamento sem gesso. Após a colheita verificou-se que $91 \mathrm{~kg} \mathrm{~N} \cdot \mathrm{ha}^{-1}$ foram imobilizados nos grãos e palha no tratamento sem gesso, e $135 \mathrm{~kg} \mathrm{~N} \mathrm{ha}^{-1}$ no tratamento com gesso. QUAGGlO (1992) e CARVALHO et al.(1986) também observaram resposta mais expressiva do milho ao gesso em anos onde ocorreu déficit hídrico.

Avaliando a resposta à aplicação de gesso de vários cultivos sucessivos de milho em três estados na região do cerrado, SOUSA et al. (1992), verificaram melhoria do ambiente radicular do milho, com ganhos de 17 a $82 \%$ na produção de grãos.

RABUFETTI \& KAMPRATH (1977), analisando resultados de dois ensaios realizados para estudar a resposta do milho a doses de nitrogênio e enxofre fornecidos por nitrato de amônio e gesso respectivamente, verificaram que houve efeito favorável do gesso em aumentar a produção, o teor e o conteúdo de nitrogênio nos grãos de milho, apenas quando o nitrogênio foi fornecido em doses superiores a $168 \mathrm{~kg} \mathrm{~N}$.ha ${ }^{-1}$.

RAIJ et al. (1988) estudaram o efeito do gesso na reação do solo e na absorção de nitrogênio pelo sorgo. Através da técnica da raiz bipartida vertical utilizaram duas camadas de solo diferentes. O solo da parte inferior recebeu $120 \mathrm{mg} \mathrm{N}^{\mathrm{N}}$ vaso ${ }^{-1}$ das 
seguintes fontes: nitrato de cálcio, nitrato de magnésio, sulfato de amônio e nitrato de amônio. O efeito da absorção de nitratos provocou redução na acidez do solo, ocorrida pela aplicação de nitrato de cálcio e nitrato de magnésio. O sulfato de amônio promoveu acidificação do solo, enquanto que o nitrato de amônio proporcionou apenas leve acidificação. A aplicação de nitratos reduziu a acidez potencial em média em 0,25 meq $/ 100 \mathrm{~cm}^{3}$ de $\mathrm{H}^{+}+\mathrm{Al}^{+3}$ possivelmente por reação de troca de ligantes. O gesso reduziu a acidez do subsolo. Em média, o valor de $\mathrm{pH}$ aumentou de 4,12 para 4,23 com a aplicação de gesso. O gesso também favoreceu a absorção de nitrogênio: sem gesso as plantas absorveram em média 12,9 meq N.vaso ${ }^{-1}$, contra 14,4 meq $\mathrm{N} \cdot \mathrm{vaso}^{-1}$ nos tratamentos com gesso. Além do nitrogênio, o gesso favoreceu também a absorção de potássio do subsolo.

Melhor utilização de nitrogênio, responsável por aumentos de 50\% na produção de trigo onde se aplicou gesso, também foi obtida por SOUSA et al. (1992). Estes mesmos autores relatam, ainda, resposta positiva nos teores de nitrogênio dos grãos de sorgo como efeito da aplicação de gesso, com exportação de $55 \%$ a mais de nitrogênio pelos grãos. 


\section{MATERIAL E MÉTODOS}

\subsection{Local}

O experimento foi realizado em 1993 na fazend a Areão, área pertencente à ESALQUSP, município de Piracicaba,SP. As coordenadas geográficas do município são $22^{\circ} 42^{\prime} 30^{\prime \prime}$ de latitude sul e $47^{\circ} 38^{\prime} 00^{\prime \prime}$ de longitude oeste. A altitude é de $546 \mathrm{~m}$ acima do nível do mar. A região é caracterizada por médias anuais de $1257 \mathrm{~mm}$ de precipitação pluviométrica, $21^{\circ} \mathrm{C}$ de temperatura média e $71,1 \%$ de umidade relativa do $\operatorname{ar}($ OMETTO,1991). As variações de temperatura, precipitação e evapotranspiração ocorridas durante o desenvolvimento da cultura, constam da Figura 1.

\subsection{Solo}

O experimento foi instalado em um Latossolo Vermelho-escuro, distrófico, muito argiloso. O solo foi preparado através de uma aração e duas gradagens, sendo que antes da instalação dos tratamentos, foi amostrado para análise química e granulométrica (Tabelas 1 e 2). 


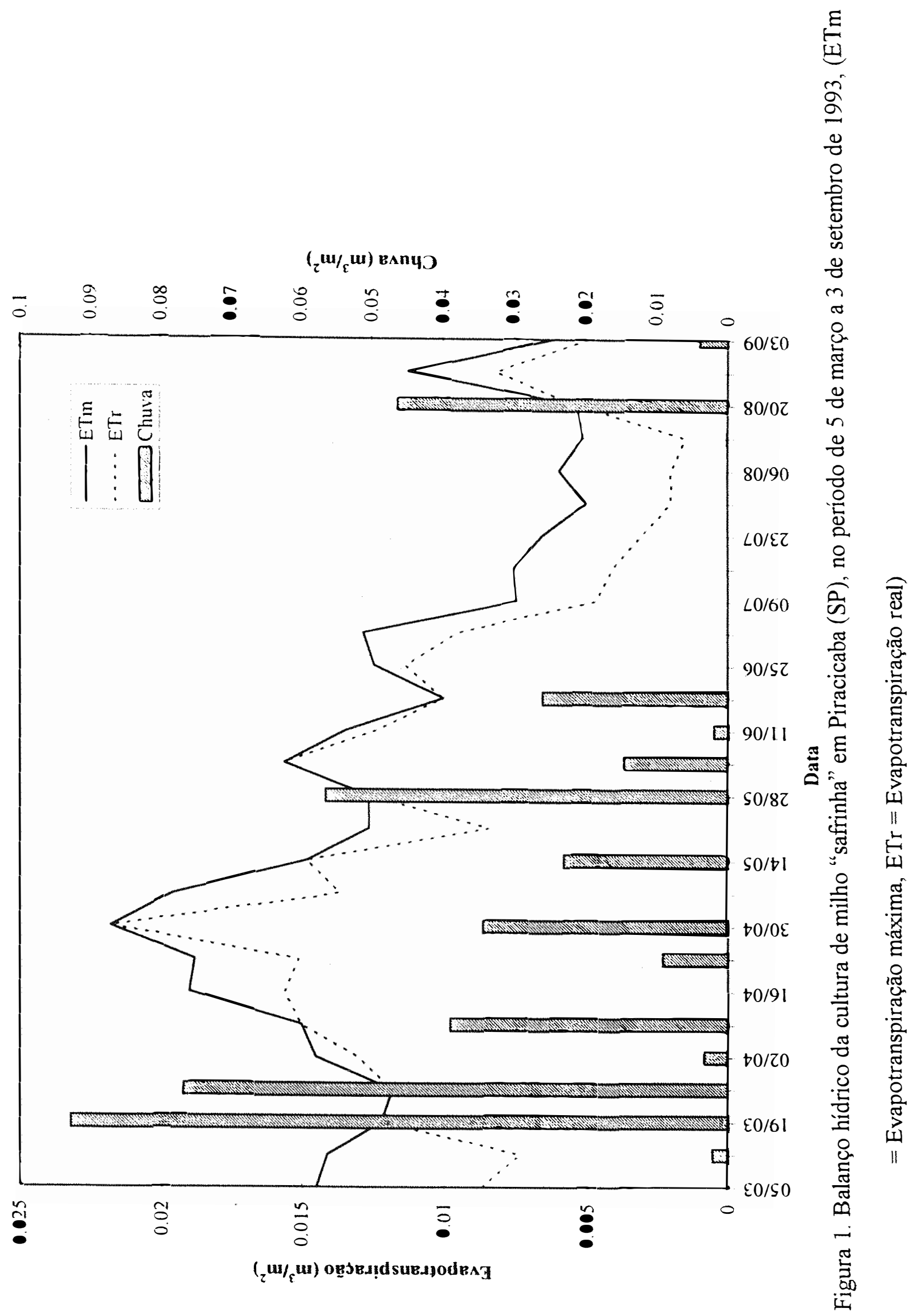




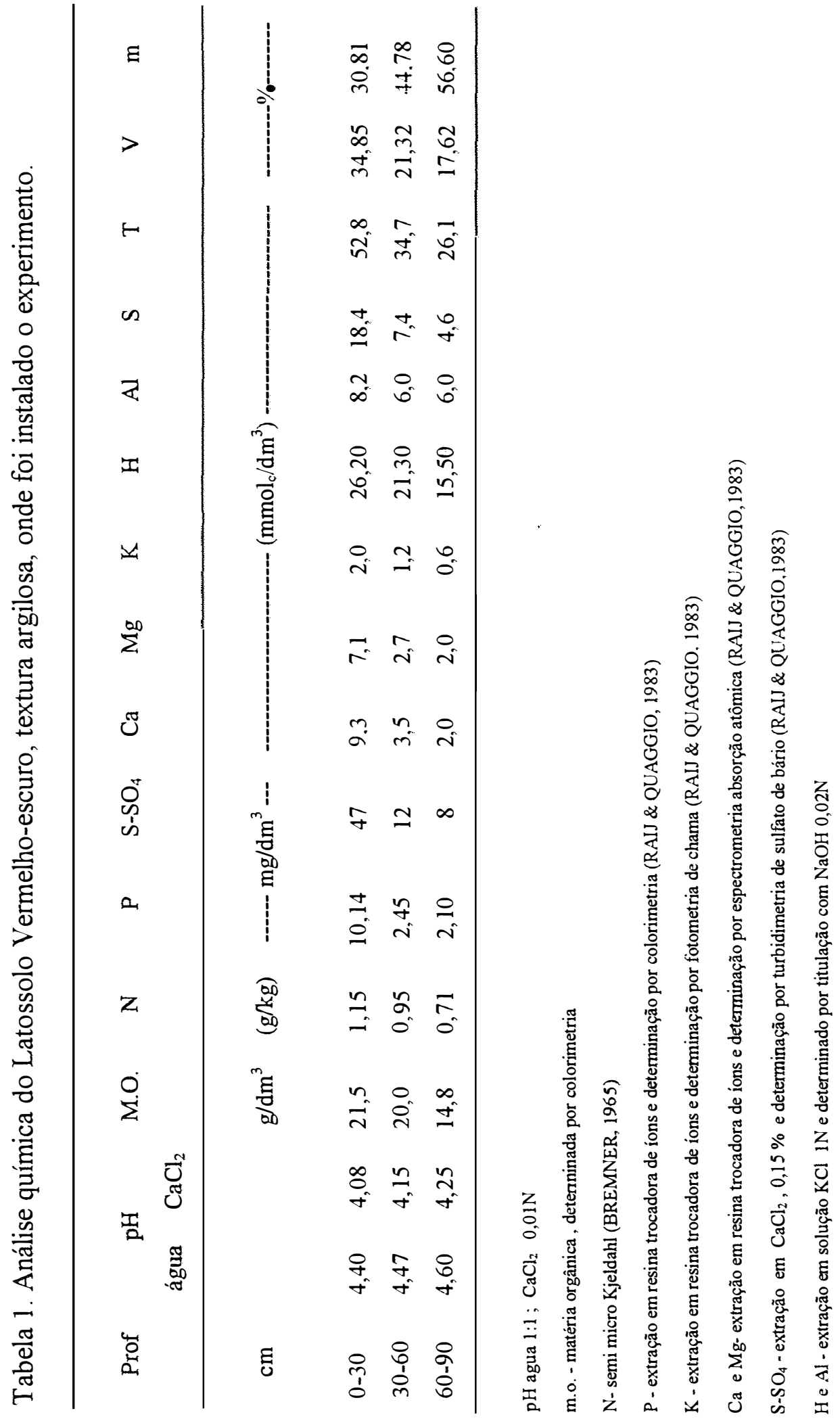


Tabela 2. Composição granulométrica e densidade do solo utilizado no experimento.

\begin{tabular}{|c|c|c|c|c|c|}
\hline \multirow[t]{2}{*}{ Profundidade } & \multicolumn{2}{|c|}{ Areia } & \multirow[t]{2}{*}{ Silte } & \multirow[t]{2}{*}{ Argila } & \multirow[t]{2}{*}{ Densidade } \\
\hline & Grossa & Fina & & & \\
\hline$(\mathrm{cm})$ & \multicolumn{4}{|c|}{ - } & $\left(\mathrm{g} / \mathrm{cm}^{3}\right)$ \\
\hline $0-30$ & 6 & 4 & 14 & 76 & 1,10 \\
\hline $30-60$ & 5 & 3 & 12 & 80 & 0,90 \\
\hline $60-90$ & 5 & 0 & 13 & 83 & 0,90 \\
\hline
\end{tabular}

Análise granulométrica - método densímetro, BOUYOUCOS (1927).

Densidade do solo - método anel volumétrico, CAMARGO et al. (1986).

\section{3. Área e Delineamento Experimental}

A área experimental de $40,5 \mathrm{~m}$ de largura por $54,5 \mathrm{~m}$ de comprimento foi subdividida em quatro blocos contendo 72 parcelas. O experimento foi instalado em esquema de blocos ao acaso, com 18 tratamentos e quatro repetições. Os tratamentos estudados e as respectivas siglas constam da Tabela 3.

Cada parcela constou de cinco linhas de milho, com espaçamento de $0,9 \mathrm{~m}$ por $6 \mathrm{~m}$ de comprimento, sendo a área da parcela, portanto, de $27 \mathrm{~m}^{2}$. 
Tabela 3. Tratamentos estudados no experimento e suas respectivas siglas.

\begin{tabular}{|c|c|}
\hline$T_{1}=$ Test & Testemunha \\
\hline$T_{2}=$ Test $+G$ & Aplicação de 2,5 t/ha de gesso \\
\hline $\mathbf{T}_{3}=\mathrm{NCa}_{1}$ & Adubação nitrogenada com nitrato de cálcio, dose $1=60 \mathrm{~kg} \mathrm{~N} / \mathrm{ha}$ \\
\hline $\mathrm{T}_{4}=\mathrm{NCa}_{2}$ & Adubação nitrogenada com nitrato de cálcio, dose $2=120 \mathrm{~kg} \mathrm{~N} / \mathrm{ha}$ \\
\hline $\mathrm{T}_{5}=\mathrm{NCa} \mathbf{a}_{1}+\mathrm{G}$ & Adubação nitrogenada com nitrato de cálcio, dose 1 + Gesso \\
\hline $\mathrm{T}_{6}=\mathrm{NCa} \mathrm{a}_{2}+\mathrm{G}$ & Adubação nitrogenada com nitrato de cálcio, dose 2 + Gesso \\
\hline $\mathrm{T}_{7}=\mathbf{N M g _ { 1 }}$ & Adubação nitrogenada com nitrato de magnésio, dose 1 \\
\hline $\mathrm{T}_{8}=\mathrm{NMg}$ & Adubação nitrogenada com nitrato de magnésio, dose 2 \\
\hline $\mathbf{T}_{9}=\mathbf{N M} \mathrm{g}_{1}+\mathbf{G}$ & Adubação nitrogenada com nitrato de magnésio, dose 1 + Gesso \\
\hline $\mathrm{T}_{10}=\mathrm{NMg}+\mathrm{G}$ & Adubação nitrogenada com nitrato de magnésio, dose $2+$ Gesso \\
\hline $\mathbf{T}_{11}=\mathbf{S A}_{1}$ & Adubação nitrogenada com sulfato de amônio, dose 1 \\
\hline $\mathrm{T}_{12}=\mathrm{SA}_{2}$ & Adubação nitrogenada com sulfato de amônio, dose 2 \\
\hline $\mathbf{T}_{13}=\mathrm{SA}_{1}+\mathrm{G}$ & Adubação nitrogenada com sulfato de amônio, dose 1 + Gesso \\
\hline $\mathrm{T}_{14}=\mathrm{SA}_{2}+\mathrm{G}$ & Adubação nitrogenada com sulfato de amônio, dose 2 + Gesso \\
\hline $\mathbf{T}_{15}=\mathrm{SN}_{1}$ & Adubação nitrogenada com sulfnitro, dose 1 \\
\hline $\mathrm{T}_{16}=\mathrm{SN}_{2}$ & Adubação nitrogenada com sulfnitro, dose 2 \\
\hline $\mathrm{T}_{17}=\mathrm{SN}_{1}+\mathrm{G}$ & Adubação nitrogenada com sulfnitro, dose 1 + Gesso \\
\hline $\mathrm{T}_{18}=\mathrm{SN}_{2}+\mathrm{G}$ & Adubação nitrogenada com sulfnitro, dose 2 + Gesso \\
\hline
\end{tabular}




\subsection{Instalação e Condução do Experimento}

A dose de gesso utilizada foi de $2,5 \mathrm{t} \cdot \mathrm{ha}^{-1}$, aplicada a lanço em cada parcela e incorporada com enxada, levemente ao solo. O gesso agrícola $\left(\mathrm{CaSO}_{4} \cdot 2 \mathrm{H}_{2} \mathrm{O}\right)$ utilizado é subproduto da indústria de fertilizantes Petrofértil e foi cedido pela Usina Costa Pinto S/A, para este ensaio. Segundo a análise da própria usina continha aproximadamente $10 \%$ de umidade; $28 \%$ de $\mathrm{CaO} ; 15,5 \%$ de $\mathrm{S}$ e $0,59 \%$ de $\mathrm{P}_{2} \mathrm{O}_{5}$

Sementes de milho híbrido duplo DINA-70 da Dinamilho Carol, foram utilizadas neste ensaio. Por ser um híbrido de ciclo precoce (125 a 140 dias), é indicado para o plantio na safrinha (plantio entre fevereiro e abril). Durante a semeadura que ocorreu em março de 1993, foram colocadas oito sementes por metro linear e posteriormente fez-se desbaste para manter um stand de 52.000 plantas.ha' ${ }^{-1}$.

Entretanto, devido a chuvas com ventos fortes após o plantio, o stand da cultura ficou próximo a 42.000 plantas. ha ${ }^{-1}$.

As fontes nitrogenadas foram adquiridas no comércio local e apresentavam, segundo especificações das indústrias produtoras, as seguintes concentrações de nitrogênio: nitrato de cálcio $\left(\mathrm{Ca}\left(\mathrm{NO}_{3}\right)_{2}\right), 15,5 \% \mathrm{~N}$ e $19 \% \mathrm{Ca}$; nitrato de magnésio $\left(\mathrm{Mg}_{\left.\left(\mathrm{NO}_{3}\right)_{2}\right)}\right)_{28} \% \mathrm{~N}$ e $16 \%$ de $\mathrm{Mg}$; sulfato de amônio $\left(\left(\mathrm{NH}_{4}\right)_{2} \mathrm{SO}_{4}\right), 20 \% \mathrm{~N}$. O sulfnitro é produzido pela indústria Norsk Hidro, sendo uma mistura granulada de uréia $(80 \%)$ e sulfato de amônio $(20 \%)$, apresentando $40 \%$ de $\mathrm{N}$ e $5 \%$ de $\mathrm{S}$. 
Um mês após a semeadura fez-se a adubação nitrogenada nos tratamentos com dose $60 \mathrm{~kg} \cdot \mathrm{ha}^{-1}$ e o primeiro parcelamento da dose $120 \mathrm{~kg} \cdot \mathrm{ha}^{-1}$. Nessa ocasião também foram aplicados em todas as parcelas $100 \mathrm{~kg} \mathrm{P}_{2} \mathrm{O}_{5} \cdot \mathrm{ha}^{-1}$ e 80 $\mathrm{kg} \mathrm{K}_{2} \mathrm{O} \cdot \mathrm{ha}^{-1}$ como superfosfato triplo e cloreto de potássio. O segundo parcelamento do $\mathrm{N}$ ocorreu um mês após a primeira adubação.

Trinta e cinco dias após a semeadura foi feita uma aplicação de herbicida Gesaprin (10 g/L), para controle das matoespécies predominantes, e de inseticida Decis ( $1 \mathrm{~mL} / \mathrm{L})$ para controle das pragas do milho.

\subsection{A plicação de ${ }^{15} \mathrm{~N}$}

Fertilizantes sulfato de amônio e nitrato de cálcio marcados com ${ }^{15} \mathrm{~N}$ foram aplicados nas parcelas relativas a esses tratamentos. Demarcou-se um metro na linha central da parcela onde foram aplicados $50 \mathrm{~mL}$ de uma solução contendo $\mathrm{Ca}\left({ }^{15} \mathrm{NO}_{3}\right)_{2}$ com $1,1777 \%$ átomos ${ }^{15} \mathrm{~N}$ em excesso e $50 \mathrm{~mL}$ de uma solução contendo $\left({ }^{15} \mathrm{NH}_{4}\right)_{2} \mathrm{SO}_{4}$ com 1,582\% átomos ${ }^{15} \mathrm{~N}$ em excesso. O restante da linha central foi adubada com os fertilizantes não marcados referentes à parcela. O fertilizante- ${ }^{15} \mathrm{~N}$ foi aplicado em solução a fim de garantir melhor distribuição do fertilizante. Para o preparo de soluções com ${ }^{15} \mathrm{~N}$, seguiu-se a metodologia indicada por ZAPATA (1990). 


\subsection{Parâmetros Observados}

Após seis meses da semeadura, as plantas das subparcelas onde foi aplicado o ${ }^{15} \mathrm{~N}$ foram colhidas, pesadas e as espigas foram separadas, pesadas e contadas. Tanto a parte aérea como as espigas foram secas ao ar, pesadas e moídas, retirando-se sub-amostras para análises químicas.

As três linhas centrais de cada parcela foram avaliadas quanto ao: número de plantas; número de espigas; massa da parte aérea incluindo as espigas; massa das espigas. Amostras de 20 plantas por parcela foram levadas ao laboratório a fim de avaliar a percentagem de umidade da matéria vegetal (folhas + colmos + espigas), e avaliar a produção de grãos. Posteriormente essas amostras foram picadas e moídas, das quais se retiraram sub-amostras para análises.

As amostras sofreram digestão sulfúrica e nitro-perclórica, sendo que o nitrogênio foi analisado pelo método semi-micro Kjeldahl (BREMNER, 1965); o P por colorimetria de molibdato vanadato; o K por fotometria de chama, o Ca e o Mg por espectrofotometria de absorção atômica, e o S por turbidimetria de sulfato de bário, segundo SARRUGE \& HAAG (1974).

Amostras de solo foram coletadas após a colheita do milho, nas linhas centrais de cada parcela, nas profundidades de 0-30 cm, 30-60 cm e 60-90 $\mathrm{cm}$, através de tradagens. Em cada parcela retiraram-se três amostras parciais para

compor uma amostra. Posteriormente foram secas ao ar e peneiradas em peneira $0,2 \mathrm{~mm}$. Os seguintes parâmetros foram analisados: 
- $\mathrm{pH}$ em $\mathrm{CaCl}_{2}$ 0,01M;

- $\mathrm{N}$ - semi micro Kjeldahl (BREMNER, 1965);

- P - extração em resina trocadora de íons e determinação por colorimetria (RAIJ \& QUAGGIO (1983);

- $\mathrm{K}^{+}$- extração em resina trocadora de íons e determinação por fotometria de chama (RAIJ \& QUAGGIO (1983);

- $\mathrm{Ca}^{+2}$ e $\mathrm{Mg}^{+2}$ - extração em resina trocadora de íns e determinação por espectrometria de absorção atômica (RAIJ \& QUAGGIO (1983);

- $\mathrm{S}-\mathrm{SO}_{4}{ }^{-2}$ extração em $\mathrm{CaCl}_{2} 0,15 \%$ e determinação por turbidimetria de sulfato de bário (RAIJ \& QUAGGIO (1983);

- $\mathrm{H}^{+}$e $\mathrm{Al}^{+3}$ - extração em solução $\mathrm{KCl} 1 \mathrm{~N}$ e determinado por titulação com $\mathrm{NaOH}$ $0,02 \mathrm{~N}$

- A soma de bases ( $\mathrm{S}$ ), foi obtida por $\mathrm{S}=\mathrm{Ca}+\mathrm{Mg}+\mathrm{K}$;

- A capacidade de troca catiônica (CTC ou $\mathrm{T}$ ) foi obtida por $\mathrm{T}=\mathrm{S}+\mathrm{H}+\mathrm{Al}$;

- A saturação da CTC por bases (V\%) foi obtida por $\mathrm{V}=(\mathrm{S} / \mathrm{T}) .100$;

- A saturação da CTC em alumínio $(\mathrm{m} \%)$ foi obtida por $\mathrm{m}=(\mathrm{Al} / \mathrm{S}+\mathrm{Al}) \cdot 100$

As amostras coletadas das subparcelas onde foi aplicado ${ }^{15} \mathrm{~N}$ foram processadas de acordo com o descrito por HAUCK \& BREMNER (1976). A determinação da composição isotópica do $\mathrm{N}$ foi efetuada por espectrômetro de massa Varian-Mat $\mathrm{CH}_{4}$, pertencente ao Centro de Energia Nuclear na Agricultura.

A percentagem de nitrogênio na planta proveniente do fertilizante (NPPF\%) foi calculada segundo a relação abaixo (IAEA-1976).

$$
\text { NPPF } \%=\frac{\% \text { Átomos }{ }^{15} \mathrm{~N} \text { excesso planta }}{\% \text { Átomos }{ }^{15} \mathrm{~N} \text { excesso fertilizante }} \cdot 100
$$


sendo que $\%$ átomos de ${ }^{15} \mathrm{~N}$ em excesso na planta $=\%$ átomos ${ }^{15} \mathrm{~N}$ na planta abundância natural $\left(0,3663 \%{ }^{15} \mathrm{~N}\right) . \quad$ A quantidade de $\mathrm{N}$ na planta proveniente do fertilizante- NPPF (g), foi calculada por:

$$
\operatorname{NPPF}(g)=\frac{\% N P P F \cdot \% N \cdot \text { produção mat. seca }(g)}{10000}
$$

A eficiência de utilização do fertilizante EUF pelo método ${ }^{15} \mathrm{~N}$ foi calculada por:

$$
\text { EUF } \%=\frac{\operatorname{NPPF}(g)}{\text { Dose } N \text { aplicado fertilizante }(g)} \quad .100
$$

De maneira indireta, a eficiência de utilização do fertilizante, EUF $_{\text {ind. }}(\%)$, foi calculada por:

$$
\text { EUF }_{\text {ind }}(\%)=\frac{\text { conteúdo } \mathrm{N} \text { tratam. adubado }(\mathrm{g})-\text { conteúdo } \mathrm{N} \text { tratam. testemunha }(\mathrm{g})}{\text { dose } \mathrm{N} \text { aplicado no fertilizante }(\mathrm{g})} \cdot 100
$$


A percentagem de nitrogênio que permaneceu no solo proveniente do fertilizante foi determinada para as profundidades em estudo, e calculada por:

$$
\text { NSPF }(\%)=\frac{\text { átomos }{ }^{15} \mathrm{~N} \text { excesso no solo }}{\text { átomos }{ }^{15} \mathrm{~N} \text { excesso fertilizante }} \quad .100
$$

sendo, $\%$ átomos ${ }^{15} \mathrm{~N}$ excesso no solo $=\%$ átomos ${ }^{15} \mathrm{~N}$ no solo - abundância natural $\left(0,3663 \%{ }^{15} N\right)$

A quantidade de nitrogênio proveniente do fertilizante nas diversas profundidades, foi calculada por:

$$
\mathrm{NSPF}\left(\mathrm{mg} \cdot \mathrm{kg}^{-1}\right)=\frac{\% \mathrm{NSPF} . \mathrm{N} \text { solo }\left(\mathrm{mg} \cdot \mathrm{kg}^{-1}\right)}{100}
$$

A percentagem de fertilizante que permaneceu nas diversas profundidades do solo ( $\%$ fertilizante aplicado remanescente) , foi obtida por:

$$
\begin{gathered}
\% \text { Fertilizante aplicado } \\
\text { remanescente }
\end{gathered}=\frac{\operatorname{NSPF}\left(\mathrm{g} \mathrm{kg}^{-1}\right) \cdot \text { massa solo na camada }(\mathrm{kg})}{\mathrm{N} \text { aplicado }(\mathrm{g})}
$$




\subsection{Análises Estatísticas}

Os dados obtidos foram analisados estatisticamente através de análise de variância (teste F) para experimentos em blocos ao acaso, comparando as médias pelo teste de Tukey. Uma segunda análise de variância foi realizada, considerando o esquema fatorial, apenas para os tratamentos com fertilizantes nitrogenados. Considerou-se entretanto, o mesmo grau de liberdade do resíduo do experimento contendo todos os tratamentos. As médias foram comparadas pelo teste de Tukey. Análises de regressão foram feitas para os parâmetros produção de grãos e no conteúdo de macronutrientes nas plantas de milho. Para as análises estatísticas foi utilizado o programa SANEST- Sistema de Análises Estatísticas, para microcomputadores IBM-PC, de autoria de ZONTA \& MACHADO (s.d.) 


\section{RESULTADOS E DISCUSSÃO}

\subsection{Produção de Milho}

A Tabela 4 apresenta as médias obtidas para os parâmetros: número de espigas; massa seca de espigas ; massa seca de grãos e massa seca de folhas e colmos. Verifica-se que o número de espigas não foi afetado pelos tratamentos, e a massa seca de espigas foi consideravelmente maior apenas para o tratamento onde se aplicou a maior dosagem de nitrato de cálcio na presença de gesso.

A produção de folhas e colmos do tratamento testemunha e testemunha + gesso foi similar obtida nos tratamentos onde se aplicou nitrogênio, indicando que não houve resposta ao nitrogênio ou à aplicação de gesso na produção de folhas + colmos das plantas.

Quanto à produção de grãos, verifica-se que houve resposta à adição de fontes nitrogenadas. As menores médias foram obtidas nos tratamentos testemunha e testemunha mais gesso. Entre esses dois tratamentos não se obteve diferenças estatísticas, portanto apenas o gesso sem a adição de nitrogênio não promoveu aumentos de produção de grãos. Utilizando o gesso e os fertilizantes nitrogenados, o aumento na produção de grãos em relação à testemunha foi de $57 \%$ (média dos tratamentos com gesso + fertilizantes nitrogenados $=11,43 \mathrm{~kg}$; média da testemunha $=7,28 \mathrm{~kg}$ ). 
Tabela 4. Valores médios de número de espigas, massa seca de espigas, massa seca de grãos, massa seca de folhas + colmos $\left(\mathrm{kg} \cdot\right.$ parcela $\left.^{-1}\right)$ e produção relativa, obtidos para os diversos tratamentos.

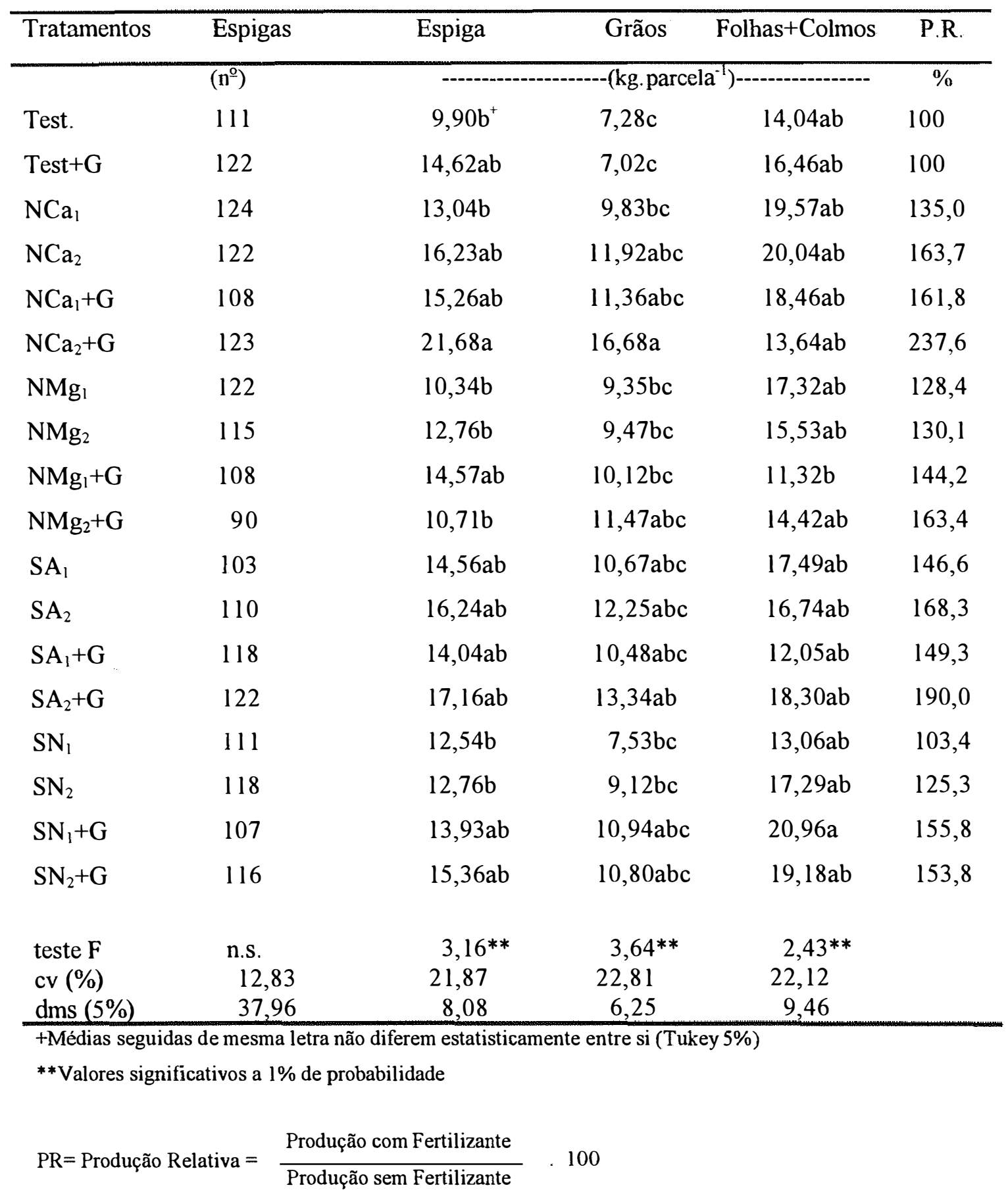


Comparando apenas os tratamentos onde se aplicou nitrogênio (Tabela 5), nota-se que a média de produção de grãos dos tratamentos com gesso foi, superior à média dos tratamentos sem gesso, sendo o aumento da ordem de 14,1\%. Aumentos de produtividade do milho devidos à aplicação de gesso são freqüentes na literatura. SMYTH \& CRAVO (1992), obtiveram aumentos médios de produção de milho de 5,85 vezes pela aplicação de uma tonelada de gesso.ha ${ }^{-1}$ em um Oxissolo da Amazônia.

QUAGGIO (1992), em experimento com a cultura de milho conduzido por quatro anos sucessivos, obteve respostas mais expressivas ao gesso no ano em que ocorreu déficit hídrico. Através de análise de regressão polinomial, o autor verificou também que, para cada tonelada de gesso houve um acréscimo de produção de milho da ordem de $50 \mathrm{~kg} \cdot \mathrm{ha}^{-1}$. Neste experimento, considerando apenas o efeito do gesso ( Tabela 5), o aumento foi de $522 \mathrm{~kg} \cdot \mathrm{ha}^{-1}$, para a dose de $2,5 \mathrm{t} \mathrm{de} \mathrm{gesso.} \mathrm{ha}^{-1}$.

Tabela 5. Médias de massa seca de folhas + colmos e grãos, $\left(\mathrm{kg} \cdot\right.$ parcela $\left.^{-1}\right)$ obtidas nas parcelas de milho, considerando os tratamentos com ou sem gesso, independentemente das fontes e doses de nitrogênio.

\begin{tabular}{lcc}
\hline Tratamentos & Folhas+Colmos & Grãos \\
\hline \multirow{2}{*}{ sem gesso } & $--------\left(\right.$ kg.parcela $\left.{ }^{-1}\right)$ & -------- \\
& 17,13 & $10,02 b^{+}$ \\
com gesso & 16,04 & $11,43 \mathrm{a}$ \\
F & n.s. & $5,58^{*}$ \\
cv $(\%)$ & 22,5 & 22,24 \\
dms (5\%) & 1,88 & 1,20 \\
\hline *Valores significativos a 5\% de probabilidade & \\
+Médias seguidas de mesma letra não diferem estatisticamente entre si (Tukey 5\%) &
\end{tabular}


A utilização de gesso tem promovido maiores ganhos em produtividade, quando problemas de acidez e baixo teor de cálcio no solo, estão aliados a períodos longos de déficit hídrico. Parte dos ganhos em produtividade podem ser explicados por melhor utilização de água, pois um aprofundamento do sistema radicular em solos com restrições químicas e sempre observados com a plicação do gesso, a exemplo dos resultados obtidos por SOUSA \& RITCHEY (1986), os quais obtiveram $68 \%$ a mais de produção de grãos de milho, através da aplicação de 6 thha $^{-1}$ de gesso em solo de cerrado. Esses autores avaliaram que o milho, tratado com gesso e submetido a 25 dias de déficit hídrico utilizou água até $120 \mathrm{~cm}$ de profundidade, enquanto as plantas não tratadas extraíram água apenas até $60 \mathrm{~cm}$ de profundidade. QUAGGIO (1992) e CARVALHO et al.(1986) também obtiveram resposta à aplicação do gesso na produtividade do milho em anos onde ocorreu déficit hídrico.

Neste experimento, o milho "safrinha" esteve sob longo período de déficit hídrico, como demonstra a Figura 1 ( períodos onde a evapotranspiração máxima-ETm é maior que a evapotranspiração real-ETr). Estádios fenológicos nos quais a falta de água prejudica de forma irrecuperável a produção, como o florescimento, que ocorre 2 meses após a semeadura, estiveram praticamente sob restrições hídricas, sendo que prejuízos maiores só não ocorreram porque o veranico foi interrompido nesse período com a chuva do dia 14 de maio. Embora o sistema radicular do milho não tenha sido avaliado neste experimento, é provável que a aplicação de gesso tenha sido efetiva na melhor utilização de água pelo milho, contribuindo para a resposta significativa na produtividade. Entretanto, a maior concentração de alguns elementos na planta, como 
será discutido em itens posteriores, revela que a resposta na produtividade é também resultado de maior eficiência na absorçãó de nutrientes.

A Tabela 6, apresenta o efeito das fontes de nitrogênio sobre a produção de matéria seca e de grãos, independentemente das doses de nitrogênio e da aplicação de gesso. O nitrato de cálcio foi a fonte que mais aumentou a produção de grãos, não diferindo do sulfato de amônio.

O sulfnitro foi a fonte menos eficiente no aumento da produção de grãos, embora, como se verifica na Tabela 4, pequeno aumento ocorreu em relação à testemunha e testemunha mais gesso, principalmente quando se utilizou essa fonte adicionando o gesso. $\mathrm{O}$ sulfato de amônio e o nitrato de magnésio foram fontes intermediárias. Estudando a adubação em cobertura com várias fontes de nitrogênio, após a adubação padrão no plantio, VILLAS BÔAS (1990) observou que a cobertura com sulfnitro foi o único tratamento que elevou a produtividade de grãos de milho quando comparado com ausência de cobertura nitrogenada. É possível que a aplicação desta fonte em cobertura, quando as plantas estão com seu sistema radicular estabelecido, aumente sua eficiência de utilização. 
Tabela 6. Médias de massa seca de folhas + colmos e grãos, $\left(\mathrm{kg}\right.$.parcela $\left.{ }^{-1}\right)$ obtidas nas parcelas de milho, considerando as fontes nitrogenadas, independentemente das doses de nitrogênio e da aplicação de gesso.

\begin{tabular}{|c|c|c|}
\hline Tratamentos & Folhas + Colmos & Grãos \\
\hline & \multicolumn{2}{|c|}{ - } \\
\hline Nitrato Cálcio & 17,93 & $12,45 \mathrm{a}^{+}$ \\
\hline Nitrato Magnésio & 14,65 & $10,10 \mathrm{bc}$ \\
\hline Sulfato Amônio & 16,15 & $11,68 \mathrm{ab}$ \\
\hline Sulfnitro & 17,62 & $9,60 \mathrm{c}$ \\
\hline $\mathrm{F}$ & n.s. & $8,03^{*}$ \\
\hline cv $(\%)$ & 22,5 & 22,24 \\
\hline $\mathrm{dms}(5 \%)$ & 3,53 & 2,01 \\
\hline
\end{tabular}

Em relação às doses de nitrogênio estudadas (Tabela 7), a aplicação de $60 \mathrm{~kg} \mathrm{~N} \cdot \mathrm{ha}^{-1}$ produziu em média $10 \mathrm{~kg}$ grãos.parcela ${ }^{-1}$, correspondente a $3704 \mathrm{~kg} \cdot \mathrm{ha}^{-1}$, quantia $40,3 \%$ superior à média de $7,15 \mathrm{~kg}_{\text {grãos.parcela }}{ }^{-1}$, correspondente a 2648 kg.ha ${ }^{-1}$, obtida nos tratamentos sem nitrogênio. Com a dose de $120 \mathrm{~kg} \mathrm{~N}$.ha ${ }^{-1}$ obteveram-se $66,2 \%$ a mais que o tratamento sem nitrogênio. 
Quanto às interações entre a aplicação de gesso e fertilizante nitrogenado (Tabela 8), verificou-se que o efeito do gesso sobre a produção de folhas + colmos e de grãos dependeu da fonte de nitrogênio. Com a aplicação de gesso, o efeito do sulfnitro se mostrou na maior produção de massa vegetal ,mas em baixa produção de grãos. O nitrato de cálcio por sua vez, foi a fonte mais eficiente na produção de grãos, apenas quando se aplicou gesso.

A Figura 2 apresenta as médias de produção de grãos estimada em kg.ha ${ }^{-1}$. Comparadas com as médias de produtividade para o Estado de São Paulo que se situa por volta de $2.811 \mathrm{~kg} \cdot \mathrm{ha}^{-1}$, segundo dados do IBGE-1993, observa-se que a maioria dos tratamentos induziu a produtividades maiores que a média do Estado.

Em ensaio realizado com 25 cultivares de milho safrinha, em oito locais do Estado de São Paulo, SAWAZAKI et al. (1994) obtiveram média de produtividade de $3.241 \mathrm{~kg} \cdot \mathrm{ha}^{-1}$. 
Tabela 7. Médias de massa seca de folhas + colmos e grãos, $\left(\mathrm{kg}\right.$.parcela $\left.{ }^{-1}\right)$ obtidas nas parcelas de milho em função das doses de nitrogênio, independentemente das fontes e da aplicação de gesso.

\begin{tabular}{|c|c|c|}
\hline Tratamentos & Folhas+Colmos & Grãos \\
\hline & \multicolumn{2}{|c|}{ - } \\
\hline $60 \mathrm{~kg} \mathrm{~N} \cdot \mathrm{ha}^{-1}$ & 16,28 & $10,03 \mathrm{~b}^{+}$ \\
\hline $120 \mathrm{~kg} \mathrm{~N} . \mathrm{ha}^{-1}$ & 16,89 & $11,41 \mathrm{a}$ \\
\hline$F(5 \%)$ & n.s. & $5,32 *$ \\
\hline $\operatorname{cv}(\%)$ & 22,55 & 22,24 \\
\hline $\mathrm{dms}(5 \%)$ & 1,89 & 1,20 \\
\hline
\end{tabular}

Tabela 8. Valores do Teste $\mathrm{F}$ a $5 \%$ de probabilidade para as interações entre gesso, fonte de nitrogênio e dose de nitrogênio para os parâmetros massa seca de folhas + colmos e grãos.

\begin{tabular}{|c|c|c|}
\hline Interação & Folhas+Colmos & Grãos \\
\hline Gesso x Fonte $\mathrm{N}$ & $4,74 * *$ & $3,01^{*}$ \\
\hline Gesso x Dose $N$ & n.s. & n.s. \\
\hline Fonte $\mathrm{N} \times$ Dose $\mathrm{N}$ & n.s. & n.s. \\
\hline Gesso $x$ Fonte $x$ Dose $N$ & n.s. & n.s. \\
\hline
\end{tabular}




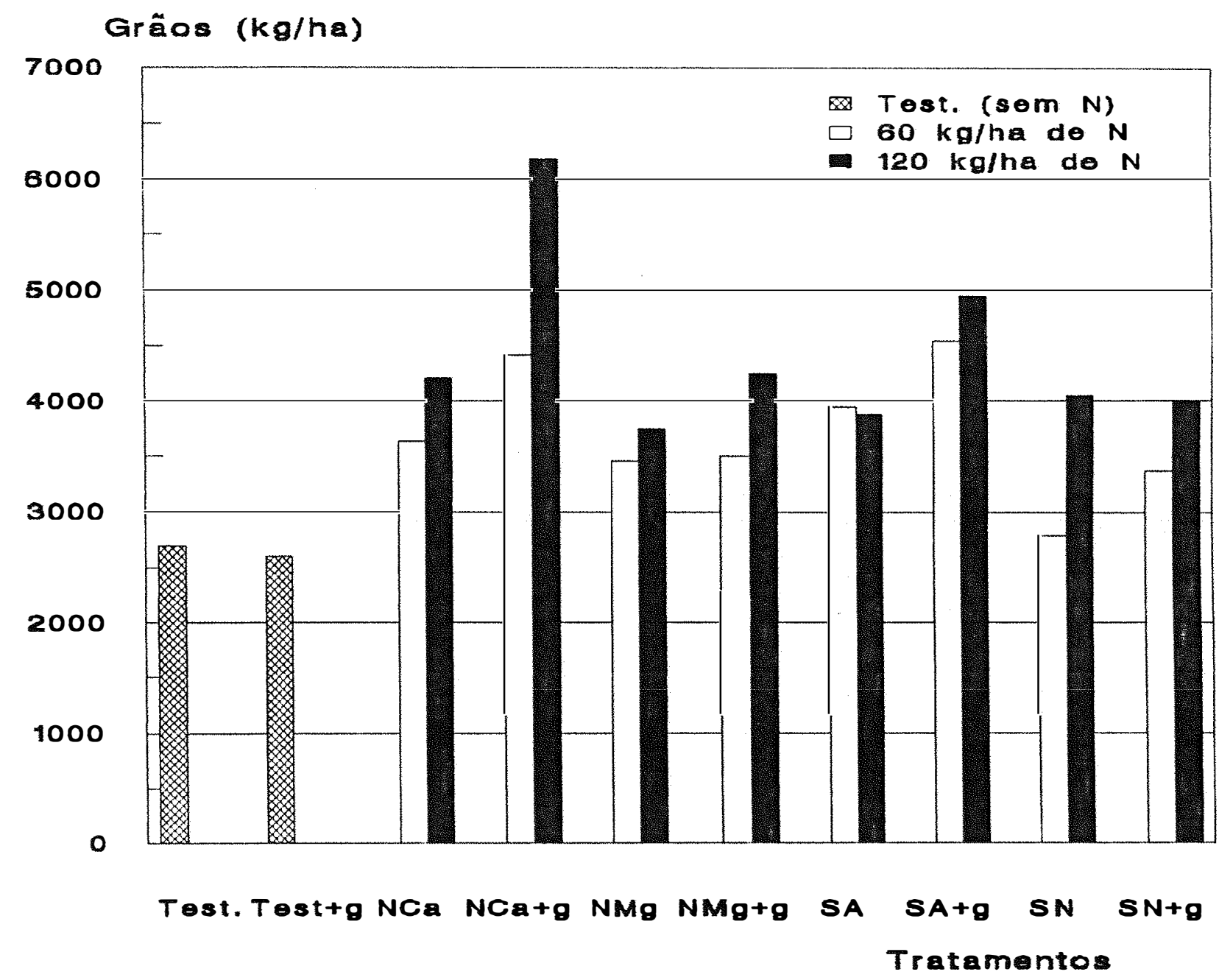

Figura 2. Produção estimada de grãos de milho $\left(\mathrm{kg}_{\mathrm{g}} \mathrm{ha}^{-1}\right)$ para os diversos tratamentos estudados. 


\subsection{Teores de Macronutrientes na Matéria Seca de Folhas+Colmos}

A Tabela 9 compara os tratamentos estudados quanto aos teores de macronutrientes na parte aérea das plantas coletadas ao final do experimento.

Os teores de $\mathrm{P}$ e $\mathrm{K}$ na parte aérea das plantas não diferiram significativamente em função dos tratamentos estudados. Os teores de $\mathrm{N}, \mathrm{Ca}, \mathrm{Mg}$ e $\mathrm{S}$ foram alterados em função da aplicação de gesso e fertilizantes nitrogenados.

A aplicação de gesso promoveu maiores concentrações de $\mathrm{N}$ nas plantas apenas quando se utilizaram fontes nitrogenadas. Mesmo quando a fonte foi o sulfnitro, utilizado na maior dosagem, ocorreu efeito positivo da aplicação de gesso (Tabela 9 e Tabela 13, interação positiva gesso $x$ dose $N$ ).

$\mathrm{Na}$ Tabela 10 verifica-se que a aplicação de gesso, independentemente das fontes e doses de nitrogênio, proporcionou aumentos de $\mathrm{N}, \mathrm{Ca}, \mathrm{Mg}$ e $\mathrm{S}$ na matéria seca das plantas de milho. Teores baixos de nitrogênio (média geral= $8,2 \mathrm{~g} \cdot \mathrm{kg}^{-1}$ ) são esperados para plantas de milho em final de ciclo.

No trabalho de SMYTH \& CRAVO (1992), o teor de cálcio nas folhas de milho no estádio de florescimento praticamente dobrou com a aplicação de uma tonelada. ha ${ }^{-1}$ gesso. Aumentos nos teores de N, P, Ca, Cu e Mn no tecido foliar de milho em função das doses de gesso também foram relatadas por SOUSA et al. (1992). 
Tabela 9. Médias dos teores de macronutrientes nos colmos + folhas das plantas de milho (g.kg matéria seca ${ }^{-1}$ ), obtidas nos diversos tratamentos.

\begin{tabular}{|c|c|c|c|c|c|c|}
\hline Tratamentos & $\bar{N}$ & $\bar{P}$ & $\bar{K}$ & $\mathrm{Ca}$ & $\mathrm{Mg}$ & $S$ \\
\hline \multicolumn{7}{|c|}{ - } \\
\hline Test. & $5,52 \mathrm{~g}^{+}$ & 0,45 & 15,42 & $2,10 \mathrm{f}$ & $2,27 \mathrm{abcd}$ & $1,07 \mathrm{fg}$ \\
\hline Test. $+\mathrm{G}$. & $6,07 \mathrm{fg}$ & 0,40 & 16,92 & $2,87 \mathrm{ab}$ & $2,80 \mathrm{ab}$ & $1,75 \mathrm{abc}$ \\
\hline $\mathrm{NCa}_{1}$ & $7,42 \mathrm{dcfg}$ & 0,40 & 15,75 & $2,30 \mathrm{ef}$ & 2,30abcd & $1,10 \mathrm{efg}$ \\
\hline $\mathrm{NCa}_{2}$ & $9,42 \mathrm{bcd}$ & 0,52 & 15,90 & $2,32 \mathrm{def}$ & 2,32abcd & $1,10 \mathrm{efg}$ \\
\hline $\mathrm{NCa}_{1}+\mathrm{G}$ & $7,65 \mathrm{dcf}$ & 0,52 & 16,67 & $2,80 \mathrm{abcd}$ & $2,75 a b c$ & $1,65 \mathrm{abcd}$ \\
\hline $\mathrm{NCa}_{2}+\mathrm{G}$ & $11,77 \mathrm{a}$ & 0,50 & 19,52 & $2,95 \mathrm{a}$ & $2,95 \mathrm{a}$ & $1,87 \mathrm{ab}$ \\
\hline $\mathrm{NMg}_{\mathrm{I}}$ & $7,10 \mathrm{efg}$ & 0,37 & 17,05 & $2,05 \mathrm{f}$ & $2,05 \mathrm{~cd}$ & $0,90 \mathrm{~g}$ \\
\hline $\mathrm{NMg}_{2}$ & $9,40 \mathrm{bcd}$ & 0,52 & 18,22 & $2,35 \mathrm{def}$ & $2,35 \mathrm{abcd}$ & $1,35 \mathrm{cdef}$ \\
\hline $\mathrm{NMg}_{1}+\mathrm{G}$ & 8,70 bcde & 0,40 & 15,97 & $2,97 a$ & $2,45 \mathrm{abcd}$ & $1,77 \mathrm{ab}$ \\
\hline $\mathrm{NMg}_{2}+\mathrm{G}$ & $9,77 \mathrm{abc}$ & 0,60 & 16,92 & $2,87 \mathrm{ab}$ & 2,52abcd & $1,95 a$ \\
\hline $\mathrm{SA}_{1}$ & 7,70 cdef & 0,55 & 17,62 & $2,17 f$ & $2,42 \mathrm{abcd}$ & 1,70abc \\
\hline $\mathrm{SA}_{2}$ & 8,90 bcde & 0,55 & 15,87 & $2,37 \mathrm{cdef}$ & $2,37 \mathrm{abcd}$ & $1,50 \mathrm{bcde}$ \\
\hline $\mathrm{SA}_{1}+\mathrm{G}$ & $9,40 \mathrm{bcd}$ & 0,62 & 17,17 & $2,92 \mathrm{a}$ & $2,27 \mathrm{abcd}$ & $1,82 \mathrm{ab}$ \\
\hline $\mathrm{SA}_{2}+\mathrm{G}$ & $10,80 \mathrm{ab}$ & 0,52 & 15,40 & $2,10 \mathrm{f}$ & $2,37 \mathrm{abcd}$ & 1,75abc \\
\hline $\mathrm{SN}_{1}$ & $6,10 \mathrm{fg}$ & 0,35 & 15,52 & $2,40 \mathrm{bcdef}$ & 2,40abcd & $1,25 \mathrm{defg}$ \\
\hline $\mathrm{SN}_{2}$ & 7,00 efg & 0,47 & 18,67 & $1,92 \mathrm{f}$ & $1,97 \mathrm{~d}$ & $1,55 \mathrm{abcd}$ \\
\hline $\mathrm{SN}_{1}+\mathrm{G}$ & $7,00 \mathrm{efg}$ & 0,45 & 17,05 & 2,77abcde & $2,15 b c d$ & $1,85 \mathrm{ab}$ \\
\hline $\mathrm{SN}_{2}+\mathrm{G}$ & $8,45 \mathrm{cde}$ & 0,52 & 17,85 & $2,10 \mathrm{f}$ & $2,15 \mathrm{bcd}$ & 1,70abc \\
\hline $\begin{array}{c}\mathrm{F} \\
\mathrm{cV}(\%)\end{array}$ & $\begin{array}{c}16,79 * * \\
9,94\end{array}$ & $\begin{array}{r}\text { n.s. } \\
29,57\end{array}$ & $\begin{array}{c}\text { n.s. } \\
10,77\end{array}$ & $\begin{array}{c}15,75^{* *} \\
7,20\end{array}$ & $\begin{array}{c}3,09 * * \\
12,01 \\
074\end{array}$ & $\begin{array}{l}16,18 * * \\
10,53 \\
042\end{array}$ \\
\hline $\mathrm{dms}(5 \%)$ & 2,11 & 0,37 & 4,73 & 0,48 & 0,74 & 0,42 \\
\hline
\end{tabular}

** Valores significativos a $1 \%$ de probabilidade

+ Médias seguidas de mesma letra não diferem estatisticamente entre si (Tukey 5\%) 
Tabela 10. Médias dos teores de macronutrientes (g.kg de matéria seca ${ }^{-1}$ ) na parte aérea das plantas de milho, considerando o efeito do gesso, independentemente das fontes e doses de nitrogênio aplicadas.

\begin{tabular}{|c|c|c|c|c|c|c|}
\hline Tratamentos & $\mathrm{N}$ & $\mathrm{P}$ & $\mathrm{K}$ & $\mathrm{Ca}$ & $\mathrm{Mg}$ & $\overline{\mathrm{S}}$ \\
\hline & \multicolumn{6}{|c|}{ - } \\
\hline sem gesso & $7,88 \mathrm{~b}^{+}$ & 0,47 & 16,83 & $2,24 b$ & $2,27 \mathrm{~b}$ & $1,31 \mathrm{~b}$ \\
\hline com gesso & $9,19 \mathrm{a}$ & 0,52 & 17,07 & $2,80 \mathrm{a}$ & $2,46 \mathrm{a}$ & $1,80 \mathrm{a}$ \\
\hline $\mathrm{F}$ & $30,74 * *$ & n.s. & n.s. & $161,26 * *$ & $5,81^{* *}$ & $143,44 * *$ \\
\hline $\operatorname{cv}(\%)$ & 10,26 & 28,51 & 10,89 & 7,00 & 12,72 & 10,56 \\
\hline dms $(5 \%)$ & 0,44 & 0,70 & 0,93 & 0,09 & 0,15 & 0,08 \\
\hline
\end{tabular}

A Tabela 11 apresenta as médias dos teores de nutrientes obtidas com a aplicação de fontes nitrogenadas, independente das doses de nitrogênio e da aplicação de gesso. Verifica-se que quando foi aplicado o fertilizante sulfnitro, as plantas continham menores teores de nitrogênio, cálcio e magnésio. As demais fontes não diferiram entre si. Os tratamentos com nitrato de cálcio induziram a menores teores de enxofre na matéria seca das plantas de milho. 
Tabela 11. Médias dos teores de macronutrientes (g.kg matéria seca ${ }^{-1}$ ), na parte aérea das plantas de milho, independentemente da aplicação de gesso e das doses de nitrogênio aplicadas.

\begin{tabular}{|c|c|c|c|c|c|c|}
\hline Tratamentos & $\mathrm{N}$ & $\bar{P}$ & $\bar{K}$ & $\mathrm{Ca}$ & $\mathrm{Mg}$ & $\mathrm{S}$ \\
\hline & \multicolumn{6}{|c|}{--- } \\
\hline Nitrato de Cálcio & $9,07 \mathrm{a}^{+}$ & 0,50 & 16,96 & $2,59 a$ & $2,89 a$ & $1,43 c$ \\
\hline Nitrato de Magnésio & $8,80 \mathrm{a}$ & 0,47 & 17,04 & $2,56 a$ & $2,30 \mathrm{ab}$ & $1,49 b c$ \\
\hline Sulfato de Amônio & $9,20 \mathrm{a}$ & 0,56 & 16,52 & $2,61 \mathrm{a}$ & $2,45 \mathrm{ab}$ & $1,69 a$ \\
\hline Sulfnitro & $7,14 b$ & 0,45 & 12,27 & $2,30 b$ & $2,20 \mathrm{~b}$ & $1,59 \mathrm{ab}$ \\
\hline $\mathrm{F}$ & $17,28 * *$ & n.s. & n.s. & $11,02 * *$ & $5,21^{* *}$ & $7,81 * *$ \\
\hline $\operatorname{cv}(\%)$ & 10,26 & 28,51 & 10,89 & 7,00 & 12,72 & 10,56 \\
\hline $\mathrm{dms}(5 \%)$ & 0,82 & 0,13 & 1,74 & 0,17 & 0,28 & 0,15 \\
\hline
\end{tabular}

Comparando as doses de nitrogênio (Tabela 12), verifica-se que as plantas apresentaram maiores teores apenas de $\mathrm{N}$ e $\mathrm{S}$, em função da dose maior de nitrogênio aplicada.

A interação positiva entre gesso e fontes de nitrogênio (Tabela 13), indica que na presença de gesso as fontes promoveram maior teor de $\mathrm{N}$, Ca e $\mathrm{S}$ na parte aérea das plantas, do que o teor obtido nos tratamentos com as mesmas fontes na ausência de gesso (Figura 3).

Pela interação positiva entre doses e fontes de nitrogênio, para o parâmetro concentração de $\mathrm{N}$ nas plantas (Tabela 13), verifica-se que as fontes se comportaram diferentemente no fornecimento de $\mathrm{N}$ às plantas, tanto na dose menor 
como na dose maior de $\mathrm{N}$, sem considerar a aplicação de gesso. Em qualquer das doses de $\mathrm{N}$, o sulfnitro foi sempre a fonte que menos forneceu $\mathrm{N}$ às plantas, fato que pode ser verificado também na Tabela 9 .

Quanto ao fornecimento de enxofre, a interação positiva entre fonte e gesso mostra que na ausência de gesso, o sulfato de amônio e o sulfnitro forneceram mais enxofre que as fontes nitrato de cálcio e nitrato de magnésio. Com a aplicação de gesso, não ocorreram diferenças entre as fontes. A mesma diferenciação entre as fontes ocorreu para a interação fonte $\mathrm{x}$ dose, apenas para a dose menor de $\mathrm{N}$.

Tabela 12. Médias dos teores de macronutrientes (g. kg matéria seca ${ }^{-1}$ ), na parte aérea das plantas de milho, independentemente da aplicação de gesso e das doses de nitrogênio aplicadas.

\begin{tabular}{|c|c|c|c|c|c|c|}
\hline Tratamentos & $\mathrm{N}$ & $\mathrm{P}$ & $\overline{\mathrm{K}}$ & $\mathrm{Ca}$ & $\mathrm{Mg}$ & $\bar{S}$ \\
\hline & \multicolumn{6}{|c|}{ - } \\
\hline 60 kg N.ha ${ }^{-1}$ & $7,63 b^{+}$ & 0,46 & 16,60 & 2,55 & 2,35 & $1,51 b$ \\
\hline $120 \mathrm{~kg} \mathrm{~N} \cdot \mathrm{ha}^{-1}$ & $9,47 \mathrm{a}$ & 0,53 & 17,30 & 2,48 & 2,38 & $1,60 \mathrm{a}$ \\
\hline $\mathrm{F}$ & $81,88^{* *}$ & n.s. & n.s. & n.s. & n.s. & $4,89 * *$ \\
\hline Cv $(\%)$ & 10,26 & 28,51 & 10,89 & 7,00 & 12,72 & 10,56 \\
\hline $\mathrm{dms}(5 \%)$ & 0,44 & 0,07 & 0,93 & 0,09 & 0,15 & 0,08 \\
\hline
\end{tabular}

Tabela 13. Valores de teste $\mathrm{F}$ a $5 \%$ ou a $1 \%$ de probabilidade para as interações entre gesso, fonte de nitrogênio e dose de nitrogênio, para os teores de $\mathrm{N}, \mathrm{P}, \mathrm{K}, \mathrm{Ca}$, $\mathrm{Mg}$ e S na matéria seca da parte aérea do milho.

\begin{tabular}{lclllll}
\hline Interação & $\mathrm{N}$ & $\mathrm{P}$ & $\mathrm{K}$ & $\mathrm{Ca}$ & $\mathrm{Mg}$ & $\mathrm{S}$ \\
\hline Gesso x Fonte N & $3,35^{*}$ & n.s. & n.s. & $5,22^{* *}$ & $3,84^{*}$ & $9,72^{* *}$ \\
Gesso x Dose N & $3,17^{*}$ & n.s. & n.s. & n.s. & n.s. & n.s. \\
Fonte N x Dose N & $3,29^{*}$ & n.s. & $3,31^{*}$ & $14,89^{* *}$ & n.s. & $5,06^{* *}$ \\
Gesso x Fonte N x Dose N & n.s. & n.s. & n.s. & n.s. & n.s. & $3,84^{*}$ \\
& & & & & & \\
\hline
\end{tabular}

* Valores significativo a $5 \%$ de probabilidade

**Valores significativos a $1 \%$ de probabilidade 


\section{g. Kg tollese+otinos 1}

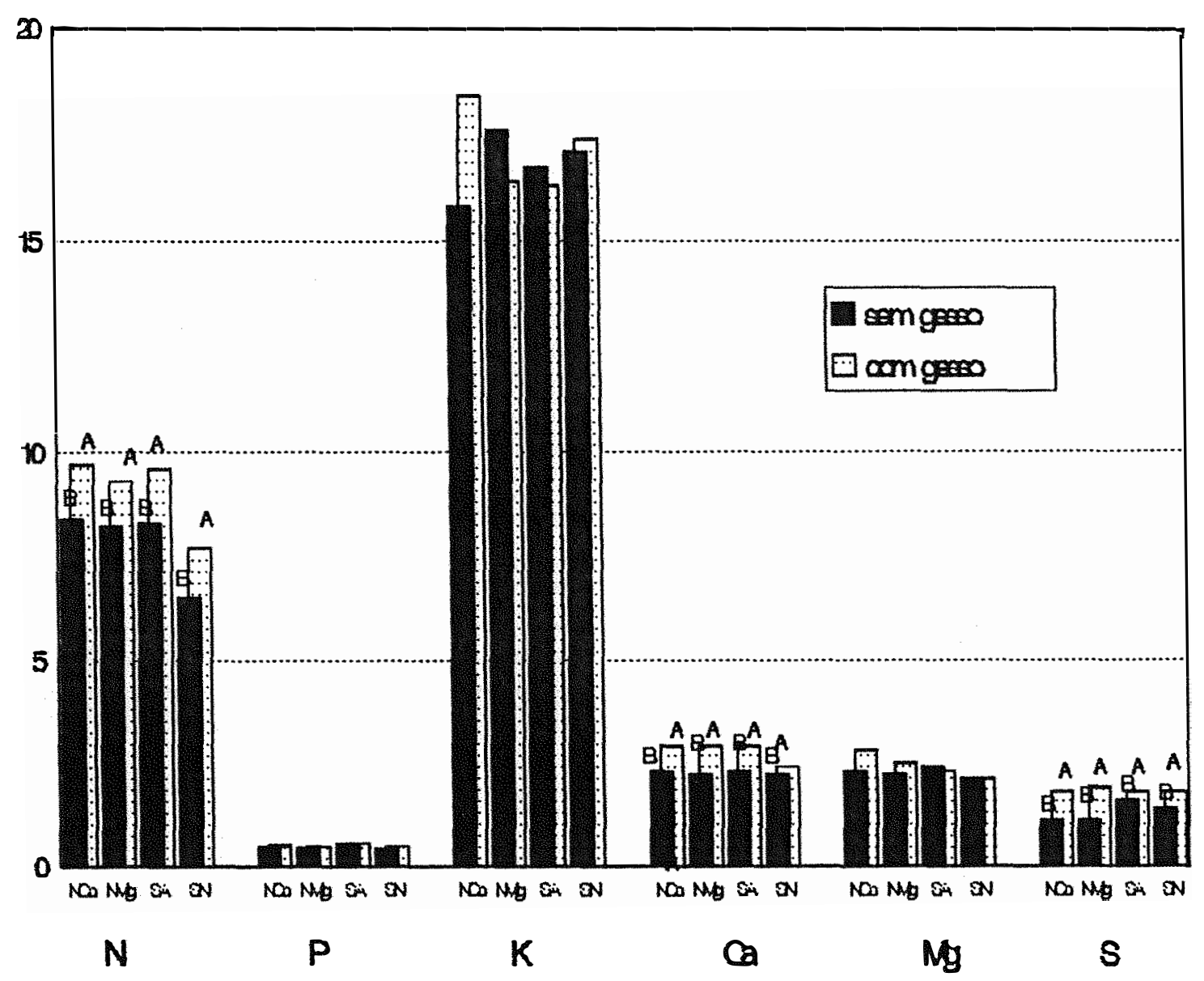

Figura 3. Médias dos teores de N, P, K, Ca, Mg e S obtidos na parte aérea das plantas de milho (folhas + colmos), considerando as fontes nitrogenadas independentemente das doses, na presença ou ausência de gesso. 


\subsection{Quantidades Acumuladas de Macronutrientes na Matéria Seca de Folhas + Colmos}

A Tabela 14 apresenta os dados obtidos para conteúdo de macronutrientes nas folhas + colmos das plantas de milho. Os tratamentos estudados promoveram diferenças significativas do ponto de vista estatístico apenas para os parâmetros N, K, Ca e S. Entre os tratamentos testemunha e testemunha + gesso, não se verificou diferença significativa nos conteúdos de macronutrientes, indicando que os aumentos verificados nas quantidades acumuladas foram devidos à presença de fertilizantes nitrogenados associados ou não ao gesso.

A Tabela 15 mostra que como efeito do gesso houve aumento no acúmulo de $\mathrm{Ca}$ e $\mathrm{S}$ das plantas; esse fato era esperado por ser o gesso uma fonte desses nutrientes. Embora tenha ocorrido efeito significativo do gesso no aumento do teor de nitrogênio da parte aérea (Tabela 10), o fato do crescimento das plantas não ter sido muito diferenciado em função dos tratamentos (Tabelas 4 e 5), teve como consequência, acúmulos similares de nitrogênio. Entretanto, verifica-se tendência a acúmulos maiores de nitrogênio em função do efeito do gesso. 
Tabela 14. Médias dos conteúdos de macronutrientes ( $\mathrm{g}$. kg matéria seca de folhas + colmos $^{-1}$ ), acumulados pelas plantas de milho nos diversos tratamentos.

\begin{tabular}{|c|c|c|c|c|c|c|}
\hline Tratamentos & $\mathrm{N}$ & $\mathrm{P}$ & $\mathrm{K}$ & $\mathrm{Ca}$ & $\mathrm{Mg}$ & $\mathrm{S}$ \\
\hline & \multicolumn{6}{|c|}{ 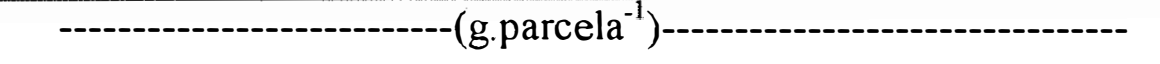 } \\
\hline Test. & $76,57 \mathrm{c}+$ & 6,727 & $216,1 \mathrm{ab}$ & $29,48 b$ & 31,77 & $15,26 \mathrm{c}$ \\
\hline Test. $+\mathrm{G}$. & $99,68 \mathrm{bc}$ & 6,555 & $277,1 \mathrm{ab}$ & $47,47 \mathrm{ab}$ & 46,07 & $28,70 \mathrm{abc}$ \\
\hline $\mathrm{NCa}_{1}$ & $146,18 \mathrm{abc}$ & 8,885 & $309,8 \mathrm{ab}$ & $44,94 \mathrm{ab}$ & 44,94 & $21,63 \mathrm{bc}$ \\
\hline $\mathrm{NCa}_{2}$ & $188,46 a$ & 10,462 & $318,1 \mathrm{ab}$ & $46,71 \mathrm{ab}$ & 46,71 & 22,0 labc \\
\hline $\mathrm{NCa}_{1}+\mathrm{G}$ & $142,93 \mathrm{abc}$ & 9,485 & $304,9 \mathrm{ab}$ & $51,83 \mathrm{ab}$ & 51,33 & $30,54 \mathrm{abc}$ \\
\hline $\mathrm{NCa}_{2}+\mathrm{G}$ & $160,55 \mathrm{abc}$ & 6,897 & $267,1 \mathrm{ab}$ & $40,15 \mathrm{ab}$ & 40,15 & $25,52 \mathrm{abc}$ \\
\hline $\mathrm{NMg}_{1}$ & $120,96 \mathrm{abc}$ & 6,440 & $291,6 a b$ & $35,58 \mathrm{ab}$ & 35,58 & $15.55 \mathrm{c}$ \\
\hline $\mathrm{NMg}_{2}$ & $144,67 \mathrm{abc}$ & 7,820 & $278,8 \mathrm{ab}$ & $36,53 \mathrm{ab}$ & 36,53 & $20,52 b c$ \\
\hline $\mathrm{NMg}_{1}+\mathrm{G}$ & $98,21 b c$ & 4,337 & $181,9 b$ & $33,50 \mathrm{ab}$ & 27,15 & $20,04 \mathrm{bc}$ \\
\hline $\mathrm{NMg}_{2}+\mathrm{G}$ & $141,27 \mathrm{abc}$ & 8,657 & $243,7 \mathrm{ab}$ & $41,51 \mathrm{ab}$ & 36,49 & $28,16 a b c$ \\
\hline $\mathrm{SA}_{1}$ & $136,02 \mathrm{abc}$ & 9,910 & $312,0 \mathrm{ab}$ & $38,02 \mathrm{ab}$ & 41,88 & $22,03 \mathrm{abc}$ \\
\hline $\mathrm{SA}_{2}$ & $149,28 \mathrm{abc}$ & 9,025 & $265,1 \mathrm{ab}$ & $40,53 \mathrm{ab}$ & 40,53 & $25,88 \mathrm{abc}$ \\
\hline $\mathrm{SA}_{1}+\mathrm{G}$ & $113,27 \mathrm{abc}$ & 8,212 & $205,9 \mathrm{ab}$ & $35,32 \mathrm{ab}$ & 26,29 & $22,03 \mathrm{abc}$ \\
\hline $\mathrm{SA}_{2}+\mathrm{G}$ & $198,17 \mathrm{a}$ & 9,662 & $278,6 \mathrm{ab}$ & $54,35 \mathrm{ab}$ & 43,90 & $32,11 \mathrm{ab}$ \\
\hline $\mathrm{SN}_{1}$ & $79,35 b c$ & 4,585 & $202,4 \mathrm{ab}$ & $31,50 \mathrm{~b}$ & 31,50 & $16,30 b c$ \\
\hline $\mathrm{SN}_{2}$ & $123,56 a b c$ & 8,270 & $317,2 \mathrm{ab}$ & $32,79 \mathrm{ab}$ & 33,40 & $27,44 a b c$ \\
\hline $\mathrm{SN}_{1}+\mathrm{G}$ & $143,50 \mathrm{abc}$ & 9,292 & $357,2 \mathrm{a}$ & $58,30 \mathrm{a}$ & 45,28 & $38,40 \mathrm{a}$ \\
\hline $\mathrm{SN}_{2}+\mathrm{G}$ & $163,95 \mathrm{ab}$ & 10,315 & $344,1 \mathrm{a}$ & $40,88 \mathrm{ab}$ & 41,33 & $32,41 \mathrm{ab}$ \\
\hline $\begin{array}{c}F \\
\operatorname{cv}(\%)\end{array}$ & $\begin{array}{c}4,34^{* *} \\
24,27\end{array}$ & $\begin{array}{r}\text { n.s. } \\
39,33\end{array}$ & $\begin{array}{c}2,58^{*} \\
22,46\end{array}$ & $\begin{array}{c}2,26^{*} \\
24,24\end{array}$ & $\begin{array}{r}\text { n.s. } \\
24,99\end{array}$ & $\begin{array}{c}4,08^{* *} \\
25,30\end{array}$ \\
\hline dms $(5 \%)$ & 84,70 & 8,274 & 161,40 & 26,29 & 25,32 & 16,54 \\
\hline
\end{tabular}

* Valores significativos a $5 \%$ de probabilidade

**Valores significativos a $1 \%$ de probabilidade

+ Médias seguidas de mesma letra não diferem estatisticamente entre si (Tukey 5\%) 
Tabela 15. Médias dos conteúdos de macronutrientes (g.kg total de matéria seca de folhas $\left.+\operatorname{colmos}^{-1}\right)$, acumulados pelas plantas de milho nas parcelas, considerando os tratamentos com ou sem gesso, independentemente das fontes e doses de nitrogênio.

\begin{tabular}{|c|c|c|c|c|c|c|}
\hline Tratamentos & $\mathrm{N}$ & $\mathrm{P}$ & $\mathrm{K}$ & $\mathrm{Ca}$ & $\mathrm{Mg}$ & $\mathrm{S}$ \\
\hline & \multicolumn{6}{|c|}{ - } \\
\hline sem gesso & 136,06 & 8,17 & 285,94 & $38,01 \mathrm{~b}+$ & 33,96 & $22,37 b$ \\
\hline com gesso & 145,23 & 8,34 & 272,92 & $44,47 \mathrm{a}$ & 38,97 & $28,64 a$ \\
\hline $\mathrm{F}$ & n.s. & n.s. & n.s. & $6,79 * *$ & n.s. & $14,75^{* *}$ \\
\hline $\operatorname{cv}(\%)$ & 24,55 & 38,89 & 23,08 & 24,05 & 28,86 & 25,59 \\
\hline $\mathrm{dms}(5 \%)$ & 17,3 & 1,62 & 32,50 & 5,00 & 5,30 & 3,30 \\
\hline
\end{tabular}

A Tabela 16 relaciona as médias de macronutrientes acumulados em função das fontes de $\mathrm{N}$ aplicadas, independentemente das doses e da aplicação de gesso. A utilização de nitrato de cálcio promoveu maiores acúmulos de $\mathrm{N}$ e Mg. Nesse sentido, foi uma fonte superior ao próprio nitrato de magnésio, indicando que a aplicação de magnésio não influenciou a produção e os conteúdos acumulados desse nutriente.

O sulfato de amônio e o sulfnitro levaram a altos acúmulos de enxofre na parte aérea das plantas. 
Dentro de cada dose de nitrogênio estudada, não houve variação do ponto de vista estatístico entre as médias dos nutrientes acumulados na matéria seca de folhas + colmos, exceto para o $\mathrm{N}$ (Tabela 17).

Tabela 16. Médias dos conteúdos de macronutrientes (g. parcela), acumulados pelas plantas de milho nas parcelas, em função das fontes nitrogenadas, independentemente das doses de $\mathrm{N}$ e da aplicação de gesso.

\begin{tabular}{lcccccc}
\hline Tratamentos & $\mathrm{N}$ & $\mathrm{P}$ & $\mathrm{K}$ & $\mathrm{Ca}$ & $\mathrm{Mg}$ & $\mathrm{S}$ \\
\hline & & & & & & \\
Nitrato Cálcio & $159,52 \mathrm{a}^{+}$ & 8,92 & 299,97 & 45,90 & $45,77 \mathrm{a}$ & $24,92 \mathrm{ab}$ \\
Nitrato Magnésio & $126,26 \mathrm{~b}$ & 6,79 & 247,12 & 36,77 & $33,92 \mathrm{~b}$ & $21,06 \mathrm{~b}$ \\
Sulfato Amônio & $149,02 \mathrm{ab}$ & 9,20 & 265,39 & 41,44 & $28,34 \mathrm{~b}$ & $27,42 \mathrm{a}$ \\
Sulfnitro & $127,59 \mathrm{ab}$ & 8,11 & 305,24 & 40,85 & $37,85 \mathrm{ab}$ & $28,63 \mathrm{a}$ \\
F & $3,44^{*}$ & n.s. & n.s. & n.s. & $7,75^{* *}$ & $4,20^{* *}$ \\
cv (\%) & 24,55 & 38,89 & 23,08 & 24,05 & 28,86 & 25,59 \\
dms (5\%) & 32,42 & 3,03 & 60,91 & 9,37 & 9,94 & 6,16 \\
\hline
\end{tabular}

**Valores significativos a $1 \%$ probabilidade

*Valores significativos a $5 \%$ probabilidade

${ }^{\dagger}$ Médias seguidas de mesma letra não diferem estatisticamente entre si (Tukey 5\%).

Tabela 17. Médias dos conteúdos de macronutrientes ( $\mathrm{g} . \mathrm{kg}$ total de matéria seca de folhas $\left.+\operatorname{colmos}^{-1}\right)$, acumulados pelas plantas de milho nas parcelas, em função das doses de nitrogênio, independentemente das fontes e da aplicação de gesso.

\begin{tabular}{|c|c|c|c|c|c|c|}
\hline Tratamentos & $\bar{N}$ & $\bar{P}$ & $\overline{\mathrm{K}}$ & $\overline{\mathrm{Ca}}$ & $\mathrm{Mg}$ & $\bar{S}$ \\
\hline & \multicolumn{6}{|c|}{ - } \\
\hline $60 \mathrm{~kg} \mathrm{~N} \cdot \mathrm{ha}^{-1}$ & $122,55 b+$ & 7,63 & 270,72 & 40,80 & 37,21 & 24,26 \\
\hline $120 \mathrm{~kg} \mathrm{~N} \cdot \mathrm{ha}^{-1}$ & $158,73 a$ & 8,89 & 288,14 & 41,68 & 35,73 & 26,76 \\
\hline $\mathrm{F}$ & $19,33 * *$ & n.s. & n.s. & n.s. & n.s. & n.s. \\
\hline $\operatorname{cv}(\%)$ & 24,55 & 38,90 & 23,08 & 24,06 & 28,86 & 25,59 \\
\hline $\mathrm{dms}(5 \%)$ & 17,31 & 1,62 & 32,52 & 5,00 & 5,31 & 3,29 \\
\hline
\end{tabular}

** Valores significativos a $1 \%$ probabilidade

+Médias seguidas de mesma letra não diferem estatisticamente entre si (Tukey 5\%). 
A Tabela 18 apresenta interações significativas entre os fatores gesso $\mathrm{x}$ fonte de $\mathrm{N}$ para os acúmulos de $\mathrm{N}, \mathrm{K}$ e $\mathrm{S}$. Analisando as interações e observando os dados da Tabela 14 e da Figura 4, verifica-se que com a utilização do gesso, as fontes não diferiram entre si, quanto ao acúmulo de nitrogênio na matéria seca das folhas + colmos do milho. Sem gesso, o sulfnitro teve eficiência inferior. Quanto ao potássio, utilizando gesso, as fontes mais efetivas foram o nitrato de cálcio e o sulfnitro, principalmente na dose menor de nitrogênio.

Para o cálcio, houve interação positiva entre fonte de $\mathrm{N}$ e dose de $\mathrm{N}$, sendo que na dose menor de nitrogênio, apenas o nitrato de magnésio induziu a menores conteúdos de $\mathrm{Ca}$ na matéria seca de folhas + colmos. Para o enxofre, avaliando a interação entre gesso e fonte de $\mathrm{N}$, obteve-se que nitrato de magnésio levou a menores acúmulos de $\mathrm{S}$ na matéria seca de folhas + colmos, tanto nas plantas tratadas com gesso quanto nas não tratadas.

Tabela 18. Valores do teste $\mathrm{F}$ a $5 \%$ de probabilidade para as interações entre gesso, fonte de nitrogênio e dose de-nitrogênio, para os conteúdos de macronutrientes nas folhas + colmos de milho.

\begin{tabular}{lcccccc}
\hline Interação & $\mathrm{N}$ & $\mathrm{P}$ & $\mathrm{K}$ & $\mathrm{Ca}$ & $\mathrm{Mg}$ & $\mathrm{S}$ \\
\hline Gesso x Fonte N & $3,35^{*}$ & n.s. & $4,87^{*}$ & n.s. & n.s. & $3,17^{*}$ \\
Gesso x Dose N & n.s. & n.s. & n.s. & n.s. & n.s. & n.s. \\
Fonte N x Dose N & n.s. & n.s. & n.s. & $3,40^{*}$ & n.s. & n.s. \\
Gesso x Fonte N x Dose N & n.s. & n.s. & $3,15^{*}$ & $4,04^{*}$ & n.s. & $4,04^{*}$ \\
\hline
\end{tabular}

*Valores significativos a $5 \%$ probabilidade 


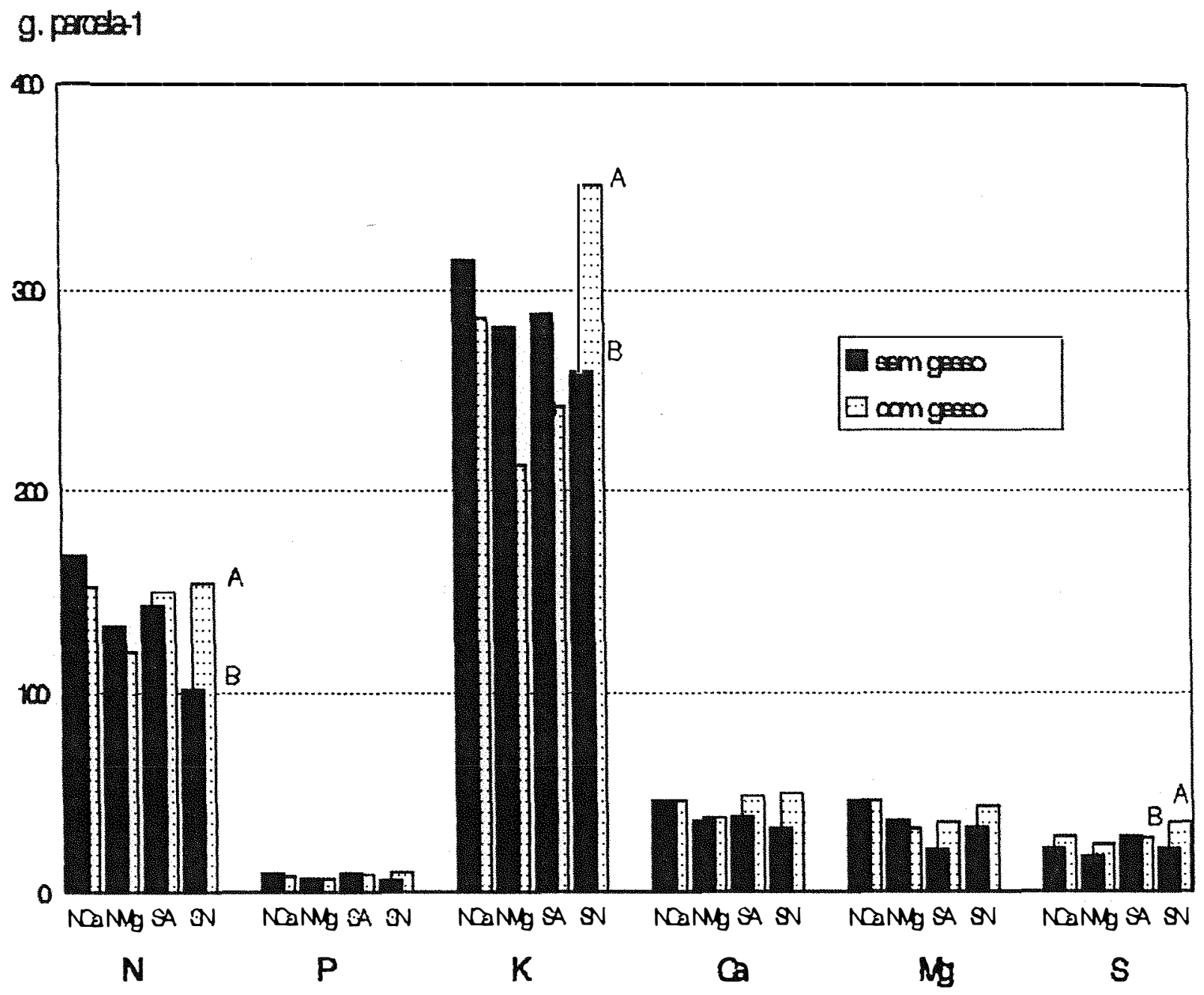

Figura 4. Médias dos acúmulos de $\mathrm{N}, \mathrm{P}, \mathrm{K}, \mathrm{Ca}, \mathrm{Mg}$ e $\mathrm{S}$ obtidos na parte aérea das plantas de milho (folhas + colmos), considerando as fontes nitrogenadas independente das doses, na presença ou ausênciâ de gesso. 


\subsection{Teores e Conteúdos de Macronutrientes nos Grãos de Milho}

A Tabela 19 apresenta os teores de macronutrientes nos grãos de milho. Não ocorreram diferenças significativas entre os tratamentos e, portanto, nem a aplicação de gesso e nem a utilização de fertilizantes nitrogenados foi capaz de alterar o teor desses nutrientes nos grãos de milho. O teor de nutrientes pelos grãos de milho foi, contudo, muito similar à obtida por BARBER \& OLSEN (1968), em experimento de marcha de absorção em milho, exceto para o cálcio que foi extraído cerca de 10 vezes mais nesse experimento.

Como não ocorreram diferenças estatísticas nos teores de nutrientes, as diferenças obtidas nos acúmulos de nutrientes nos grãos são devidas principalmente às diferenças de massa obtidas entre os tratamentos.

Assim, na Tabela 20, verifica-se que os acúmulos de $\mathrm{N}, \mathrm{P}, \mathrm{K}, \mathrm{Ca}$, e $\mathrm{Mg}$ nos grãos de milho aumentaram significativamente somente quando se aplicou o nitrato de cálcio na maior dosagem + gesso. O conteúdo de enxofre não variou em função dos tratamentos. 
Tabela 19. Médias dos teores de macronutrientes nos grãos de milho (g.kg matéria seca de grãos $^{-1}$ ), obtidas nos diversos tratamentos.

\begin{tabular}{|c|c|c|c|c|c|c|}
\hline Tratamentos & $\bar{N}$ & $\bar{P}$ & $\mathrm{~K}$ & $\mathrm{Ca}$ & $\mathrm{Mg}$ & $\mathrm{S}$ \\
\hline & \multicolumn{6}{|c|}{ - } \\
\hline Test. & 15,47 & 2,52 & 3,80 & 2,50 & 1,37 & 1,97 \\
\hline Test. $+\mathrm{G}$ & 18,70 & 2,75 & 3,95 & 2,25 & 1,40 & 1,35 \\
\hline $\mathrm{NCa}_{1}$ & 15,42 & 2,57 & 3,50 & 2,45 & 1,27 & 1,30 \\
\hline $\mathrm{NCa}_{2}$ & 18,30 & 2,30 & 3,52 & 2,10 & 1,25 & 1,27 \\
\hline $\mathrm{NCa}_{1}+\mathrm{G}$ & 16,47 & 3,22 & 4,82 & 2,35 & 1,62 & 1,30 \\
\hline $\mathrm{NCa}_{2}+\mathrm{G}$ & 16,82 & 2,57 & 4,47 & 2,25 & 1,95 & 1,35 \\
\hline $\mathrm{NMg}_{1}$ & 15,60 & 3,20 & 4,30 & 2,10 & 1,85 & 1,32 \\
\hline $\mathrm{NMg}_{2}$ & 15,72 & 2,62 & 4,22 & 2,20 & 1,42 & 1,20 \\
\hline $\mathrm{NMg}_{1}+\mathrm{G}$ & 16,95 & 3,85 & 4,37 & 2,25 & 2,00 & 1,47 \\
\hline $\mathrm{NMg}_{2}+\mathrm{G}$ & 17,17 & 3,07 & 4,17 & 2,15 & 1,60 & 1,77 \\
\hline $\mathrm{SA}_{1}$ & 15,20 & 2,92 & 3,92 & 2,15 & 1,50 & 1,35 \\
\hline $\mathrm{SA}_{2}$ & 16,67 & 3,65 & 5,02 & 2,20 & 1,82 & 1,45 \\
\hline $\mathrm{SA}_{1}+\mathrm{G}$ & 18,70 & 3,07 & 3,92 & 2,45 & 1,70 & 1,55 \\
\hline $\mathrm{SA}_{2}+\mathrm{G}$ & 16,32 & 2,90 & 3,97 & 2,25 & 1,37 & 1,25 \\
\hline $\mathrm{SN}_{1}$ & 17,02 & 2,65 & 3,75 & 2,10 & 1,52 & 1,15 \\
\hline $\mathrm{SN}_{2}$ & 15,92 & 3,27 & 4,45 & 2,45 & 1,62 & 1,25 \\
\hline $\mathrm{SN}_{1}+\mathrm{G}$ & 16,90 & 3,55 & 4,42 & 2,45 & 1,92 & 1,40 \\
\hline $\mathrm{SN}_{2}+\mathrm{G}$ & 16,10 & 2,97 & 3,77 & 2,05 & 1,65 & 1,30 \\
\hline F & n.s. & n.s. & n.s. & n.s. & n.s. & n.s. \\
\hline cv $(\%)$ & 8,5 & 24,3 & 18,22 & 12,31 & 26,28 & 35,48 \\
\hline $\mathrm{dms}(5 \%)$ & 3,68 & 1,92 & 1,96 & 0,72 & 1,09 & 1,28 \\
\hline
\end{tabular}


Tabela 20. Médias dos acúmulos de macronutrientes nos grãos de milho (g.kg de grãos total da parcela $\left.{ }^{-1}\right)$, obtidas nos diversos tratamentos.

\begin{tabular}{|c|c|c|c|c|c|c|}
\hline Tratamentos & $\bar{N}$ & $\bar{P}$ & $\bar{K}$ & $\mathrm{Ca}$ & $\mathrm{Mg}$ & $\bar{S}$ \\
\hline & \multicolumn{6}{|c|}{ 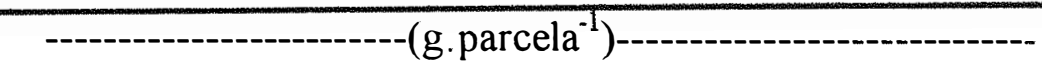 } \\
\hline Test. & $111,4 \mathrm{lb}^{+}$ & $18,86 \mathrm{~b}$ & $28,27 \mathrm{~b}$ & $18,14 \mathrm{~b}$ & $10,45 b$ & 15,71 \\
\hline Test $+\mathrm{G}$ & $132,67 b$ & $19,48 b$ & $27,68 b$ & $15,56 \mathrm{~b}$ & $9,81 \mathrm{~b}$ & 9,60 \\
\hline $\mathrm{NCa}_{1}$ & $151,06 b$ & $25,3 \mathrm{lb}$ & $34,57 \mathrm{~b}$ & $23,92 \mathrm{ab}$ & $12,53 \mathrm{~b}$ & 12,32 \\
\hline $\mathrm{NCa}_{2}$ & $219,94 \mathrm{ab}$ & $27,3 \mathrm{lb}$ & $41,94 \mathrm{ab}$ & $25,07 \mathrm{ab}$ & $14,82 \mathrm{ab}$ & 15,40 \\
\hline $\mathrm{NCa}_{1}+\mathrm{G}$ & $187,25 \mathrm{ab}$ & $37,02 \mathrm{ab}$ & $54,90 \mathrm{ab}$ & $26,80 \mathrm{ab}$ & $18,61 \mathrm{ab}$ & 14,75 \\
\hline $\mathrm{NCa}_{2}+\mathrm{G}$ & $280,06 a$ & $61,71 \mathrm{a}$ & $74,18 \mathrm{a}$ & $37,52 \mathrm{a}$ & $32,23 a$ & 22,48 \\
\hline $\mathrm{NMg}_{\mathrm{l}}$ & $145,69 b$ & $29,92 \mathrm{ab}$ & $40,3 \mathrm{lab}$ & $19,52 b$ & $17,12 \mathrm{ab}$ & 12,12 \\
\hline $\mathrm{NMg}_{2}$ & $148,88 b$ & $24,81 b$ & $40,14 \mathrm{ab}$ & $20,66 \mathrm{~b}$ & $13,56 b$ & 11,38 \\
\hline $\mathrm{NMg}_{1}+\mathrm{G}$ & $170,42 \mathrm{ab}$ & $38,73 \mathrm{ab}$ & $43,38 \mathrm{ab}$ & $22,45 b$ & $20,01 \mathrm{ab}$ & 15,10 \\
\hline $\mathrm{NMg}_{2}+\mathrm{G}$ & $197,32 \mathrm{ab}$ & $35,72 \mathrm{ab}$ & $48,14 \mathrm{ab}$ & $24,64 \mathrm{ab}$ & $18,60 \mathrm{ab}$ & 19,33 \\
\hline $\mathrm{SA}_{1}$ & $162,18 b$ & $31,48 \mathrm{ab}$ & $41,71 \mathrm{ab}$ & $23,13 a b$ & $16,10 \mathrm{ab}$ & 14,38 \\
\hline $\mathrm{SA}_{2}$ & $205,24 \mathrm{ab}$ & $43,87 \mathrm{ab}$ & $60,23 \mathrm{ab}$ & $27,4 \mathrm{lab}$ & $22,04 \mathrm{ab}$ & 17,80 \\
\hline $\mathrm{SA}_{1}+\mathrm{G}$ & $195,96 \mathrm{ab}$ & $32,18 \mathrm{ab}$ & $41,10 \mathrm{ab}$ & $25,53 \mathrm{ab}$ & $18,07 \mathrm{ab}$ & 15,83 \\
\hline $\mathrm{SA}_{2}+\mathrm{G}$ & $216,84 a b$ & $38,48 \mathrm{ab}$ & $53,88 \mathrm{ab}$ & $29,53 \mathrm{ab}$ & $18,61 \mathrm{ab}$ & 16,59 \\
\hline $\mathrm{SN}_{1}$ & $125,57 \mathrm{~b}$ & $19,42 b$ & $27,57 b$ & $15,82 \mathrm{~b}$ & $11,15 b$ & 8,54 \\
\hline $\mathrm{SN}_{2}$ & $141,39 b$ & $28,84 \mathrm{~b}$ & $39,38 \mathrm{ab}$ & $21,50 \mathrm{~b}$ & $14,40 \mathrm{~b}$ & 11,38 \\
\hline $\mathrm{SN}_{1}+\mathrm{G}$ & $190,82 \mathrm{ab}$ & $42,84 a b$ & $51,91 \mathrm{ab}$ & $27,29 \mathrm{ab}$ & $22,64 \mathrm{ab}$ & 15,84 \\
\hline $\mathrm{SN}_{2}+\mathrm{G}$ & $175,58 \mathrm{ab}$ & $32,11 \mathrm{ab}$ & $40,78 \mathrm{ab}$ & $22,21 b$ & $17,83 \mathrm{ab}$ & 14,05 \\
\hline $\begin{array}{l}\mathrm{F} \\
\mathrm{CV}(\%)\end{array}$ & $\begin{array}{c}3,62^{* *} \\
24,41\end{array}$ & $\begin{array}{c}2,87^{* *} \\
36,92\end{array}$ & $\begin{array}{l}2,71 * * \\
33,02\end{array}$ & $\begin{array}{l}3,24^{* *} \\
24,43\end{array}$ & $\begin{array}{c}2,48^{* *} \\
39,39\end{array}$ & $\begin{array}{r}\text { n.s. } \\
15,14\end{array}$ \\
\hline $\operatorname{dms}(5 \%)$ & 111,29 & 32,29 & 37,73 & 15,07 & 17,60 & 15,14 \\
\hline
\end{tabular}


A Tabela 21 compara as médias dos conteúdos obtidos nos tratamentos com ou sem gesso independentemente das fontes e doses de nitrogênio. Verifica-se que houve efeito da aplicação de gesso no aumento dos conteúdos de todos os macronutrientes.

Em ensaio de trigo, SOUSA et al. (1992) obtiveram 50\% a mais na produção de grãos em solo de cerrado, sendo que este aumento de produtividade foi explicado pela maior utilização de nutrientes do solo, principalmente o nitrogênio.

Tabela 21. Médias dos conteúdos de macronutrientes nos grãos de milho (g.kg de grãos total da parcela ${ }^{-1}$ ), considerando os tratamentos com ou sem gesso, independentemente das fontes e doses de nitrogênio aplicadas.

\begin{tabular}{|c|c|c|c|c|c|c|}
\hline Tratamentos & $\mathrm{N}$ & $\mathrm{P}$ & $\mathrm{K}$ & $\mathrm{Ca}$ & $\mathrm{Mg}$ & $\mathrm{S}$ \\
\hline & \multicolumn{6}{|c|}{ 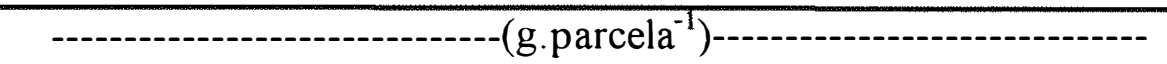 } \\
\hline sem gesso & $162,49 \mathrm{~b}^{+}$ & $28,86 \mathrm{~b}$ & $40,74 b$ & $22,12 b$ & $15,20 b$ & $12,91 \mathrm{~b}$ \\
\hline com gesso & $201,78 \mathrm{a}$ & $39,84 a$ & $51,03 \mathrm{a}$ & $27,00 \mathrm{a}$ & $20,82 \mathrm{a}$ & $16,75 a$ \\
\hline $\mathrm{F}$ & $7,79 * *$ & $8,21^{* *}$ & $5,43^{*}$ & $8,27 * *$ & $7.41^{* *}$ & $6,19 * *$ \\
\hline cv $(\%)$ & 23,63 & 37,96 & 32,95 & 23,31 & 38,75 & 36,28 \\
\hline $\mathrm{dms}(5 \%)$ & 21,34 & 6,39 & 7,48 & 2,84 & 3,42 & 2,66 \\
\hline
\end{tabular}


A Tabela 22 compara as fontes nitrogenadas independentemente das doses e da aplicação de gesso. Não houve efeito das fontes nos conteúdos de $\mathrm{P}, \mathrm{Mg}$ e $\mathrm{S}$. O nitrato de cálcio foi a fonte que promoveu os maiores acúmulos de $\mathrm{N}, \mathrm{K}$ e $\mathrm{Ca}$, não diferindo significativamente do sulfato de amônio.

A uréia + sulfato de amônio (sulfnitro), foi a fonte que proporcionou os menores conteúdos de $\mathrm{N}, \mathrm{K}$ e $\mathrm{Ca}$, sendo que quando se aplicou o nitrato de magnésio os acúmulos foram intermediários aos obtidos com as outras fontes. Uma das principais causas da diminuição do aproveitamento de $\mathrm{N}$ pelas plantas quando se utiliza a uréia são as perdas de $N$ por volatilização. ANJOS \& TEDESCO (1976) obtiveram valores entre 15 e $45 \%$ para perdas por volatilização de $\mathrm{N}$ quando utilizaram a uréia e 0,5 a $5 \%$ quando aplicaram o sulfato de amônio. A mistura de uréia e sulfato de amônio no mesmo grânulo apresentou tendência a menores perdas de $\mathrm{NH}_{3}$ no trabalho de LARA CABEZAS et al. (1989), quando comparadas com aquelas originadas da aplicação de uréia de granulações diferentes. Maior recuperação de $\mathrm{N}$ por plantas de milho foi obtida por VILLAS BÔAS (1990), quando utilizou o sulfnitro comparando com uréias de várias ganulometrias aplicadas em cobertura. As perdas por volatilização existiram entretanto, nos vários trabalhos citados acima. 
Tabela 22. Médias dos conteúdos de macronutrientes nos grãos de milho (g.kg de grãos total da parcela $\left.{ }^{-1}\right)$, considerando as fontes nitrogenadas, independentemente das doses de $\mathrm{N}$ e da aplicação de gesso.

\begin{tabular}{|c|c|c|c|c|c|c|}
\hline Tratamentos & $\mathrm{N}$ & $\mathrm{P}$ & $\mathrm{K}$ & $\mathrm{Ca}$ & $\mathrm{Mg}$ & $\mathrm{S}$ \\
\hline & \multicolumn{6}{|c|}{ 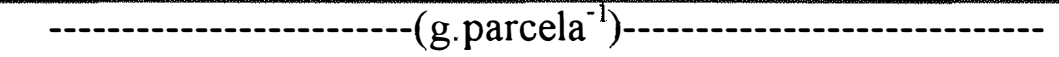 } \\
\hline Nitrato Cálcio & $209,56 \mathrm{a}^{+}$ & 37,19 & $51,41 \mathrm{a}$ & $28,31 \mathrm{la}$ & 19,54 & 16,24 \\
\hline Nitrato Magnésio & $165,06 \mathrm{bc}$ & 27,65 & $42,97 \mathrm{bc}$ & $21,81 \mathrm{bc}$ & 17,31 & 14,48 \\
\hline Sulfato Amônio & $195,05 \mathrm{ab}$ & 36,48 & $49,24 \mathrm{ab}$ & $26,40 \mathrm{ab}$ & 18,69 & 16,151 \\
\hline Sulfnitro & $158,34 \mathrm{c}$ & 31,03 & $40,01 \mathrm{c}$ & $21,70 \mathrm{c}$ & 16,65 & 12,32 \\
\hline$F$ & $6,97 * *$ & n.s. & $3,23^{*}$ & $7,53 * *$ & n.s. & n.s. \\
\hline cv $(\%)$ & 23,63 & 37,96 & 32,95 & 23,31 & 38,75 & 36,28 \\
\hline $\mathrm{dms}(5 \%)$ & 35,56 & 11,97 & 7,80 & 4,63 & 6,41 & 4,99 \\
\hline
\end{tabular}

A Tabela 23 mostra que o efeito da adição de nitrogênio independentemente da fonte e da aplicação de gesso foi significativo apenas para o acúmulo desse nutriente nos grãos de milho.

A Tabela 24 apresenta a significância estatística para o teste F a 5\% de probabilidade para as interações duplas e triplas dos fatores estudados.

Para o acúmulo de nitrogênio e magnésio as diferenças entre as fontes ocorreram apenas quando se utilizou a maior dosagem de $\mathrm{N}$, sendo que a sequência de eficiência das fontes seguiu a mesma tendência da Tabela 22 . 
Para o conteúdo de fósforo, cálcio e magnésio, a interação tripla apresentou significância estatística.

Quando se aplicou o nitrato de cálcio na maior dosagem de nitrogênio a média de conteúdo de $\mathrm{P}, \mathrm{Ca}$ e $\mathrm{Mg}$ com a aplicação de gesso foi significativamente superior à média onde não se aplicou gesso. O mesmo ocorreu na aplicação de nitrato de magnésio, só que para a menor dosagem de nitrogênio.

Quanto ao conteúdo de $\mathrm{K}$ nos grãos, as médias obtidas com as diversas fontes foram diferentes do ponto de vista estatístico quando se aplicou o gesso, sendo que a sequência quanto à eficiência das fontes foi similar ao da Tabela 22.

Tabela 23. Médias dos conteúdos de macronutrientes nos grãos de milho (g.kg de grãos total da parcela ${ }^{-1}$ ), considerando as doses de nitrogênio, independentemente das fontes nitrogenadas e da aplicação de gesso.

\begin{tabular}{|c|c|c|c|c|c|c|}
\hline Tratamentos & $\mathrm{N}$ & $\mathrm{P}$ & $\mathrm{K}$ & $\mathrm{Ca}$ & $\mathrm{Mg}$ & $\mathrm{S}$ \\
\hline & \multicolumn{6}{|c|}{ 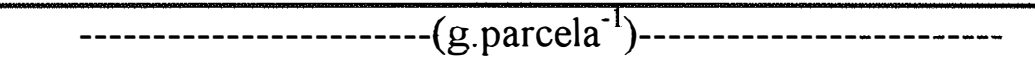 } \\
\hline $60 \mathrm{~kg} \mathrm{~N} \cdot \mathrm{ha}^{-1}$ & $166,12 b^{+}$ & 34,70 & 41,93 & 23,06 & 17,02 & 13,61 \\
\hline $120 \mathrm{~kg} \mathrm{~N} \cdot \mathrm{ha}^{-1}$ & $198,16 \mathrm{a}$ & 36,60 & 49,83 & 26,06 & 19,01 & 16,05 \\
\hline F & $6,74^{* *}$ & n.s. & n.s. & n.s. & n.s. & n.s. \\
\hline $\operatorname{cv}(\%)$ & 23,63 & 37,96 & 32,95 & 23,31 & 38,75 & 36,28 \\
\hline $\operatorname{dms}(5 \%)$ & 21,34 & 6,39 & 7,72 & 3,15 & 3,42 & 2,66 \\
\hline
\end{tabular}


Tabela 24. Valores de teste $\mathrm{F}$ a $5 \%$ de probabilidade para as interações entre gesso, fonte de nitrogênio e dose de nitrogênio, para os conteúdos de $\mathrm{N}, \mathrm{P}, \mathrm{K}, \mathrm{Ca}, \mathrm{Mg}$ e S nos grãos de milho.

\begin{tabular}{lcccccc}
\hline Interação & $\mathrm{N}$ & $\mathrm{P}$ & $\mathrm{K}$ & $\mathrm{Ca}$ & $\mathrm{Mg}$ & $\mathrm{S}$ \\
\hline Gesso x Fonte N & n.s. & n.s. & $2,87^{*}$ & n.s. & n.s. & n.s. \\
Gesso x Dose N & n.s. & n.s. & n.s. & n.s. & n.s. & n.s. \\
Fonte N x Dose N & $4,01^{*}$ & n.s. & n.s. & n.s. & $2,87^{*}$ & n.s. \\
Gesso x Fonte N x Dose N & n.s. & $3,02^{*}$ & n.s. & $4,04^{*}$ & $2,92^{*}$ & n.s. \\
\hline
\end{tabular}

*Valores significativos a $5 \%$ probabilidade

\subsection{Conteúdo de Nutrientes nas Folhas, Colmos e Grãos}

A Tabela 25 contém as médias obtidas para o total de macronutrientes acumulados nas folhas + colmos + grãos. A aplicação de fertilizantes nitrogenados associados ou não ao gesso, foi responsável por acúmulos mais expressivos de macronutrientes nas plantas.

Houve efeito da aplicação de gesso (Tabela 26), independentemente do fertilizante nitrogenado e da dosagem de $\mathrm{N}$, no aumento de acúmulos de $\mathrm{N}, \mathrm{P}, \mathrm{Ca}, \mathrm{Mg}$ e S nas plantas de milho. Os incrementos foram aproximadamente $15 \% ; 24 \% ; 17 \% ; 19 \%$ e 
$25 \%$, respectivamente. Apenas o acúmulo de $\mathrm{K}$ nas plantas não foi influenciado pela aplicação de gesso.

De forma geral, o nitrato de cálcio e o sulfato de amônio foram as fontes mais eficientes em promover acúmulos dos macronutrientes $\mathrm{N}$, Ca e $\mathrm{S}$ (Tabela 27). Maiores acúmulos de $\mathrm{N}$ e $\mathrm{S}$ também foram obtidos como efeito da aplicação da maior dosagem de nitrogênio (Tabela 28).

Na Tabela 29 verifica-se que ocorreram interações positivas apenas para os fatores gesso e fonte de $\mathrm{N}$, para os acúmulos de N, P, K e S. As fontes nitrato de cálcio e sulfnitro promoveram acúmulos significativamente maiores do ponto de vista estatístico de N, P e S, quando na presença de gesso (Figura 5). Análises de regressão entre o teor de macronutrientes absorvidos e a produção de grãos estimada em $\mathrm{kg} \cdot \mathrm{ha}^{-1}$, mostraram que houve correlação estatisticamente significativa apenas entre o conteúdo de $\mathrm{N}$ e a produção de grãos. A Figura 6 apresenta as equações matemáticas de regressão entre o $\mathrm{N}$ absorvido e a produção de grãos, para os tratamentos com e sem gesso. Na presença de gesso, os acréscimos de produção foram proporcionais ao teor de $\mathrm{N}$ absorvido pelas pelas plantas. 
Tabela 25. Médias dos conteúdos de macronutrientes (g.parcela ${ }^{-1}$ ), acumulados pelas plantas de milho (folhas+colmos+grãos), nos diversos tratamentos.

\begin{tabular}{|c|c|c|c|c|c|c|}
\hline Tratam. & $\mathrm{N}$ & $\bar{P}$ & $\mathrm{~K}$ & $\mathrm{Ca}$ & $\mathrm{Mg}$ & $S$ \\
\hline \\
\hline Test. & $187,95 \mathrm{e}^{+}$ & $25,25 b$ & $244,44 a b$ & $47,62 \mathrm{c}$ & $42,22 \mathrm{ab}$ & $30,95 \mathrm{abc}$ \\
\hline Test. $+\mathrm{G}$ & $232,25 \mathrm{cde}$ & $26,03 b$ & $304,78 \mathrm{ab}$ & $63,03 \mathrm{abc}$ & $55,88 \mathrm{ab}$ & $38,30 \mathrm{abc}$ \\
\hline $\mathrm{NCa}_{1}$ & 297,22abcde & $34,17 \mathrm{ab}$ & $344,37 \mathrm{ab}$ & $68,85 \mathrm{abc}$ & $57,47 \mathrm{ab}$ & $33,95 \mathrm{abc}$ \\
\hline $\mathrm{NCa}_{2}$ & $408,37 \mathrm{ab}$ & $37,75 \mathrm{ab}$ & $360,05 \mathrm{ab}$ & $71,80 \mathrm{abc}$ & $61,50 \mathrm{a}$ & $37,45 \mathrm{abc}$ \\
\hline $\mathrm{NCa}_{1}+\mathrm{G}$ & 330,17 abcde & $46,47 \mathrm{ab}$ & $359,82 \mathrm{ab}$ & $78,63 \mathrm{ab}$ & $69,92 \mathrm{a}$ & 45,3 labc \\
\hline $\mathrm{NCa}_{2}+\mathrm{G}$ & $440,60 \mathrm{a}$ & $66,09 a$ & $341,33 \mathrm{ab}$ & $77,67 \mathrm{ab}$ & $72,40 \mathrm{a}$ & $48,02 \mathrm{ab}$ \\
\hline $\mathrm{NMg}_{1}$ & 236,65 cde & $36,32 \mathrm{ab}$ & $331,90 \mathrm{ab}$ & $55,17 \mathrm{abc}$ & $52,65 \mathrm{ab}$ & $27,65 \mathrm{bc}$ \\
\hline $\mathrm{NMg}_{2}$ & $286,07 \mathrm{bcde}$ & $36,62 \mathrm{ab}$ & $318,23 \mathrm{ab}$ & $58,02 \mathrm{abc}$ & $50,90 \mathrm{ab}$ & $31,90 \mathrm{abc}$ \\
\hline $\mathrm{NMg}_{1}+\mathrm{G}$ & $289,03 \mathrm{bcde}$ & $47,17 \mathrm{ab}$ & $233,84 a b$ & $60,80 \mathrm{abc}$ & $49,77 \mathrm{ab}$ & $35,85 \mathrm{abc}$ \\
\hline $\mathrm{NMg}_{2}+\mathrm{G}$ & $273,85 \mathrm{bcde}$ & $28,17 \mathrm{~b}$ & $271,37 \mathrm{ab}$ & $57,05 \mathrm{abc}$ & $46,28 \mathrm{ab}$ & $37,75 \mathrm{abc}$ \\
\hline $\mathrm{SA}_{l}$ & 298,20abcde & $41,37 \mathrm{ab}$ & $353,73 \mathrm{ab}$ & $61,12 \mathrm{abc}$ & $51,85 \mathrm{ab}$ & $44,05 \mathrm{abc}$ \\
\hline $\mathrm{SA}_{2}$ & $354,52 \mathrm{abcd}$ & $52,89 \mathrm{ab}$ & $325,39 \mathrm{ab}$ & $67,90 \mathrm{abc}$ & $29,47 b$ & $43,67 \mathrm{abc}$ \\
\hline $\mathrm{SA}_{1}+\mathrm{G}$ & 309,23abcde & $40,37 \mathrm{ab}$ & $247,00 \mathrm{ab}$ & $60,87 \mathrm{abc}$ & $44,34 \mathrm{ab}$ & $37,82 \mathrm{abc}$ \\
\hline $\mathrm{SA}_{2}+\mathrm{G}$ & $415,01 \mathrm{ab}$ & $48,12 \mathrm{ab}$ & $332,54 \mathrm{ab}$ & $83,90 \mathrm{a}$ & $62,47 a$ & $48,67 \mathrm{ab}$ \\
\hline $\mathrm{SN}_{l}$ & $204,92 \mathrm{de}$ & $20,03 b$ & $223,05 b$ & $47,30 \mathrm{c}$ & $42,60 \mathrm{ab}$ & $24,82 \mathrm{c}$ \\
\hline $\mathrm{SN}_{2}$ & 272,45 bcde & $33,07 \mathrm{ab}$ & $357,31 \mathrm{ab}$ & $53,42 b c$ & $46,95 \mathrm{ab}$ & $38,82 \mathrm{abc}$ \\
\hline $\mathrm{SN}_{1}+\mathrm{G}$ & 313,90abcde & $48,02 \mathrm{ab}$ & $400,65 a$ & $80,72 \mathrm{ab}$ & $63,35 a$ & $53,47 a$ \\
\hline $\mathrm{SN}_{2}+\mathrm{G}$ & $339,53 \mathrm{abcd}$ & $42,42 \mathrm{ab}$ & $384,48 \mathrm{ab}$ & $63,09 \mathrm{abc}$ & $59,16 \mathrm{ab}$ & $46,45 \mathrm{ab}$ \\
\hline $\mathrm{F}$ & $5,57 * *$ & $2,45^{* *}$ & $2,67 * *$ & $3,26^{* *}$ & $3,54 * *$ & $3,34 * *$ \\
\hline $\operatorname{cv}(\%)$ & 18,92 & 32,48 & 20,25 & 17,36 & 21,99 & 22,41 \\
\hline $\mathrm{dms}(5 \%)$ & 151,50 & 34,30 & 168,70 & 29,54 & 30,85 & 23,13 \\
\hline
\end{tabular}

** Valores significativos a $1 \%$ de probabilidade

${ }^{\dagger}$ Médias seguidas de mesma letra não diferem estatisticamente entre si (Tukey 5\%). 
Tabela 26. Médias dos conteúdos de macronutrientes (g.parcela ${ }^{-1}$ ), acumulados pelas plantas de milho (folhas+colmos+grãos), considerando os tratamentos com ou sem gesso, independentemente das fontes e doses de nitrogênio.

\begin{tabular}{|c|c|c|c|c|c|c|}
\hline Tratamentos & $\bar{N}$ & $\overline{\mathrm{P}}$ & $\overline{\mathrm{K}}$ & $\mathrm{Ca}$ & $\mathrm{Mg}$ & $\bar{S}$ \\
\hline & \multicolumn{6}{|c|}{--- } \\
\hline sem gesso & $294,80 b^{+}$ & $37,04 b$ & 327,60 & $60,45 b$ & $49,17 b$ & $35,29 b$ \\
\hline com gesso & $338,91 \mathrm{a}$ & $45,84 \mathrm{a}$ & 321,32 & $70,64 a$ & $58,80 \mathrm{a}$ & $44,20 \mathrm{a}$ \\
\hline $\mathrm{F}$ & $7,65 * *$ & $9,29 * *$ & n.s. & $13,60 * *$ & $10,68 * *$ & $20,05^{* *}$ \\
\hline cv $(\%)$ & 18,46 & 31,76 & 20,32 & 16,87 & 21,82 & 21,27 \\
\hline $\mathrm{dms}(5 \%)$ & 29,52 & 6,75 & 33,30 & 5,58 & 5,94 & 4,30 \\
\hline
\end{tabular}

Tabela 27. Médias dos conteúdos de macronutrientes (g.parcela ${ }^{-1}$ ), acumulados pelas plantas de milho (folhas+colmos+grãos), em função das fontes nitrogenadas, independentemente das doses de $\mathrm{N}$ e da aplicação de gesso.

\begin{tabular}{|c|c|c|c|c|c|c|}
\hline Tratamentos & $\mathrm{N}$ & $P$ & $\mathrm{~K}$ & $\mathrm{Ca}$ & $\mathrm{Mg}$ & $\mathrm{S}$ \\
\hline & \multicolumn{6}{|c|}{ - } \\
\hline Nitrato Cálcio & $369,08 \mathrm{a}^{+}$ & 46,13 & $351,37 \mathrm{a}$ & $74,23 a$ & $65,32 \mathrm{a}$ & $41,17 \mathrm{ab}$ \\
\hline Nitrato Magnésio & $271,40 b$ & 37,07 & $288,8 \mathrm{lb}$ & $57,76 \mathrm{c}$ & $49,91 b$ & $33,29 b$ \\
\hline Sulfato Amônio & $344,24 a$ & 45,69 & $314,63 \mathrm{ab}$ & $68,44 \mathrm{ab}$ & $47,04 b$ & $43,56 a$ \\
\hline Sulfnitro & $282,70 \mathrm{~b}$ & 35,88 & $341,34 \mathrm{ab}$ & $61,13 b c$ & $53,02 b$ & $40,89 \mathrm{ab}$ \\
\hline $\mathrm{F}$ & $9,56 * *$ & n.s. & $3,07 *$ & $6,93 * *$ & $7,43 * *$ & $4,70^{* *}$ \\
\hline cv (\%) & 18,46 & 31,76 & 20,32 & 16,87 & 21,82 & 21,27 \\
\hline dms (5\%) & 55,30 & 12,64 & 62,37 & 10,44 & 11,12 & 8,05 \\
\hline
\end{tabular}

**Valores significativos a $1 \%$ probabilidade

*Valores significativos a $5 \%$ probabilidade

${ }^{+}$Médias seguidas de mesma letra não diferem estatisticamente entre si (Tukey 5\%). 
Tabela 28. Médias dos conteúdos de macronutrientes (g.parcela ${ }^{-1}$ ), acumulados pelas plantas de milho (folhas+colmos+grãos), em função das doses de nitrogênio, independentemente das fontes e da aplicação de gesso.

\begin{tabular}{|c|c|c|c|c|c|c|}
\hline Tratamentos & $N$ & $P$ & $\mathrm{~K}$ & $\mathrm{Ca}$ & $\mathrm{Mg}$ & $S$ \\
\hline & \multicolumn{6}{|c|}{ - } \\
\hline $60 \mathrm{~kg} \mathrm{~N} \cdot \mathrm{ha}^{-1}$ & $284,91 b+$ & 39,74 & 312,64 & 64,18 & 54,24 & $37,87 \mathrm{~b}$ \\
\hline $120 \mathrm{~kg} \mathrm{~N} \cdot \mathrm{ha}^{-1}$ & $348,80 \mathrm{a}$ & 43,54 & 334,28 & 65,91 & 53,73 & $41,59 \mathrm{a}$ \\
\hline $\mathrm{F}$ & $21,93 * *$ & n.s. & n.s. & n.s. & n.s. & $4,23 *$ \\
\hline cv $(\%)$ & 18,46 & 31,76 & 20,32 & 16,87 & 21,82 & 21,27 \\
\hline dms $(5 \%)$ & 29,53 & 6,75 & 33,30 & 5,58 & 5,94 & 3,70 \\
\hline
\end{tabular}

Tabela 29. Valores do teste $\mathrm{F}$ a $5 \%$ de probabilidade para as interações entre gesso, fonte de nitrogênio e dose de nitrogênio, para conteúdos de macronutrientes, acumulados pelas plantas de milho (folhas +colmos +grãos).

\begin{tabular}{lcllllc}
\hline Interação & $\mathrm{N}$ & $\mathrm{P}$ & $\mathrm{K}$ & $\mathrm{Ca}$ & $\mathrm{Mg}$ & $\mathrm{S}$ \\
\hline Gesso x Fonte N & $3,01^{*}$ & $3,71^{*}$ & $5,56^{*}$ & n.s. & n.s. & $4,36^{*}$ \\
Gesso x Dose N & n.s. & n.s. & n.s. & n.s. & n.s. & n.s. \\
Fonte N x Dose N & n.s. & n.s. & n.s. & n.s. & n.s. & n.s. \\
Gesso x Fonte N x Dose N & n.s. & n.s. & n.s. & n.s. & n.s. & n.s. \\
\hline
\end{tabular}

*Valores significativos a $5 \%$ probabilidade 


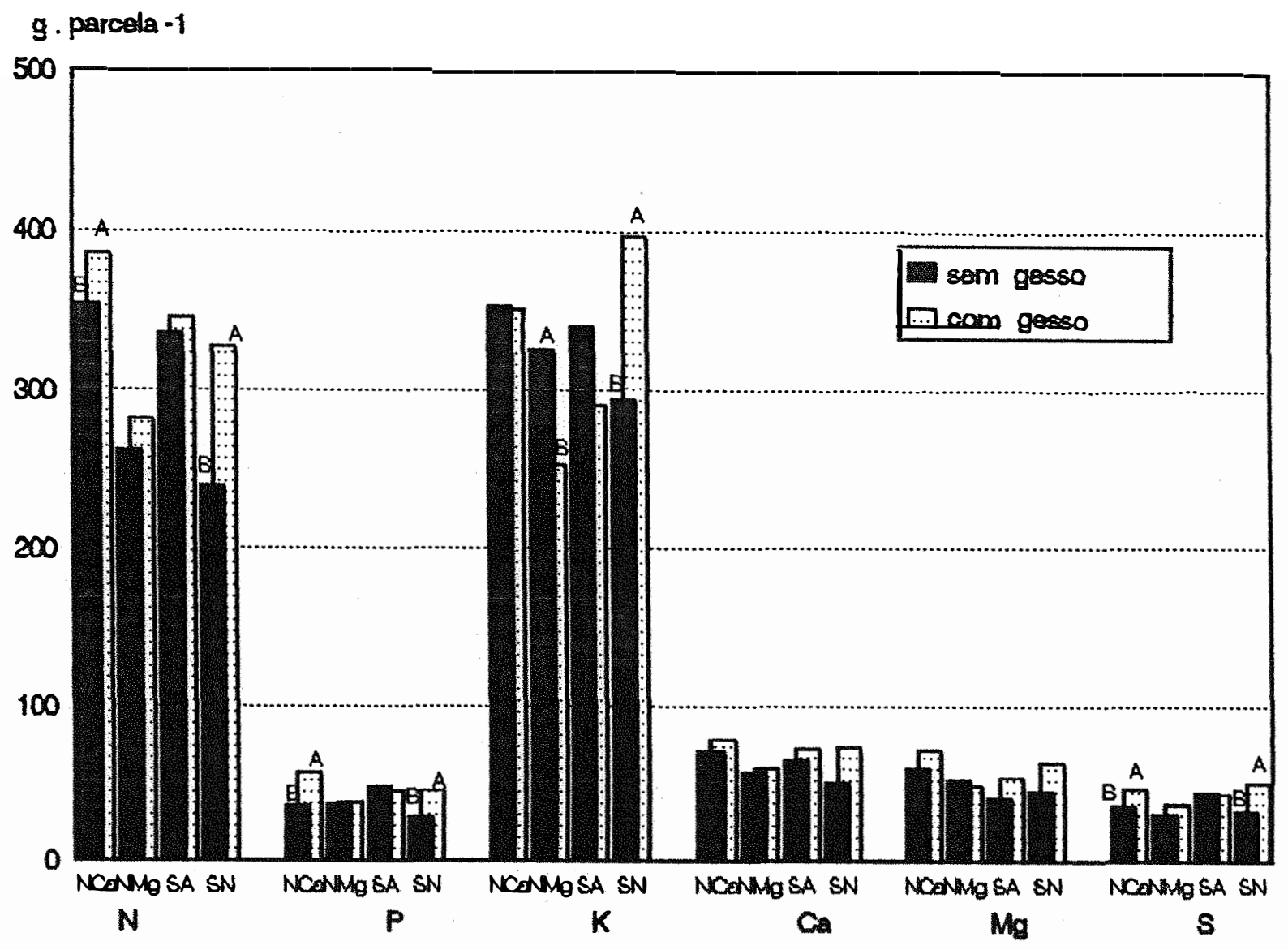

Figura 5. Médias dos acúmulos de $\mathrm{N}, \mathrm{P}, \mathrm{K}, \mathrm{Ca}, \mathrm{Mg}$ e $\mathrm{S}$ obtidos na parte aérea das plantas de milho (folhas + colmos + grãos), considerando as fontes nitrogenadas independentemente das doses, na presença ou ausência de gesso. 


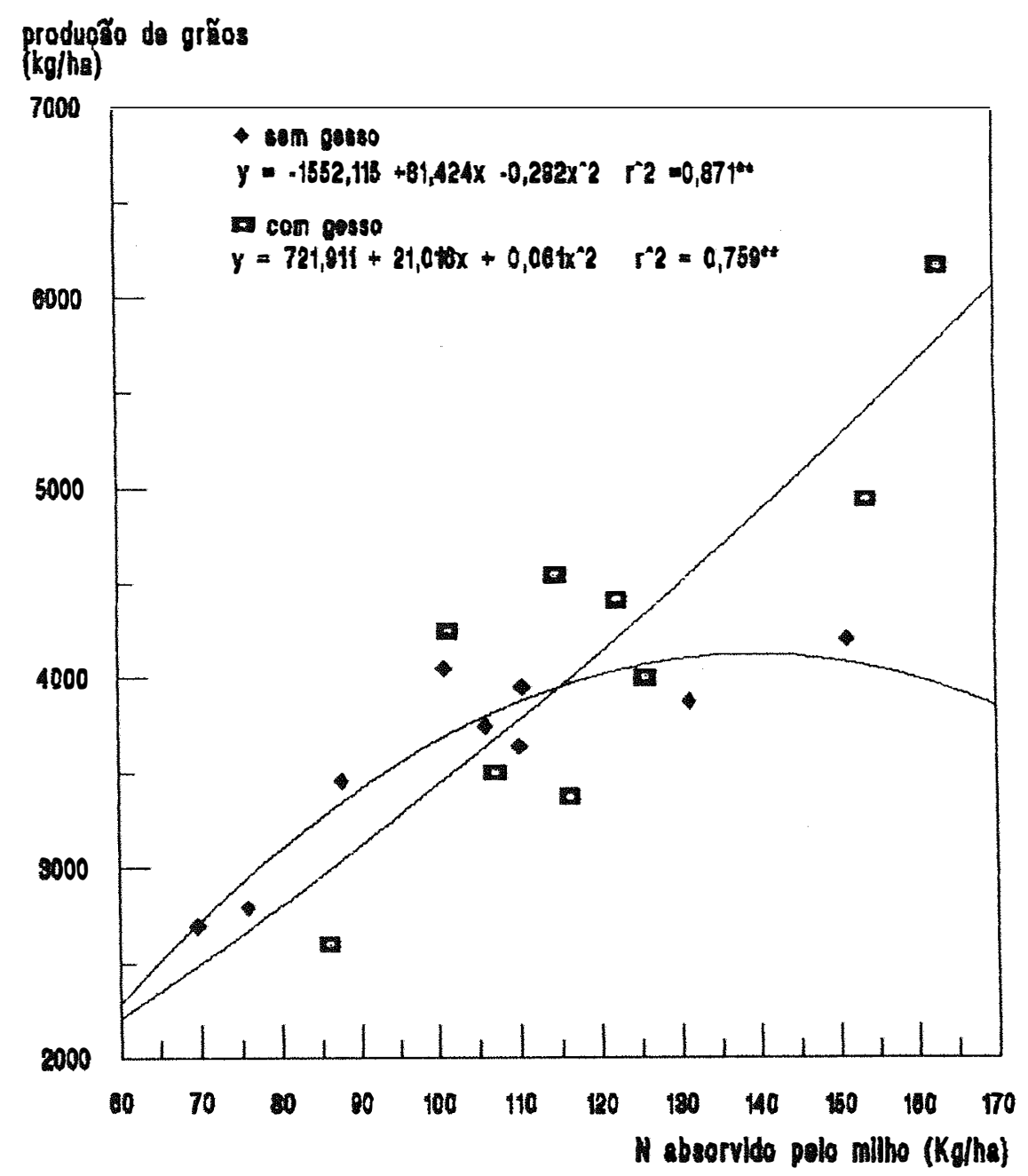

Figura 6. Curvas de regressão entre os parâmetros $N$ absorvido pelo milho e produção de grãos. 


\subsection{Efeitos da Aplicação do Gesso e Fertilizantes Nitrogenados no Solo}

\subsubsection{Macronutrientes no Solo}

A Tabela 30 apresenta as médias obtidas ao final do experimento para os cátions trocáveis $\left(\mathrm{Ca}^{+2}, \mathrm{Mg}^{+2} \mathrm{e} \mathrm{K}^{+}\right)$, além de nitrogênio total, fósforo e enxofre na profundidade de $0-30 \mathrm{~cm}$. Todos os tratamentos alteraram os teores dos elementos nessa profundidade. Em relação à testemunha sem gesso, as maiores variações foram obtidas para os teores de cálcio e enxofre, uma vez que esses íons foram adicionados pelo gesso e verifica-se, portanto, que parte desses íons permaneciam nessa camada de solo ao final do experimento.

Quanto ao nitrogênio, a Tabela 30 revela que a variação entre os tratamentos com adubação nitrogenada e a testemunha foi muito pequena, indicando que o nitrogênio foi absorvido pelas plantas ou poderia ter ocorrido algum processo de perda, dessa profundidade.

As Tabelas 35 e 40 apresentam as médias obtidas para os teores de $\mathrm{Ca}^{+2}, \mathrm{Mg}^{+2}, \mathrm{~K}^{+}, \mathrm{N}, \mathrm{P}$ e $\mathrm{S}-\mathrm{SO}_{4}^{-2}$ obtidos nas profundidades de $30-60 \mathrm{~cm}$ e $60-90 \mathrm{~cm}$. Poucos tratamentos diferiram da testemunha, sendo que o cálcio apresentou a maior amplitude de resposta entre os tratamentos e a testemunha nas duas profundidades, por ter sido adicionado ao solo na forma de gesso. O teor de fósforo apresentou alto coeficiente de variação (180 e 68\% nas duas profundidades respectivamente). Ressaltase que pelo fato de serem valores muito baixos a sensibilidade analítica fica dificultada. Para a fertilidade do solo, os valores obtidos estão considerados dentro da faixa de 
teores baixos de $\mathrm{P}$ no solo, sendo que a grande variação estatística não altera a interpretação dos resultados.

Tabela 30. Médias dos teores de macronutrientes obtidos para os diversos tratamentos em amostras de solo retiradas da profundidade $0-30 \mathrm{~cm}$.

\begin{tabular}{|c|c|c|c|c|c|c|}
\hline Tratament & $\mathrm{Ca}^{+2}$ & $\mathrm{Mg}^{+2}$ & $\mathrm{~K}^{+}$ & $\bar{N}$ & $\mathrm{P}$ & $\mathrm{S}-\mathrm{SO}_{4}^{-2}$ \\
\hline 0 & \multicolumn{3}{|c|}{$-\mathrm{mmol}_{\mathrm{d}} / \mathrm{dm}^{3}$} & $\mathrm{~g} / \mathrm{kg}$ & \multicolumn{2}{|c|}{------mg/dm ${ }^{3}--\cdot--$} \\
\hline Test & $9,70 \mathrm{~d}^{+}$ & $6,97 \mathrm{~cd}$ & $1,43 \mathrm{bcd}$ & $1,30 \mathrm{ab}$ & $10,40 \mathrm{ab}$ & $12,67 \mathrm{f}$ \\
\hline Test $+\mathrm{G}$ & $16,20 \mathrm{~b}$ & $5,30 \mathrm{def}$ & 1,90abcd & $1,26 a b$ & $14,05 \mathrm{ab}$ & $85,67 a b$ \\
\hline $\mathrm{NCa}_{3}$ & $15,30 \mathrm{bcd}$ & $5,53 \mathrm{cdef}$ & $2,07 \mathrm{abc}$ & $1,37 \mathrm{ab}$ & $17,75 \mathrm{a}$ & $18,67 \mathrm{def}$ \\
\hline $\mathrm{NCa}_{2}$ & $13,53 \mathrm{bcd}$ & $5,27 \mathrm{def}$ & $2,07 \mathrm{abc}$ & $1,35 \mathrm{ab}$ & $9,37 \mathrm{ab}$ & $11,33 \mathrm{f}$ \\
\hline $\mathrm{NCa}_{1}+\mathrm{G}$ & $13,60 \mathrm{bcd}$ & $6,20 \mathrm{cde}$ & $2,00 \mathrm{abcd}$ & $1,2 \mathrm{lb}$ & $6,51 \mathrm{lab}$ & $60,33 b c$ \\
\hline $\mathrm{NCa}_{2}+\mathrm{G}$ & $23,53 \mathrm{a}$ & $4,07 \mathrm{ef}$ & $2,03 \mathrm{abcd}$ & $1,26 b$ & $9,37 \mathrm{ab}$ & $56,33 \mathrm{bcd}$ \\
\hline $\mathrm{NMg}_{1}$ & $11,20 \mathrm{bcd}$ & $9,27 \mathrm{ab}$ & $1,83 \mathrm{abcd}$ & $1,26 \mathrm{ab}$ & $6,73 \mathrm{ab}$ & $12,33 \mathrm{f}$ \\
\hline $\mathrm{NMg}_{2}$ & $11,30 \mathrm{bcd}$ & $9,27 \mathrm{ab}$ & $2,43 \mathrm{a}$ & $1,40 \mathrm{ab}$ & $12.74 \mathrm{ab}$ & $17.33 \mathrm{ef}$ \\
\hline $\mathrm{NMg}_{1}+\mathrm{G}$ & $10,20 \mathrm{~cd}$ & $7,57 b c$ & $2,13 \mathrm{ab}$ & $1.25 \mathrm{ab}$ & $4,05 b$ & $61,33 b c$ \\
\hline $\mathrm{NMg}_{2}+\mathrm{G}$ & $15,03 \mathrm{bcd}$ & $10,07 \mathrm{a}$ & $2,03 \mathrm{abcd}$ & $1,2 \mathrm{lb}$ & $6,28 \mathrm{ab}$ & $28,67 \mathrm{cdef}$ \\
\hline $\mathrm{SA}_{1}$ & $10,57 \mathrm{~cd}$ & $5,07 \mathrm{def}$ & $1,43 \mathrm{bcd}$ & $1,46 \mathrm{a}$ & $8,45 \mathrm{ab}$ & $30,33 \mathrm{cdef}$ \\
\hline $\mathrm{SA}_{2}$ & $13,80 \mathrm{bcd}$ & $5,70 \mathrm{cdef}$ & $1,70 \mathrm{abcd}$ & $1,47 \mathrm{a}$ & $7,54 \mathrm{ab}$ & $39,67 \mathrm{cdef}$ \\
\hline $\mathrm{SA}_{1}+\mathrm{G}$ & $11,17 \mathrm{bcd}$ & $6,00 \mathrm{cde}$ & $1,30 \mathrm{~d}$ & $1,27 \mathrm{ab}$ & $9,32 \mathrm{ab}$ & 54,00 bcde \\
\hline $\mathrm{SA}_{2}+\mathrm{G}$ & $15,80 \mathrm{bc}$ & $7,20 \mathrm{bcd}$ & $2,20 \mathrm{a}$ & $1,27 \mathrm{ab}$ & $6,17 \mathrm{ab}$ & $99,67 \mathrm{a}$ \\
\hline $\mathrm{SN}_{\mathrm{l}}$ & $11,43 \mathrm{bcd}$ & $4,77 \mathrm{ef}$ & $1,30 \mathrm{~d}$ & $1,37 \mathrm{ab}$ & $8,62 a b$ & $29,67 \mathrm{cdef}$ \\
\hline $\mathrm{SN}_{2}$ & $10,87 \mathrm{bcd}$ & $5,40 \mathrm{def}$ & $1,37 \mathrm{~cd}$ & $1,30 \mathrm{ab}$ & $12,06 \mathrm{ab}$ & $15,33 \mathrm{f}$ \\
\hline $\mathrm{SN}_{1}+\mathrm{G}$ & $11,93 \mathrm{bcd}$ & $3,60 \mathrm{f}$ & $1,40 \mathrm{bcd}$ & $1,17 b$ & $6,98 \mathrm{ab}$ & $53,67 \mathrm{bcde}$ \\
\hline $\mathrm{SN}_{2}+\mathrm{G}$ & $11,57 \mathrm{bcd}$ & $5,33 \mathrm{def}$ & $1,87 \mathrm{abcd}$ & $1,28 \mathrm{ab}$ & $10,97 \mathrm{ab}$ & $35,00 \mathrm{cdef}$ \\
\hline $\begin{array}{l}\mathrm{F} \\
\mathrm{CV}(\%) \\
\mathrm{dms}(5 \%)\end{array}$ & $\begin{array}{c}9,78^{* *} \\
13,84 \\
5,61\end{array}$ & $\begin{array}{c}20,05 * * \\
11,19 \\
2,15\end{array}$ & $\begin{array}{c}6,33^{* *} \\
13,37 \\
0,74 \\
\end{array}$ & $\begin{array}{l}3,57^{* *} \\
5,76 \\
0,23\end{array}$ & $\begin{array}{c}2,00^{*} \\
43,78 \\
12,54\end{array}$ & $\begin{array}{l}13,45^{* *} \\
30,52 \\
37,72\end{array}$ \\
\hline
\end{tabular}

$* *$ Valores de $\mathrm{F}$ significativos a $1 \%$ de probabilidade

* Valores de $\mathrm{F}$ significativos a $5 \%$ de probabilidade

+ Médias seguidas de mesma letra não diferem estatisticamente entre si (Tukey 5\%) 
A Tabela 31 indica que o gesso aumentou significativamente os teores de $\mathrm{Ca}^{+2}$ e S- $\mathrm{SO}_{4}^{-2}$ na primeira camada do solo em estudo. Aumentos nos teores de $\mathrm{Ca}^{+2}$ $\mathrm{e} \mathrm{SO}_{4}{ }^{-2}$ no solo devidos à aplicação de gesso são freqüentemente relatados na literatura, mas SMITH \& CRAVO (1992) salientam entretanto, que em seu trabalho, após o aumento houve um rápido declínio no teor de cálcio do solo (camada 0-20 cm), sugerindo um limitado efeito residual do gesso. Neste experimento o teor de cálcio elevou-se de aproximadamente $9 \mathrm{mmol}_{\mathrm{c}} / \mathrm{dm}^{3}$ (Tabela 1) na camada de 0-30 $\mathrm{cm}$, teor considerado muito baixo para a nutrição de plantas, para $14,10 \mathrm{mmol} / \mathrm{dm}^{3}$ em média (média geral de todos os tratamentos com gesso), após o ciclo da cultura.

Avaliando ainda o efeito do gesso (Tabela 31), verifica-se que maiores teores de $\mathrm{N}$ e $\mathrm{P}$ foram obtidos para os tratamentos sem gesso, indicando que esses nutrientes podem ter podem ter sido mais utilizados pelas plantas ou perdidos da camada de solo de $0-30 \mathrm{~cm}$. Como as camadas subsequentes $(30-60 \mathrm{~cm}$ e $60-90 \mathrm{~cm})$ não mostraram diferenças significativas entre os teores de $\mathrm{N}$ no solo em função da aplicação de gesso (Tabelas 36 e 41 e Figura 7), pode-se inferir que o nitrogênio foi realmente aproveitado mais eficientemente pelas plantas de milho como efeito da utilização de gesso. Este fato também é comprovado pelos dados da Tabela 26, onde os acúmulos de nitrogênio nas plantas de milho foram em média $16 \%$ superiores em função da aplicação de gesso. 
Tabela 31. Médias dos teores de macronutrientes obtidos em amostras de solo retiradas da profundidade de 0-30 cm, considerando a aplicação de gesso, independentemente das doses ou fontes de nitrogênio.

\begin{tabular}{|c|c|c|c|c|c|c|}
\hline Tratamentos & $\mathrm{Ca}^{+2}$ & $\mathrm{Mg}^{+2}$ & $\mathrm{~K}^{+}$ & $\bar{N}$ & $P$ & $\mathrm{~S}^{-\mathrm{SO}_{4}^{-2}}$ \\
\hline & \multicolumn{3}{|c|}{$-----\mathrm{mmol}_{\mathrm{c}} / \mathrm{dm}^{3} \mathrm{-a}$} & $\mathrm{g} / \mathrm{kg}$ & \multicolumn{2}{|c|}{$-\cdots---m g / d^{3}{ }^{3}-\cdots--$} \\
\hline Sem gesso & $12,25 \mathrm{~b}^{+}$ & 6.28 & 1,77 & $1,37 \mathrm{a}$ & $10,41 \mathrm{a}$ & $21,83 b$ \\
\hline Com gesso & $14,10 \mathrm{a}$ & 6,25 & 1,83 & $1,24 \mathrm{~b}$ & $7,46 b$ & $56,12 a$ \\
\hline $\begin{array}{l}\mathrm{F} \\
\mathrm{cv}(\%) \\
\mathrm{dms}(5 \%)\end{array}$ & $\begin{array}{l}12,56^{* *} \\
13,75 \\
1,07\end{array}$ & $\begin{array}{r}\text { n.s. } \\
11,64 \\
0,43\end{array}$ & $\begin{array}{l}\text { n.s. } \\
13,94 \\
0,15\end{array}$ & $\begin{array}{c}40,38^{* *} \\
5,48 \\
0,04\end{array}$ & $\begin{array}{c}7,40 * * \\
42,06 \\
2,22\end{array}$ & $\begin{array}{c}84,59 * * \\
33,13 \\
7,62\end{array}$ \\
\hline
\end{tabular}

Tabela 32. Médias dos teores de macronutrientes obtidos em amostras de solo retiradas da profundidade de $0-30 \mathrm{~cm}$, considerando as fontes de $\mathrm{N}$, independentemente das doses de $\mathrm{N}$ ou da aplicação de gesso.

\begin{tabular}{|c|c|c|c|c|c|c|}
\hline Tratamentos & $\mathrm{Ca}^{+2}$ & $\mathrm{Mg}^{+2}$ & $\mathrm{~K}^{+}$ & $\mathrm{N}$ & $\bar{P}$ & $\mathrm{~S}-\mathrm{SO}_{4}^{-2}$ \\
\hline & \multicolumn{3}{|c|}{ - $\mathrm{mmol}_{\mathrm{d}} / \mathrm{dm}^{3}-\mathrm{n}_{-}$} & $\mathrm{g} / \mathrm{kg}$ & \multicolumn{2}{|c|}{$------m g / \mathrm{dm}^{3}$} \\
\hline $\mathrm{NCa}$ & $16,49 \mathrm{a}^{+}$ & $5,27 b c$ & $2,04 \mathrm{a}$ & $1,29 \mathrm{ab}$ & 10,75 & $36.67 \mathrm{~b}$ \\
\hline $\mathrm{NMg}$ & $11,93 \mathrm{~b}$ & $9,04 \mathrm{a}$ & $2,03 \mathrm{a}$ & $1,28 b$ & 7,45 & $29.92 b$ \\
\hline SA & $12,83 b$ & $5,99 \mathrm{~b}$ & $1,65 b$ & $1,36 \mathrm{a}$ & 5,25 & $55,92 \mathrm{a}$ \\
\hline SN & $11,45 b$ & $4,77 \mathrm{c}$ & $1,48 b$ & $1,28 b$ & 9,66 & $33,42 b$ \\
\hline $\mathrm{F}$ & $19,04^{* *}$ & $82,65 * *$ & $14,73^{* *}$ & $3,65 *$ & n.s. & $9,72^{* *}$ \\
\hline $\operatorname{cv}(\%)$ & 13,75 & 11,64 & 13,94 & 5,48 & 42,06 & 33,13 \\
\hline dms $(5 \%)$ & 2,01 & 0,81 & 0,28 & 0,08 & 5,53 & 14,35 \\
\hline
\end{tabular}

**Valores de $\mathrm{F}$ significativos a $1 \%$ de probabilidade

* Valores de $\mathrm{F}$ significativos a $5 \%$ de probabilidade

+ Médias seguidas de mesma letra não diferem estatisticamente entre si (Tukey 5\%)

Tabela 33. Médias dos teores de macronutrientes obtidos em amostras de solo retiradas da profundidade de $0-30 \mathrm{~cm}$, considerando as doses de $\mathrm{N}$, independentemente das fontes de nitrogênio e da aplicação de gesso.

\begin{tabular}{|c|c|c|c|c|c|c|}
\hline Tratamentos & $\mathrm{Ca}^{+2}$ & $\mathrm{Mg}^{+2}$ & $\mathrm{~K}^{+}$ & $\mathrm{N}$ & $\bar{P}$ & $\mathrm{~S}^{-\mathrm{SO}_{4}^{-2}}$ \\
\hline & \multicolumn{3}{|c|}{ - $\mathrm{mmol}_{\mathrm{d}} \mathrm{ddm}^{3}$} & $\mathrm{~g} / \mathrm{kg}$ & \multicolumn{2}{|c|}{$-----\mathrm{mg} / \mathrm{dm}^{3} \mathrm{-------}$} \\
\hline $60 \mathrm{~kg} \mathrm{~N} \cdot \mathrm{ha}^{-1}$ & $11,92^{+}$ & $6,00 \mathrm{~b}$ & $1,68 b$ & 1,29 & 8,55 & 40,04 \\
\hline $120 \mathrm{~kg} \mathrm{N.ha}{ }^{-1}$ & $14,43 a$ & $6,54 a$ & $1,92 a$ & 1,31 & 9,31 & 37,92 \\
\hline $\mathrm{F}$ & $22,91^{* *}$ & $6,51^{*}$ & $11,07 * *$ & n.s. & n.s. & n.s. \\
\hline & 13,75 & 11,64 & 13,94 & 5,48 & 42,06 & 33,13 \\
\hline $\mathrm{dms}(5 \%)$ & 0,11 & 0,47 & 0,15 & 0,04 & 2,22 & 7,62 \\
\hline
\end{tabular}

**Valores de $\mathrm{F}$ significativos a $1 \%$ de probabilidade

* Valores de $\mathrm{F}$ significativos a $5 \%$ de probabilidade

+ Médias seguidas de mesma letra não diferem estatisticamente entre si (Tukey 5\%) 


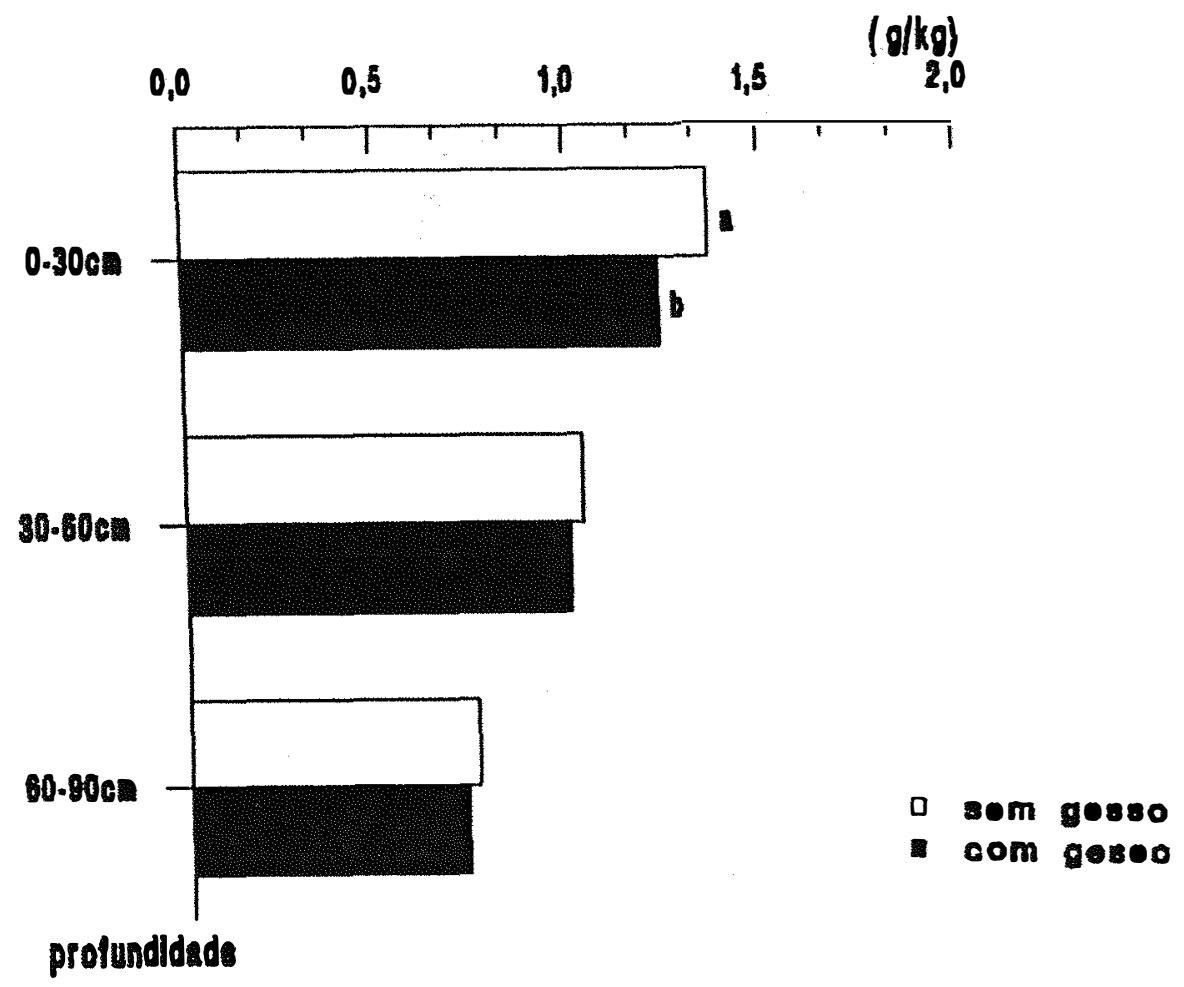

Figura 7. Médias dos teores de $\mathrm{N}\left(\mathrm{g} . \mathrm{kg} \mathrm{solo}^{-1}\right)$ obtidos, nas três profundidades analisadas, como efeito do gesso, independentemente das fontes e doses de nitrogênio estudadas.

Tabela 34. Valores do teste $\mathrm{F}$ a 5 ou $1 \%$ de probabilidade para as interações entre gesso, fonte e dose de nitrogênio para os teores de macronutrientes em amostras de solo retiradas da camada de $0-30 \mathrm{~cm}$ de profundidade.

\begin{tabular}{lclllll}
\hline Interação & $\mathrm{Ca}^{+2}$ & $\mathrm{Mg}^{+2}$ & $\mathrm{~K}^{+}$ & $\mathrm{N}$ & $\mathrm{P}$ & ${\mathrm{S}-\mathrm{SO}_{4}{ }^{-2}}^{+2}$ \\
\hline Dose Nx Fonte N & $4,07^{*}$ & $8,99^{* *}$ & $5,53^{* *}$ & n.s. & n.s. & $7,40^{* *}$ \\
Dose Nx Gesso & $18,56^{* *}$ & n.s. & n.s. & n.s. & n.s. & n.s. \\
Fonte N x Gesso & n.s. & n.s. & $4,81^{* *}$ & n.s. & n.s. & n.s. \\
Dose Nx Fonte Nx Gesso & $6,09^{* *}$ & n.s. & $14,45^{* *}$ & n.s. & n.s. & $4,15^{*}$ \\
\hline
\end{tabular}

**Valores de $\mathrm{F}$ significativos a $1 \%$ de probabilidade

* Valores de $\mathrm{F}$ significativos a $5 \%$ de probabilidade 
Tabela 35. Médias dos teores de macronutrientes obtidos para os diversos tratamentos em amostras de solo retiradas da profundidade de $30-60 \mathrm{~cm}$.

\begin{tabular}{|c|c|c|c|c|c|c|}
\hline Tratamento & $\mathrm{Ca}^{+2}$ & $\mathrm{Mg}^{+2}$ & $\mathrm{~K}^{+}$ & $\overline{\mathrm{N}}$ & $\bar{P}$ & $\mathrm{~S}^{-\mathrm{SO}_{4}^{-2}}$ \\
\hline & \multicolumn{3}{|c|}{ 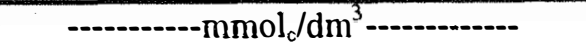 } & $\mathrm{g} / \mathrm{kg}$ & \multicolumn{2}{|c|}{$-----m g / \mathrm{dm}^{3}-\cdots--$} \\
\hline Test & $7,60 \mathrm{def}+$ & $4,03 \mathrm{c}$ & $0,77 \mathrm{bc}$ & 0,9 lbcde & 1,20 & $11,00 \mathrm{~b}$ \\
\hline Test $+\mathrm{G}$ & $8,37 \mathrm{def}$ & $4,50 \mathrm{bc}$ & $1,17 \mathrm{abc}$ & $0,85 \mathrm{e}$ & 1,60 & $18,00 \mathrm{~b}$ \\
\hline $\mathrm{NCa}_{1}$ & $12,40 \mathrm{bc}$ & $4,47 \mathrm{bc}$ & $1,50 \mathrm{abc}$ & $0.95 \mathrm{bcde}$ & 1,04 & $11,66 \mathrm{~b}$ \\
\hline $\mathrm{NCa}_{2}$ & $9,67 \mathrm{cdef}$ & $4,83 \mathrm{bc}$ & $1,00 \mathrm{abc}$ & $1,27 \mathrm{a}$ & 1,14 & $12,00 \mathrm{~b}$ \\
\hline $\mathrm{NCa}_{1}+\mathrm{G}$ & $8,93 \mathrm{cdef}$ & $5,23 \mathrm{bc}$ & $1,53 \mathrm{abc}$ & $1,10 \mathrm{ab}$ & 1,71 & $19,33 b$ \\
\hline $\mathrm{NCa}_{2}+\mathrm{G}$ & $17,40 \mathrm{a}$ & $4,57 \mathrm{bc}$ & $1,70 \mathrm{ab}$ & $0,98 \mathrm{abcde}$ & 0,91 & $9,67 b$ \\
\hline $\mathrm{NMg}_{1}$ & $8,80 \mathrm{cdef}$ & $6,57 \mathrm{abc}$ & $1,17 \mathrm{abc}$ & $0,97 \mathrm{bcde}$ & 0,10 & $9,33 b$ \\
\hline $\mathrm{NMg}_{2}$ & $10,27 \mathrm{cde}$ & $6,07 \mathrm{abc}$ & $1,60 \mathrm{abc}$ & $0,97 \mathrm{bcde}$ & 1,12 & $11,00 \mathrm{~b}$ \\
\hline $\mathrm{NMg}_{1}+\mathrm{G}$ & $6,43 \mathrm{ef}$ & $7,73 \mathrm{ab}$ & $1,26 a b c$ & $1,12 \mathrm{ab}$ & 1,89 & $22,33 b$ \\
\hline $\mathrm{NMg}_{2}+\mathrm{G}$ & $8,47 \mathrm{cdef}$ & $8,90 \mathrm{a}$ & $1,97 a$ & $0,83 \mathrm{e}$ & 2,93 & $14,00 \mathrm{~b}$ \\
\hline $\mathrm{SA}_{1}$ & $6,20 \mathrm{f}$ & $4,10 \mathrm{bc}$ & $1,00 \mathrm{abc}$ & 1,09abc & 0,80 & $17,00 \mathrm{~b}$ \\
\hline $\mathrm{SA}_{2}$ & $11,37 \mathrm{~cd}$ & $4,27 \mathrm{bc}$ & $0,80 \mathrm{bc}$ & 1,09abc & 1,27 & $10.67 \mathrm{~b}$ \\
\hline $\mathrm{SA}_{1}+\mathrm{G}$ & $9,87 \mathrm{def}$ & $5,43 a b c$ & $1,07 \mathrm{abc}$ & $1,09 \mathrm{abc}$ & 9,08 & $53,33 a$ \\
\hline $\mathrm{SA}_{2}+\mathrm{G}$ & $15,40 \mathrm{ab}$ & $4,90 \mathrm{bc}$ & $1,47 a b c$ & $1,12 \mathrm{ab}$ & 4,57 & $19,00 \mathrm{~b}$ \\
\hline $\mathrm{SN}_{1}$ & $8,60 \mathrm{cdef}$ & $6,10 a b c$ & $0,67 \mathrm{c}$ & 1,05 abcde & 0,49 & $10,33 \mathrm{~b}$ \\
\hline $\mathrm{SN}_{2}$ & $6,47 \mathrm{ef}$ & $4,03 \mathrm{c}$ & $0,93 \mathrm{bc}$ & $0,86 \mathrm{cde}$ & 1,38 & $11,33 b$ \\
\hline $\mathrm{SN}_{1}+\mathrm{G}$ & $8,73 \mathrm{cdef}$ & $3,07 \mathrm{c}$ & $0,90 \mathrm{bc}$ & $0,91 \mathrm{bcde}$ & 4,11 & $13,67 b$ \\
\hline $\mathrm{SN}_{2}+\mathrm{G}$ & $9,57 \mathrm{cdef}$ & $5,00 \mathrm{bc}$ & $1,33 \mathrm{abc}$ & 0,85 cde & 2,07 & $10,67 \mathrm{~b}$ \\
\hline F & $15.22^{* *}$ & $4,39 * *$ & $\begin{array}{c}3,89 * * \\
25,94\end{array}$ & $\begin{array}{l}7,54^{* *} \\
7,65\end{array}$ & $\begin{array}{l}\text { n.s. } \\
180,19\end{array}$ & $\begin{array}{l}15,71^{* *} \\
28.05\end{array}$ \\
\hline $\begin{array}{l}\text { CV (\%) } \\
\text { dms (5\%) }\end{array}$ & $\begin{array}{r}13,28 \\
3,98 \\
\end{array}$ & $\begin{array}{r}22,65 \\
3,64 \\
\end{array}$ & $\begin{array}{r}25,94 \\
0,97 \\
\end{array}$ & 0,23 & 11,53 & 13,65 \\
\hline
\end{tabular}

**Valores de $\mathrm{F}$ significativos a $1 \%$ de probabilidade

+ Médias seguidas de mesma letra não diferem estatisticamente entre si (Tukey 5\%) 
Pelos dados da Tabela 36 e Figura 8, percebe-se também que a profundidade de 30 a $60 \mathrm{~cm}$ sofreu aporte de $\mathrm{P}$ e S-SO${ }_{4}^{-2}$ em função da aplicação de gesso. A adsorção de fosfatos e sulfatos ocorre geralmente em subsuperfície pelo maior número de cargas positivas em relação à superficie, onde a matéria orgânica exerce influência mais pronunciada no complexo de cargas do solo. Aumentos de sulfato até 1 $\mathrm{m}$ de profundidade foram observados em Areia Quartzoza no trabalho de ZOTARELLI (1992), em função da utilização de gesso. A Tabela 36 e a Figura 9 revelam, ainda, que em relação à testemunha, havia mais potássio na camada $30-60 \mathrm{~cm}$ em função da aplicação de gesso. A lixiviação de potássio em profundidade fora do alcance das raizes, é um fato indesejável e foi também observado em muitos outros trabalhos, utilizando gesso, a exemplo de REEVE \& SUMNER (1972); RITCHEY et al. (1980); QUAGGIO et al. (1982); PAVAN et al. (1984); MARIA et al. (1993).

Tabela 36. Médias dos teores de macronutrientes obtidos em amostras de solo retiradas da profundidade de $30-60 \mathrm{~cm}$, considerando a aplicação de gesso, independentemente das doses ou fontes de nitrogênio.

\begin{tabular}{|c|c|c|c|c|c|c|}
\hline Tratamentos & $\mathrm{Ca}^{+2}$ & $\mathrm{Mg}^{+2}$ & $\mathrm{~K}^{+}$ & $\bar{N}$ & $\mathrm{P}$ & $\mathrm{S}-\mathrm{SO}_{4}{ }^{-2}$ \\
\hline & \multicolumn{3}{|c|}{$----\mathrm{mmol}_{\mathrm{c}} / \mathrm{dm}^{3}-\cdots$} & $\mathrm{g} / \mathrm{kg}$ & \multicolumn{2}{|c|}{$-----\mathrm{mg} / \mathrm{dm}^{3}------$} \\
\hline Sem gesso & $9,22 b^{+}$ & 5,05 & $1,08 \mathrm{~b}$ & 1,03 & $0,92 b$ & $11,67 \mathrm{~b}$ \\
\hline Com gesso & $10,66 a$ & 5,60 & $1,40 \mathrm{a}$ & 1,00 & $3,24 a$ & $20,25 \mathrm{a}$ \\
\hline F & $13,96 * *$ & n.s. & $11,50 * *$ & n.s. & 5,428 & $44,82 * *$ \\
\hline $\operatorname{cv}(\%)$ & $\begin{array}{r}13,44 \\
079\end{array}$ & $\begin{array}{r}22,55 \\
071\end{array}$ & $\begin{array}{r}26,35 \\
019\end{array}$ & $\begin{array}{l}8,04 \\
0\end{array}$ & $\begin{array}{r}106,37 \\
204\end{array}$ & $\begin{array}{r}27,83 \\
2,62\end{array}$ \\
\hline
\end{tabular}

**Valores significativos a $1 \%$ de probabilidade

+ Médias seguidas de mesma letra não diferem estatisticamente entre si (Tukey 5\%) 


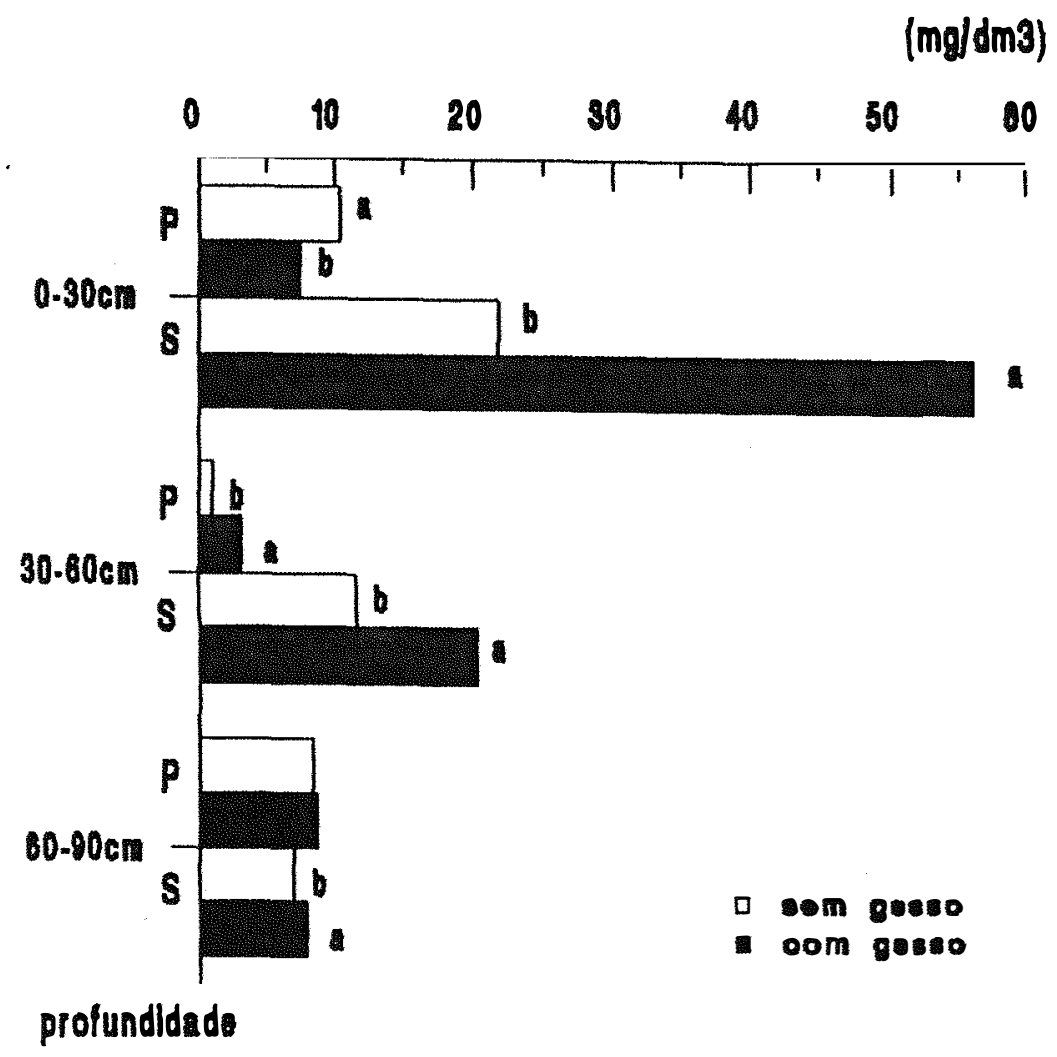

Figura 8. Médias dos teores de $\mathrm{P}$ e S-SO${ }_{4}^{-2}\left(\mathrm{mg} / \mathrm{dm}^{3}\right.$ solo) obtidos nas três profundidades analisadas, como efeito do gesso, independentemente das fontes e doses de nitrogênio estudadas. 


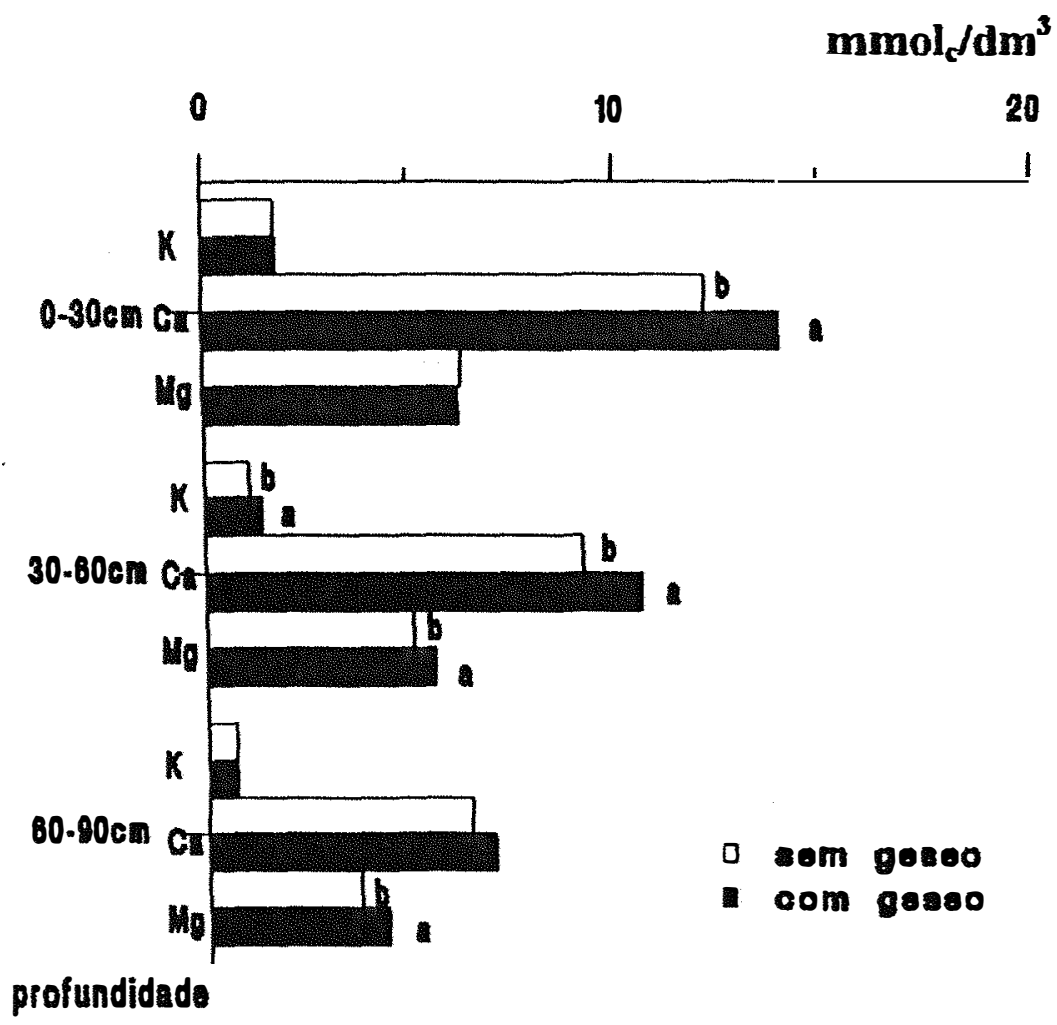

Figura 9. Médias dos teores de $\mathrm{K}$, Ca e $\mathrm{Mg}\left(\mathrm{mmol}_{\mathrm{c}} / \mathrm{dm}^{3}\right.$ solo) obtido nas três profundidades analisadas, como efeito do gesso, independentemente das fontes e doses de nitrogênio estudadas.

Analisando as médias obtidas para cada fonte nitrogenada independentemente da dose ou da aplicação de gesso (Tabelas 32, 37 e 42), verifica-se que as fontes que continham cálcio e magnésio ( $\mathrm{NCa}$ e $\mathrm{NMg}$ ) promoveram aumento nos teores desses elementos no solo principalmente nas camadas $0-30 \mathrm{~cm}$ e $30-60 \mathrm{~cm}$ de 
profundidade. O cálcio atingiu a camada de 60 a $90 \mathrm{~cm}$ de profundidade, quando se aplicou o nitrato de cálcio.

Os tratamentos com sulfato de amônio também promoveram aumentos no teor de cálcio em profundidade. Além disso, o sulfato de amônio promoveu aumentos no teor de $\mathrm{S}_{-} \mathrm{SO}_{4}^{-2}$ até $60 \mathrm{~cm}$ de profundidade, provavelmente devido à maior quantidade de sulfato aplicado nesse tratamento. O nitrato de cálcio e o sulfato de amônio proporcionaram teores maiores de $\mathrm{N}$ no solo até $60 \mathrm{~cm}$ de profundidade, não considerando o efeito de doses e do gesso.

O tratamento com uréia + sulfato de amônio (sulfnitro) apresentou sempre os menores teores de nitrogênio no solo tanto na camada 0-30 cm (Tabela 32), como na camada de 30-60 cm (Tabela 37). Como foi a fonte de menor utilização do nitrogênio pelo milho, supõe-se que perdas do nitrogênio, principalmente por volatilização, deva ter ocorrido. A mistura de sulfato de amônio com a uréia no mesmo grânulo, visa diminuir as perdas por volatilização da amônia, contudo, podem ter ocorrido perdas de $\mathrm{N}$ por volatilização.

Houve efeito de doses de $\mathrm{N}$ (Tabela 33) no aumento dos teores de cátions trocáveis, na camada de $0-30 \mathrm{~cm}$ de profundidade. Nas profundidades subsequentes, apenas o $\mathrm{Ca}$ e o $\mathrm{K}$ tiveram influência da utilização da maior dosagem de $\mathrm{N}$ (Tabelas 38 e 43).

As Tabelas 34, 39 e 44 apresentam os valores do teste $F$ para as interações dos fatores em estudo. As interações significativas não foram constantes nas 
tres profundidades. Apenas para o teor de cálcio verificou-se efeito de todas as interações nas profundidades 30-60 e $60-90 \mathrm{~cm}$.

Tabela 37. Médias dos teores de macronutrientes obtidos em amostras de solo retiradas da profundidade de $30-60 \mathrm{~cm}$, considerando as fontes de $\mathrm{N}$, independentemente das doses de $\mathrm{N}$ ou da aplicação de gesso.

\begin{tabular}{|c|c|c|c|c|c|c|}
\hline Tratamentos & $\mathrm{Ca}^{+2}$ & $\mathrm{Mg}^{+2}$ & $\mathrm{~K}^{+}$ & $\mathrm{N}$ & $\mathrm{P}$ & $\mathrm{S}-\mathrm{SO}_{4}^{-2}$ \\
\hline & \multicolumn{3}{|c|}{ - } & $\mathrm{g} / \mathrm{kg}$ & \multicolumn{2}{|c|}{$-\cdots---m g / \mathrm{dm}^{3}-\cdots-\cdot--$} \\
\hline $\mathrm{NCa}$ & $12,10 \mathrm{a}^{+}$ & $4,77 \mathrm{~b}$ & $1,43 \mathrm{ab}$ & $1,07 \mathrm{a}$ & 1,20 & $13,17 \mathrm{~b}$ \\
\hline $\mathrm{NMg}$ & $8,62 b$ & $7,32 \mathrm{a}$ & $1,50 \mathrm{a}$ & $0,97 b$ & 1,51 & $14,17 \mathrm{~b}$ \\
\hline $\mathrm{SA}$ & $10,71 \mathrm{a}$ & $4,67 b$ & $1,08 \mathrm{bc}$ & $1,10 \mathrm{a}$ & 3,59 & $25,00 a$ \\
\hline SN & $8,34 b$ & $4,55 b$ & $0,96 \mathrm{c}$ & $0,92 b$ & 2,01 & $11,50 \mathrm{~b}$ \\
\hline $\mathrm{F}$ & $21,41^{* *}$ & $14,66^{* *}$ & 7,78 & $13,39 * *$ & n.s. & $22,84^{* *}$ \\
\hline $\operatorname{cv}(\%)$ & 13,44 & 22,55 & 26,35 & 8,04 & 166.37 & 27.83 \\
\hline $\mathrm{dms}(5 \%)$ & 1,48 & 1,33 & 0,36 & 0,09 & 3.84 & 4,94 \\
\hline
\end{tabular}

**Valores de $\mathrm{F}$ significativos a $1 \%$ de probabilidade

+ Médias seguidas de mesma letra não diferem estatisticamente entre si (Tukey 5\%)

Tabela 38. Médias dos teores de macronutrientes obtidos em amostras de solo retiradas da profundidade de $30-60 \mathrm{~cm}$, considerando as doses de $\mathrm{N}$, independentemente das fontes de nitrogênio e da aplicação de gesso.

\begin{tabular}{|c|c|c|c|c|c|c|}
\hline Tratamentos & $\mathrm{Ca}^{+2}$ & $\mathrm{Mg}^{+2}$ & $\mathrm{~K}^{+}$ & $\mathrm{N}$ & $\bar{P}$ & $\mathrm{~S}-\mathrm{SO}_{4}^{-2}$ \\
\hline & ------------ & $\mathrm{nol}_{\mathrm{d}} / \mathrm{dm}$ & & $\mathrm{g} / \mathrm{kg}$ & $-\cdots---m g$ & $\cdots$ \\
\hline $60 \mathrm{~kg} \mathrm{~N} \cdot \mathrm{ha}^{-1}$ & $8,8 \mathrm{Ib}^{+}$ & $-5,34$ & $1,14 b$ & 1,03 & 2,23 & 19,62 \\
\hline $120 \mathrm{~kg} \mathrm{~N} \cdot \mathrm{ha}^{-1}$ & $11,07 \mathrm{a}$ & 5,32 & $1,35 a$ & 1,00 & 1,92 & 12,29 \\
\hline $\begin{array}{l}\mathrm{F} \\
\mathrm{cv}(\%) \\
\text { dms (5\%) }\end{array}$ & $\begin{array}{c}34,52 * * \\
13,44 \\
0,79\end{array}$ & $\begin{array}{l}\text { n.s. } \\
22,55 \\
0,71\end{array}$ & $\begin{array}{c}5,05^{*} \\
26,35 \\
0,19\end{array}$ & $\begin{array}{l}\text { n.s. } \\
8,04 \\
0,05\end{array}$ & $\begin{array}{l}\text { n.s. } \\
166,37 \\
2,04\end{array}$ & $\begin{array}{c}32,71^{* *} \\
27,83 \\
2,62\end{array}$ \\
\hline
\end{tabular}

**Valores de $\mathrm{F}$ significativos a $1 \%$ de probabilidade

* Valores de $\mathrm{F}$ significativos a $5 \%$ de probabilidade

+ Médias seguidas de mesma letra não diferem estatisticamente entre si (Tukey 5\%) 
Tabela 39. Valores do teste $\mathrm{F}$ a 5 ou $1 \%$ de probabilidade para as interações entre gesso, fonte de nitrogênio para os teores de macronutrientes em amostras de solo retiradas da camada de $30-60 \mathrm{~cm}$ de profundidade.

\begin{tabular}{lcccccc}
\hline Interação & $\mathrm{Ca}^{+2}$ & $\mathrm{Mg}^{+2}$ & $\mathrm{~K}^{+}$ & $\mathrm{N}$ & $\mathrm{P}$ & ${\mathrm{S}-\mathrm{SO}_{4}^{-2}}^{-2}$ \\
\hline Dose $\mathrm{N} x$ Fonte N & $10,62^{* *}$ & n.s. & n.s. & $6,32^{* *}$ & n.s. & $11,77^{* *}$ \\
Dose Nx Gesso & $22,38^{* *}$ & n.s. & $5,05^{*}$ & $8,27^{* *}$ & n.s. & $25,70^{* *}$ \\
Fonte N x Gesso & $9,54^{* *}$ & $3,38^{*}$ & n.s. & n.s. & n.s. & $14,05^{* *}$ \\
Dose Nx Fonte Nx Gesso & $11,35^{* *}$ & n. s. & n.s. & $8,50^{* *}$ & n.s. & $4.11^{*}$ \\
\hline
\end{tabular}

**Valores de $\mathrm{F}$ significativos a $1 \%$ de probabilidade

* Valores de F significativos a 5\% de probabilidade

Tabela 40. Médias dos teores de macronutrientes obtidos para os diversos tratamentos em amostras de solo retiradas da profundidade de $60-90 \mathrm{~cm}$

\begin{tabular}{|c|c|c|c|c|c|c|}
\hline Tratamentos & $\mathrm{Ca}^{+2}$ & $\mathrm{Mg}^{+2}$ & $\overline{\mathrm{K}^{+}}$ & $\mathrm{N}$ & $\bar{P}$ & $\mathrm{~S}-\mathrm{SO}_{4}^{-2}$ \\
\hline & \multicolumn{3}{|c|}{ 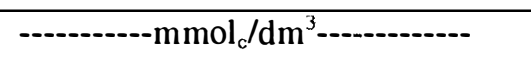 } & $\mathrm{g} / \mathrm{kg}$ & \multicolumn{2}{|c|}{$\cdots--m g / d^{-3}---$} \\
\hline Test & $5,60 \mathrm{~cd}^{+}$ & $4,73 \mathrm{ab}$ & 0,50 & 0,62 & 1,25 & 6,67 \\
\hline Test $+\mathrm{G}$ & $5,80 \mathrm{bcd}$ & $3,73 \mathrm{ab}$ & 0,57 & 0,56 & 0,46 & 5.33 \\
\hline $\mathrm{NCa}_{1}$ & 7,77abc & 4,33ab & 0,53 & 0,71 & 1,28 & 6,67 \\
\hline $\mathrm{NCa}_{2}$ & $4,37 \mathrm{~d}$ & $3,00 \mathrm{ab}$ & 0,67 & 0,82 & 0,86 & 6,00 \\
\hline $\mathrm{NCa}_{1}+\mathrm{G}$ & $7,00 \mathrm{bcd}$ & $4,80 \mathrm{ab}$ & 0,77 & 0,80 & 0,68 & 7,67 \\
\hline $\mathrm{NCa}_{2}+\mathrm{G}$ & 7,90abc & $3,77 \mathrm{ab}$ & 0,67 & 0.72 & 0,57 & 7,00 \\
\hline $\mathrm{NMg}_{\mathrm{l}}$ & $6,87 \mathrm{bcd}$ & $3,90 \mathrm{ab}$ & 0,70 & 0,67 & 0,07 & 5.00 \\
\hline $\mathrm{NMg}_{2}$ & $6,00 \mathrm{bcd}$ & $3,90 \mathrm{ab}$ & 0,93 & 0,75 & 0,80 & 7,00 \\
\hline $\mathrm{NMg}_{1}+\mathrm{G}$ & $5,87 \mathrm{bcd}$ & $5,63 \mathrm{a}$ & 0,70 & 0,74 & 1,20 & 10,00 \\
\hline $\mathrm{NMg}_{2}+\mathrm{G}$ & $5,40 \mathrm{~cd}$ & $4,37 \mathrm{ab}$ & 0,63 & 0,62 & 0,65 & 6,00 \\
\hline $\mathrm{SA}_{1}$ & $6,67 \mathrm{bcd}$ & $4,20 \mathrm{ab}$ & 0,87 & 0,91 & 1,03 & 7,67 \\
\hline $\mathrm{SA}_{2}$ & $8,50 \mathrm{ab}$ & 3,93ab & 0,47 & 0,70 & 1,38 & 8,00 \\
\hline $\mathrm{SA}_{1}+\mathrm{G}$ & $6,50 \mathrm{bcd}$ & 4,60ab & 0,93 & 0,84 & 0,38 & 9,00 \\
\hline $\mathrm{SA}_{2}+\mathrm{G}$ & $10,40 \mathrm{a}$ & $4,73 \mathrm{ab}$ & 0,60 & 0,73 & 1,37 & 9,00 \\
\hline $\mathrm{SN}_{\mathrm{l}}$ & $5,50 \mathrm{~cd}$ & $2,83 b$ & 0,73 & 0,83 & 0,39 & 8,00 \\
\hline $\mathrm{SN}_{2}$ & $6,00 \mathrm{bcd}$ & $3,87 \mathrm{ab}$ & 0,60 & 0,64 & 0,92 & 7,00 \\
\hline $\mathrm{SN}_{1}+\mathrm{G}$ & $6,37 \mathrm{bcd}$ & $3,06 a b$ & 0,80 & 0,73 & 0,41 & 8,33 \\
\hline $\mathrm{SN}_{2}+\mathrm{G}$ & $6,63 \mathrm{bcd}$ & $4,43 a b$ & 0,50 & 0,62 & 1,37 & 7,00 \\
\hline $\begin{array}{l}\mathrm{F} \\
\mathrm{CV}(\%) \\
\mathrm{dms}(5 \%)\end{array}$ & $\begin{array}{c}7,11^{* *} \\
13,45 \\
2,74\end{array}$ & $\begin{array}{c}1,98^{* *} \\
22,10 \\
2,79\end{array}$ & $\begin{array}{l}\text { n.s. } \\
26,85 \\
0,56\end{array}$ & $\begin{array}{c}\text { n.s. } \\
20,99 \\
0,47\end{array}$ & $\begin{array}{c}\text { n.s. } \\
68,26 \\
1,80 \\
\end{array}$ & $\begin{array}{r}\text { n.s. } \\
28, .91 \\
6,50\end{array}$ \\
\hline
\end{tabular}

**Valores de $\mathrm{F}$ significativos a $1 \%$ de probabilidade

+ Médias seguidas de mesma letra não diferem estatisticamente entre si (Tukey 5\%) 
Tabela 41. Médias dos teores de macronutrientes obtidos em amostras de solo retiradas da profundidade de $60-90 \mathrm{~cm}$, considerando a aplicação de gesso, independentemente das doses ou fontes de nitrogênio.

\begin{tabular}{|c|c|c|c|c|c|c|}
\hline Tratamentos & $\mathrm{Ca}^{+2}$ & $\mathrm{Mg}^{+2}$ & $\mathrm{~K}^{+}$ & $\bar{N}$ & $\mathrm{P}$ & $\mathrm{S}-\mathrm{SO}_{4}^{-2}$ \\
\hline & 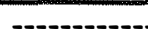 & $\mathrm{mmol}_{\mathrm{c}} / \mathrm{d}_{\mathrm{l}}$ & $\overline{-----}$ & $\mathrm{g} / \mathrm{kg}$ & \multicolumn{2}{|c|}{----mg/dm ${ }^{3}-$} \\
\hline Sem gesso & $6,46 b^{+}$ & $3,74 b$ & 0,69 & 0,75 & 0,84 & $6.92 b$ \\
\hline Com gesso & $7,01 \mathrm{a}$ & $4,42 \mathrm{a}$ & 0,70 & 0,72 & 0,87 & $8.00 \mathrm{a}$ \\
\hline $\begin{array}{l}\mathrm{F} \\
\operatorname{cv}(\%) \\
\mathrm{dms}(5 \%)\end{array}$ & $\begin{array}{c}4,21 * \\
13,79 \\
0,55\end{array}$ & $\begin{array}{c}6,36 * \\
22,83 \\
0,55\end{array}$ & $\begin{array}{l}\text { n.s. } \\
27,48 \\
0,11\end{array}$ & $\begin{array}{l}\text { n.s. } \\
21.67 \\
0,09\end{array}$ & $\begin{array}{l}\text { n.s. } \\
70,12 \\
0,36\end{array}$ & $\begin{array}{c}4.30^{*} \\
28.59 \\
1,06\end{array}$ \\
\hline
\end{tabular}

$*$ Valores significativos a $5 \%$ de probabilidade

+ Médias seguidas de mesma letra não diferem estatisticamente entre si (Tukey 5\%)

Tabela 42. Médias dos teores de macronutrientes obtidos em amostras de solo retiradas da profundidade de $60-90 \mathrm{~cm}$, considerando as fontes de $\mathrm{N}$, independente das doses de $\mathrm{N}$ ou da aplicação de gesso.

\begin{tabular}{|c|c|c|c|c|c|c|}
\hline Tratamentos & $\mathrm{Ca}^{+2}$ & $\mathrm{Mg}^{+2}$ & $\mathrm{~K}^{+}$ & $\bar{N}$ & $\mathrm{P}$ & $\mathrm{S}-\mathrm{SO}_{4}^{-2}$ \\
\hline & \multicolumn{3}{|c|}{-------mmol $\mathrm{d}_{\mathrm{d}} \mathrm{dm}-\mathrm{-}$} & $\mathrm{g} / \mathrm{kg}$ & \multicolumn{2}{|c|}{------mg/dm ${ }^{3}-----$} \\
\hline $\mathrm{NCa}$ & $6,76 \mathrm{~b}^{+}$ & 3,97 & 0,66 & 0,76 & 0,85 & 6,83 \\
\hline $\mathrm{NMg}$ & $6,03 b$ & 4,45 & 0,74 & 0,69 & 0,68 & 7,00 \\
\hline SA & $8,02 a$ & 4,37 & 0,72 & 0,79 & 1,12 & 8,42 \\
\hline SN & $6,12 b$ & 3,55 & 0,66 & 0,76 & 0,77 & 7,58 \\
\hline F & $\begin{array}{l}11,64^{* *} \\
13,79\end{array}$ & $\begin{array}{l}\text { n.s. } \\
22,83\end{array}$ & $\begin{array}{l}\text { n.s. } \\
27,48\end{array}$ & $\begin{array}{l}\text { n.s. } \\
21,67\end{array}$ & $\begin{array}{l}\text { n.s. } \\
70,49\end{array}$ & $\begin{array}{l}\text { n.s. } \\
28,59\end{array}$ \\
\hline $\mathrm{dms}(5 \%)$ & 1,03 & 1,04 & 0,21 & 0,18 & 0,67 & 2,37 \\
\hline
\end{tabular}

** Valores de F significativos a $1 \%$ de probabilidade

* Valores de F significativos a $5 \%$ de probabilidade

+ Médias seguidas de mesma letra não diferem estatisticamente entre si (Tukey 5\%) 
Tabela 43. Médias dos teores de macronutrientes obtidos em amostras de solo retiradas da profundidade de $60-90 \mathrm{~cm}$, considerando as doses de $\mathrm{N}$, independentemente das fontes de nitrogênio e da aplicação de gesso.

\begin{tabular}{|c|c|c|c|c|c|c|}
\hline Tratamentos & $\mathrm{Ca}^{+2}$ & $\mathrm{Mg}^{+}$ & $\overline{\mathrm{K}^{+}}$ & $\overline{\mathrm{N}}$ & $\bar{P}$ & $\mathrm{~S}-\mathrm{SO}_{4}^{-2}$ \\
\hline & \multicolumn{3}{|c|}{-----mmol ${ }_{\mathrm{c}} / \mathrm{dm}^{3}-\cdots$} & $\mathrm{g} / \mathrm{kg}$ & \multicolumn{2}{|c|}{$-\cdots----m g / \mathrm{dm}^{3}-\cdots$} \\
\hline $60 \mathrm{Kg} \mathrm{N} / \mathrm{ha}$ & 6,57 & 4,17 & $0,75 a$ & 0,78 & 0.68 & 7,79 \\
\hline $120 \mathrm{Kg} \mathrm{N} / \mathrm{ha}$ & 6,90 & 4,00 & $0,63 b$ & 0,70 & 1,03 & 7,12 \\
\hline $\begin{array}{l}F \\
\text { cv (\%) } \\
\text { dms (5\%) }\end{array}$ & $\begin{array}{c}\text { n.s. } \\
13,79 \\
0,55\end{array}$ & $\begin{array}{r}\text { n.s. } \\
22,83 \\
0,55\end{array}$ & $\begin{array}{c}4,82^{*} \\
27,48 \\
0,11\end{array}$ & $\begin{array}{r}\text { n.s. } \\
21,67 \\
0,09\end{array}$ & $\begin{array}{c}4,12^{*} \\
70,49 \\
0,36\end{array}$ & $\begin{array}{c}\text { n.s. } \\
28,59 \\
12,57\end{array}$ \\
\hline
\end{tabular}

* Valores de $\mathrm{F}$ significativos a $5 \%$ de probabilidade

+ Médias seguidas de mesma letra não diferem estatisticamente entre si (Tukey 5\%)

Tabela 44. Valores do teste $\mathrm{F}$ a 5 ou $1 \%$ de probabilidade para as interações entre gesso, fonte e dose de nitrogênio para os teores de macronutrientes em amostras de solo retiradas da camada de $60-90 \mathrm{~cm}$ de profundidade.

\begin{tabular}{lcccccc}
\hline Interação & $\mathrm{Ca}^{+2}$ & $\mathrm{Mg}^{+2}$ & $\mathrm{~K}^{+}$ & $\mathrm{N}$ & $\mathrm{P}$ & ${\mathrm{S}-\mathrm{SO}_{4}{ }^{-2}}^{+2}$ \\
\hline Dose Nx Fonte N & $11,52^{* *}$ & $3,60^{*}$ & $3,58^{*}$ & n.s. & n.s. & n.s. \\
Dose Nx Gesso & $9,29^{* *}$ & n.s. & n.s. & n.s. & n.s. & n.s. \\
Fonte N x Gesso & $3,08^{*}$ & n.s. & n.s. & n.s. & n.s. & n.s. \\
Dose Nx Fonte Nx Gesso & $3,57^{*}$ & n.s. & n.s. & n.s. & n.s. & n.s. \\
\hline
\end{tabular}

**Valores de $\mathrm{F}$ significativos a $1 \%$ de probabilidade

* Valores de $\mathrm{F}$ significativos a 5\% de probabilidade 


\subsubsection{Parâmetros de Acidez e Retenção de Cátions}

Não foram observadas variações significativas no parâmetro pH nas profundidades estudadas (Tabelas 45, 50 e 55), embora mudanças na reação do solo fossem esperadas para este ensaio, devido à aplicação de gesso ou de fertilizantes nitrogenados de reações ácidas como o sulfato de amônio e a uréia + sulfato de amônio (sulfnitro), ou de reações alcalinas como o nitrato de cálcio e o nitrato de magnésio. Além disso, a absorção de nitrogênio pelas plantas, em função da maior absorção de nitratos nos tratamentos com nitrato de cálcio e nitrato de magnésio poderia elevar o $\mathrm{pH}$ do solo através da excreção de $\mathrm{HCO}_{3}^{-}$pelas raízes. Questiona-se neste ponto se a determinação da reação do solo através de uma escala logarítmica seria suficientemente sensível para revelar estas modificações. Outro ponto seria a complexidade do sistema solo, onde processos dinâmicos ocorrem, envolvendo o nitrogênio. Além disso, solos muito argilosos com teores médios a altos de matéria orgânica podem apresentar alta capacidade de tamponamento, impedindo mudanças no $\mathrm{pH}$. 
Tabela 45. Médias dos valores de $\mathrm{pH}, \mathrm{H}^{+}, \mathrm{Al}^{+3}$, soma de bases (S); capacidade de troca catiônica (T), saturação em bases (V) e saturação em alumínio (m) para os diversos tratamentos, em amostras de solo, retiradas da profundidade de 0-30 $\mathrm{cm}$.

\begin{tabular}{|c|c|c|c|c|c|c|c|}
\hline Tratam. & $\mathrm{pH}$ & $\overline{\mathrm{H}^{+}}$ & $\mathrm{Al}^{+3}$ & $\mathrm{~S}$ & $\mathrm{~T}$ & $\overline{\mathrm{V}}$ & $\mathrm{m}$ \\
\hline & & \multicolumn{4}{|c|}{ - } & \multicolumn{2}{|c|}{ 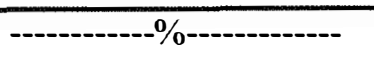 } \\
\hline Test & 4,33 & $12,93 \mathrm{a}^{+}$ & 7,27 & $18,10 \mathrm{defg}$ & $38,30 \mathrm{abc}$ & 47,3 lf & $28,63 \mathrm{ab}$ \\
\hline Test $+\mathrm{G}$ & 4,37 & $7,53 \mathrm{bc}$ & 6,47 & $23,40 \mathrm{bcd}$ & $37,40 \mathrm{abc}$ & $65,06 \mathrm{abc}$ & $21,54 \mathrm{abc}$ \\
\hline $\mathrm{NCa}_{1}$ & 4,31 & $7,17 \mathrm{c}$ & 6,80 & $22,90 \mathrm{bcdef}$ & $36,87 \mathrm{abc}$ & 62,13 abcde & $21,02 \mathrm{abc}$ \\
\hline $\mathrm{NCa}_{2}$ & 4,36 & $6,37 \mathrm{c}$ & 5,17 & $20,87 \mathrm{cdefg}$ & $32,40 \mathrm{c}$ & 64,4 labcd & $20,69 \mathrm{bc}$ \\
\hline $\mathrm{NCa}_{1}+\mathrm{G}$ & 4,37 & $7,63 \mathrm{bc}$ & 5,63 & 21,80 bcdefg & $35,07 \mathrm{bc}$ & $61,82 \mathrm{abcde}$ & $21,02 \mathrm{abc}$ \\
\hline $\mathrm{NCa}_{2}+\mathrm{G}$ & 4,23 & $8,90 \mathrm{abc}$ & 5,83 & $29,63 a$ & $44,37 \mathrm{a}$ & $66,92 a$ & $16,38 \mathrm{c}$ \\
\hline $\mathrm{NMg}_{1}$ & 4,35 & $8,63 \mathrm{abc}$ & 5,63 & 22,30 bcdefg & $36,57 \mathrm{abc}$ & 61,05 abcde & $20,14 b c$ \\
\hline $\mathrm{NMg}_{2}$ & 4,23 & $6,50 \mathrm{c}$ & 7,27 & $23,00 \mathrm{bcde}$ & $36,77 \mathrm{abc}$ & 57,36 abcdef & $23,98 \mathrm{abc}$ \\
\hline $\mathrm{NMg}_{1}+\mathrm{G}$ & 4,30 & $9,23 \mathrm{abc}$ & 5,57 & 19,90 cdefg & $36,80 \mathrm{abc}$ & $62,53 \mathrm{abcde}$ & $21,82 \mathrm{abc}$ \\
\hline $\mathrm{NMg}_{2}+\mathrm{G}$ & 4,28 & $8,00 \mathrm{abc}$ & 7,00 & $26,83 \mathrm{ab}$ & $41,83 \mathrm{ab}$ & $62,42 \mathrm{abcd}$ & $20,69 b c$ \\
\hline $\mathrm{SA}_{1}$ & 4,16 & $12,43 \mathrm{ab}$ & 8,20 & $17,07 \mathrm{fg}$ & $37,70 \mathrm{abc}$ & $45,33 \mathrm{f}$ & $32,49 a$ \\
\hline $\mathrm{SA}_{2}$ & 4,26 & $10,47 \mathrm{abc}$ & 7,40 & $21,10 \mathrm{bcdefg}$ & $39,07 \mathrm{abc}$ & $54,27 \mathrm{bcdef}$ & $26,37 \mathrm{abc}$ \\
\hline $\mathrm{SA}_{1}+\mathrm{G}$ & 4,30 & $9,23 \mathrm{bc}$ & 7,47 & $18,47 \mathrm{defg}$ & $35,17 \mathrm{abc}$ & $52,64 \mathrm{def}$ & $28,54 \mathrm{ab}$ \\
\hline $\mathrm{SA}_{2}+\mathrm{G}$ & 4,17 & $7,47 \mathrm{bc}$ & 5,43 & $25,20 \mathrm{abc}$ & $38,10 \mathrm{abc}$ & $66,22 \mathrm{ab}$ & $17,81 \mathrm{bc}$ \\
\hline $\mathrm{SN}_{1}$ & 4,26 & $9,73 \mathrm{abc}$ & 5,83 & 17,50efg & $33,07 \mathrm{c}$ & $52,88 \mathrm{def}$ & $25,07 \mathrm{abc}$ \\
\hline $\mathrm{SN}_{2}$ & 4,27 & $7,30 \mathrm{c}$ & 6,80 & $17,63 \mathrm{defg}$ & $31,73 \mathrm{c}$ & 55,32 abcdef & $28,11 a b$ \\
\hline $\mathrm{SN}_{1}+\mathrm{G}$ & 4,31 & $10,17 \mathrm{abc}$ & 6,30 & $16,93 \mathrm{~g}$ & $33,40 \mathrm{bc}$ & $50,68 \mathrm{ef}$ & $27,17 \mathrm{abc}$ \\
\hline $\mathrm{SN}_{2}+\mathrm{G}$ & 4,14 & $7,47 b c$ & 6,97 & $18,77 \mathrm{defg}$ & $35,07 \mathrm{bc}$ & $53,86 \mathrm{cdef}$ & $26,88 \mathrm{abc}$ \\
\hline & $\begin{array}{l}\text { n.s. } \\
3,48 \\
0.46\end{array}$ & $\begin{array}{c}3,88^{* * *} \\
18,40 \\
4,99\end{array}$ & $\begin{array}{l}\text { n.s. } \\
16,90 \\
3,38\end{array}$ & $\begin{array}{c}10,66 * * \\
8,97 \\
5,85\end{array}$ & $\begin{array}{l}4,01 * * \\
7,59\end{array}$ & $\begin{array}{c}8,78^{* *} \\
6,75 \\
12,06\end{array}$ & $\begin{array}{c}4,02 * * \\
15,63 \\
11,48\end{array}$ \\
\hline
\end{tabular}

**Valores de $\mathrm{F}$ significativos a $1 \%$ de probabilidade

* Valores de F significativos a $5 \%$ de probabilidade

+ Médias seguidas de mesma letra não diferem estatisticamente entre si (Tukey 5\%) 
Uma pequena elevação do $\mathrm{pH}$ na profundidade de $60-90 \mathrm{~cm}$ em relação à superficie (Tabelas 55 e 45), pode ser devida à adsorção específica de sulfatos. Segundo RAIJ (1988), a reação química do sulfato com a superfície dos óxidos de Fe e Al forma íons $\mathrm{OH}^{-}$que são liberados no solo, conforme a reação que consta no item Revisão de Literatura. OATES \& CALDWELL (1985) também não verificaram qualquer alteração do $\mathrm{pH}$ do solo em função de doses crescentes de gesso. No experimento de RAIJ et al. (1988), realizado em vasos de 1,2 kg de solo, verificou-se efeito do gesso, do nitrato de cálcio e do nitrato de magnésio na redução da acidez do subsolo. O sulfato de amônio, entretanto, elevou a acidez. Neste trabalho, embora não tendo alterado o pH do solo, o sulfato de amônio aumentou os teores de $\mathrm{H}^{+}$(Tabela 47).

As tabelas 45 e 50 revelam ainda que os tratamentos estudados não alteraram os teores de $\mathrm{Al}^{+3}$ no solo, nas camadas de 0-30 e 30-60 cm de profundidade, mas verificou-se diminuição na saturação em alumínio na CTC, em função da aplicação de gesso (Tabela 46 e 51 e Figura 10). Diferenças no teor de $\mathrm{Al}^{+3}$ na profundidade de $60-90 \mathrm{~cm}$ foram observadas em função das fontes de nitrogênio utilizadas. Apenas quando se utilizou o sulfato de amônio houve ligeira redução no teor de $\mathrm{Al}^{+3}$ (Tabelas 55 e 57). 
Tabela 46. Médias dos valores de $\mathrm{pH} ; \mathrm{H}^{+} ; \mathrm{Al}^{+3}$; soma de bases (S); capacidade de troca catiônica (T); saturação em bases (V) e saturação em $\mathrm{Al}^{+3}$, obtidos em amostras de solo retiradas da profundidade $0-30 \mathrm{~cm}$, considerando a aplicação de gesso, independentemente das doses ou fontes de nitrogênio.

\begin{tabular}{|c|c|c|c|c|c|c|c|}
\hline Tratamentos & $\mathrm{pH}$ & $\overline{\mathrm{H}^{+}}$ & $\mathrm{Al}^{+3}$ & $\bar{S}$ & $\mathrm{~T}$ & $\mathrm{~V}$ & $\bar{m}$ \\
\hline & & \multicolumn{4}{|c|}{ - } & \multicolumn{2}{|c|}{ - } \\
\hline sem gesso & 4,27 & 8,57 & 6,64 & $20,31 b$ & $35,52 b$ & 57,24 & $24,86 \mathrm{a}^{+}$ \\
\hline com gesso & 4,26 & 8,74 & 6,27 & $22,19 \mathrm{a}$ & $37,21 \mathrm{a}$ & 59,24 & $22,54 b$ \\
\hline $\begin{array}{l}F \\
\operatorname{cv}(\%) \\
d m s(5 \%)\end{array}$ & $\begin{array}{l}\text { n.s. } \\
3,61 \\
0,09\end{array}$ & $\begin{array}{c}\text { n.s. } \\
19,76 \\
1,01\end{array}$ & $\begin{array}{r}\text { n.s. } \\
17,07 \\
0,65\end{array}$ & $\begin{array}{c}11,57^{* *} \\
9.03 \\
1,13\end{array}$ & $\begin{array}{l}6,59^{*} \\
7,59 \\
1,63\end{array}$ & $\begin{array}{c}\text { n.s. } \\
7,00 \\
2,40 \\
\end{array}$ & $\begin{array}{c}4.33^{*} \\
16,29 \\
2,28 \\
\end{array}$ \\
\hline
\end{tabular}

**Valores de $\mathrm{F}$ significativos a $1 \%$ de probabilidade

* Valores de $\mathrm{F}$ significativos a $5 \%$ de probabilidade

+ Médias seguidas de mesma letra não diferem estatisticamente entre si (Tukey 5\%)

Tabela 47. Médias dos valores de $\mathrm{pH} ; \mathrm{H}^{+} ; \mathrm{Al}^{+3}$; soma de bases (S); capacidade de troca catiônica (T); saturação em bases (V) e saturação em alumínio (m), obtidos em amostras de solo retiradas da profundidade de $0-30 \mathrm{~cm}$, considerando as fontes de $\mathrm{N}$, independentemente das doses de $\mathrm{N}$ ou da aplicação de gesso.

\begin{tabular}{|c|c|c|c|c|c|c|c|}
\hline Tratam. & $\mathrm{pH}$ & $\mathrm{H}^{+}$ & $\mathrm{Al}^{+3}$ & $\bar{S}$ & $\mathrm{~T}$ & $\mathrm{~V}$ & $\mathrm{~m}$ \\
\hline & & \multicolumn{4}{|c|}{ 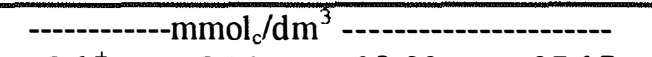 } & \multicolumn{2}{|c|}{--.-- \% ----- } \\
\hline $\mathrm{NCa}$ & 4,32 & $7,52 b^{+}$ & 5,86 & $23,80 \mathrm{a}$ & $37,17 a$ & $63,82 a$ & $20,03 b$ \\
\hline $\mathrm{NMg}$ & 4,29 & $8,09 \mathrm{ab}$ & 6,37 & $23,01 \mathrm{a}$ & $34,47 a$ & $61,34 a$ & $21,66 b$ \\
\hline SA & 4,23 & $9,90 \mathrm{a}$ & 7,12 & $20,48 b$ & 37,5 la & $54,6 \mathrm{lb}$ & $26,30 \mathrm{a}$ \\
\hline SN & 4,25 & $9,13 \mathrm{ab}$ & 6,47 & $17,71 \mathrm{c}$ & $33,32 b$ & $53,18 \mathrm{~b}$ & $26,81 \mathrm{a}$ \\
\hline $\mathrm{F}$ & n.s. & $4,63^{*}$ & n.s. & $24,71^{* *}$ & $4,51^{* *}$ & $19,13^{* *}$ & $9,14^{* *}$ \\
\hline $\begin{array}{l}\mathrm{cv} \% \\
\mathrm{dms}(5 \%)\end{array}$ & 3,61 & 19,76 & 17,07 & 9,03 & 7,59 & 7,00 & 16,29 \\
\hline dms $(5 \%)$ & 0,17 & 1,90 & 1,22 & 2,13 & 3,07 & & \\
\hline
\end{tabular}


Tabela 48. Médias dos valores de $\mathrm{pH} ; \mathrm{H}^{+} ; \mathrm{Al}^{+3}$; soma de bases (S); capacidade de troca catiônica (T); saturação em bases (V) e saturação em alumínio (m), em amostras de solo retiradas da profundidade de 0-30 cm, considerando as doses de $\mathrm{N}$, independentemente das fontes de nitrogênio e da aplicação de gesso.

\begin{tabular}{|c|c|c|c|c|c|c|c|}
\hline Tratamentos & $\mathrm{pH}$ & $\overline{\mathrm{H}^{+}}$ & $\mathrm{Al}^{+3}$ & $S$ & $\mathrm{~T}$ & $\bar{V}$ & $m$ \\
\hline & & \multicolumn{4}{|c|}{$-\mathrm{mmol}_{\mathrm{c}} / \mathrm{dm}^{3}$} & \multicolumn{2}{|c|}{ - } \\
\hline $60 \mathrm{Kg} \mathrm{N} / \mathrm{ha}$ & 4,28 & $9,28 \mathrm{a}^{+}$ & 6,43 & $19,61 \mathrm{~b}$ & $35,32 b$ & $55,48 \mathrm{~b}$ & $24,89 \mathrm{a}$ \\
\hline $120 \mathrm{Kg} \mathrm{N} / \mathrm{ha}$ & 4,26 & $8,04 b$ & 6,48 & $22,89 a$ & $37,41 \mathrm{a}$ & $60,99 \mathrm{a}$ & $22,50 \mathrm{~b}$ \\
\hline $\begin{array}{l}\mathrm{F} \\
\operatorname{cv}(\%) \\
\operatorname{dms}(5 \%)\end{array}$ & $\begin{array}{c}\text { n.s. } \\
3,61 \\
0,09\end{array}$ & $\begin{array}{c}6,27^{*} \\
19,76 \\
1,01\end{array}$ & $\begin{array}{l}\text { n.s. } \\
17,07 \\
0,65\end{array}$ & $\begin{array}{c}35,17^{*} \\
9,03 \\
1,13\end{array}$ & $\begin{array}{l}6,95 * \\
7,59 \\
1,62\end{array}$ & $\begin{array}{c}21,91^{* *} \\
7,00 \\
2,40\end{array}$ & $\begin{array}{c}4,58^{*} \\
16,29 \\
2,28\end{array}$ \\
\hline
\end{tabular}

** Valores de $\mathrm{F}$ significativos a $1 \%$ de probabilidade

*Valores de $\mathrm{F}$ significativos a $5 \%$ de probabilidade

${ }^{+}$Médias seguidas de mesma letra não diferem estatisticamente entre si (Tukey 5\%)

Tabela 49. Valores do teste $\mathrm{F}$ a 5 ou $1 \%$ de probabilidade para as interações entre gesso, fonte e dose de nitrogênio para os parâmetros: valores de $\mathrm{pH} ; \mathrm{H}^{+} ; \mathrm{Al}^{+3}$; soma de bases (S); capacidade de troca catiônica (T); saturação em bases (V) e saturação em alumínio (m); em amostras de solo retiradas da camada de 0-30 cm de profundidade.

\begin{tabular}{lccccccc}
\hline Interação & $\mathrm{pH}$ & $\mathrm{H}^{+}$ & $\mathrm{Al}^{+3}$ & $\mathrm{~S}$ & $\mathrm{~T}$ & $\mathrm{~V}$ & $\mathrm{~m}$ \\
\hline Dose N x Fonte N & n.s. & n.s. & $4,55^{* *}$ & n.s. & n.s. & n.s. & $4,48^{*}$ \\
Dose N x Gesso & n.s. & n.s. & n.s. & $21,21^{* *}$ & $15,73^{* *}$ & n.s. & n.s. \\
Fonte N x Gesso & n.s. & $4,90^{*}$ & n.s. & n.s. & $3,07^{*}$ & $4,94^{* *}$ & n.s. \\
Dose N x Fonte N x Gesso & n.s. & n.s. & n.s. & n.s. & $2,94^{*}$ & n.s. & n.s. \\
\hline
\end{tabular}

**Valores de $\mathrm{F}$ significativos a $1 \%$ de probabilidade

*Valores de $\mathrm{F}$ significativos a $5 \%$ de probabilidade 


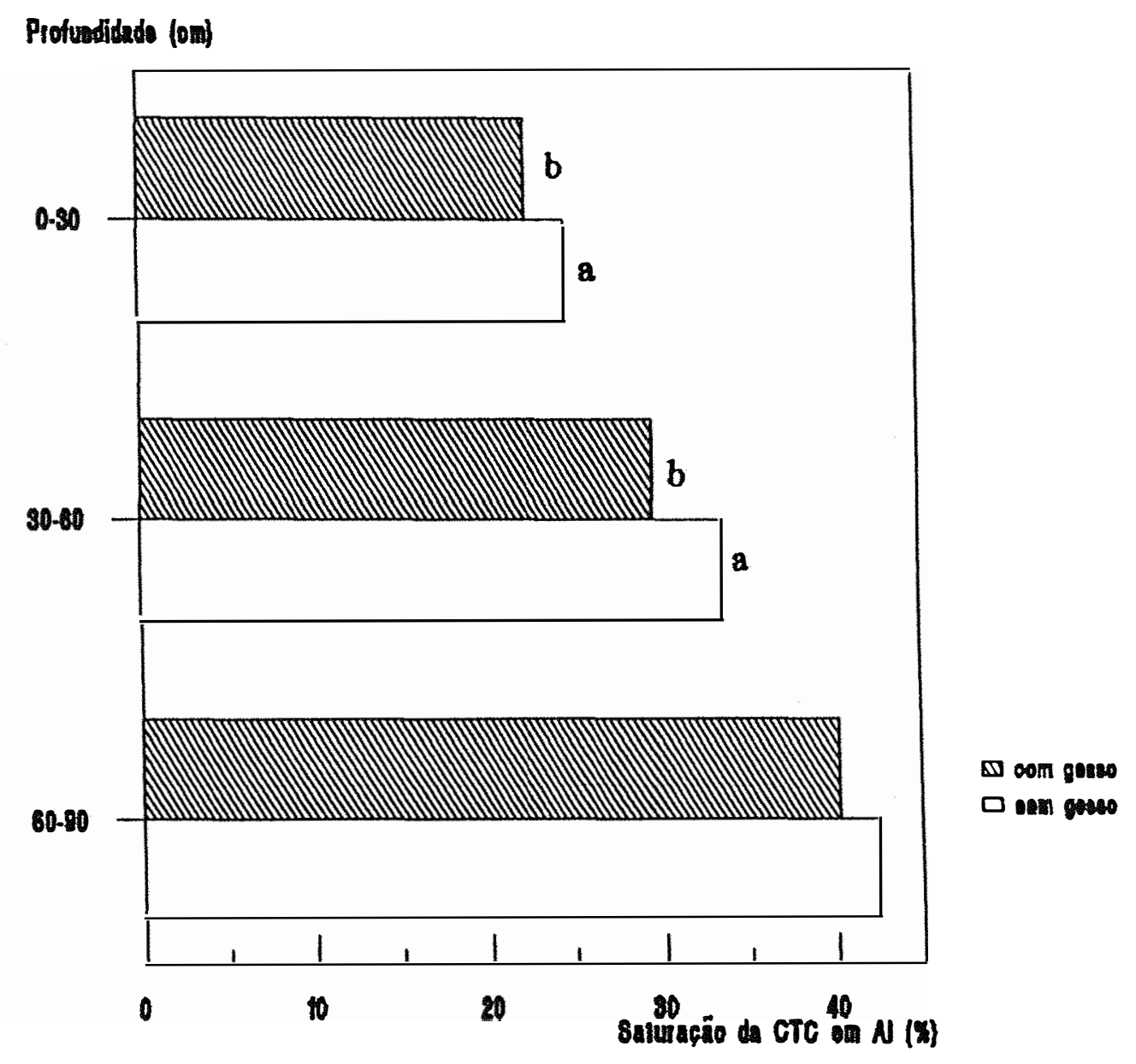

Figura 10. Médias da saturação da CTC em alumínio ( $\mathrm{m} \%$ ) obtidas nas três profundidades analisadas, como efeito do gesso, independentemente das fontes e doses de nitrogênio estudadas. 
A redução na saturação de alumínio devido à aplicação de gesso é um fato constante na literatura, mas vários autores observaram também redução no teor de aluminio, como os trabalhos de PAVAN et al. (1984), SUMNER et al. (1986); FARINA \& CHANNON (1988); SMYTH \& CRAVO (1992). A diminuição no teor de alumínio em solução, foi explicada por REEVE \& SUMNER (1972), num processo chamado de "auto calagem", onde através da adsorção de sulfato pelo solo ocorreria a liberação de íons $\mathrm{OH}^{-}$, que por sua vez poderiam reagir com o $\mathrm{Al}^{+3}$ resultando em formas hidroxiladas como $\mathrm{Al}(\mathrm{OH})^{2+}$. $\mathrm{RAIJ}$ (1988), explica entretanto que esse seria um processo reversível e limitado a solos ricos em óxidos de ferro e alumínio.

Alguns autores, a exemplo de BLACK \& CAMERON (1984); ERNANI (1986); MORELLI et al. (1987), não observaram diminuição no teor de alumínio em função da aplicação de gesso, apenas diminuição na saturação de $\mathrm{Al}^{+3}$ da CTC, concordando com o obtido neste trabalho. A redução na saturação de alumínio como consequência da elevação de bases é responsável por melhores condições para o desenvolvimento de raizes. OLMOS \& CAMARGO (1976), verificaram que teores elevados de saturação de alumínio, principalmente no horizonte $\mathrm{B}$, foram considerados responsáveis pelas baixas produções e respostas às adubações do milho no estado do Paraná. É importante considerar ainda, que o teor de $\mathrm{Al}^{3+}$ no solo nem sempre é correlacionado com fitotoxidez de alumínio porque fatores do meio como $\mathrm{pH}$, efeitos protetores de outros íons, força iônica, presença de quelatos e o próprio genótipo da planta podem atuar na resposta da planta ao alumínio (FURLANI \& BERTON, 1992). Nesse sentido a atividade do íon $\mathrm{Al}^{3+}$ seria um parâmetro mais indicado. Aumentos na 
força iônica da solução do solo ocorrem pela adição de gesso, sendo que esta seria a principal causa para a diminuição da atividade de $\mathrm{Al}^{3+}$, frequentemente observada em estudos de especiação iônica em solos onde se aplicou gesso (PAVAN et al., 1987).

Tabela 50. Médias dos valores de $\mathrm{pH}, \mathrm{H}^{+}, \mathrm{Al}^{+3}$, soma de bases (S); capacidade de troca catiônica (T), saturação em bases (V) e saturação em alumínio (m) para os diversos tratamentos, em amostras de solo, retiradas da profundidade de 30 $60 \mathrm{~cm}$.

\begin{tabular}{|c|c|c|c|c|c|c|c|}
\hline Tratam. & $\mathrm{pH}$ & $\overline{\mathrm{H}^{+}}$ & $\mathrm{Al}^{+3}$ & $\mathrm{~S}$ & $\mathrm{~T}$ & $\mathrm{~V}$ & $\mathrm{~m}$ \\
\hline & & \multicolumn{4}{|c|}{ - } & \multicolumn{2}{|c|}{ 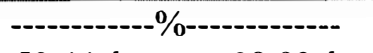 } \\
\hline Test & 4,42 & 7,13 & 5,03 & $12,40 \mathrm{f}$ & $24,57 \mathrm{c}$ & $50,44 \mathrm{abc}$ & $28,93 \mathrm{abc}$ \\
\hline Test $+\mathrm{G}$ & 4,30 & 8,33 & 6,43 & $14,03 \mathrm{def}$ & $28,80 \mathrm{~cd}$ & $48,67 \mathrm{abc}$ & $31,42 \mathrm{abc}$ \\
\hline $\mathrm{NCa}_{1}$ & 3,62 & 8,13 & 7,03 & $18,37 \mathrm{bcd}$ & $33,53 b c$ & $55,00 \mathrm{abc}$ & $27,47 \mathrm{abc}$ \\
\hline $\mathrm{NCa}_{2}$ & 4,29 & 9,30 & 6,87 & $15,50 \mathrm{cdef}$ & $31,67 \mathrm{bc}$ & $49,06 a b c$ & $30,68 \mathrm{abc}$ \\
\hline $\mathrm{NCa}_{1}+\mathrm{G}$ & 4,28 & 7,73 & 7,00 & $15,70 \mathrm{cdef}$ & $30,43 \mathrm{bcd}$ & $51,62 \mathrm{abc}$ & $30,82 \mathrm{abc}$ \\
\hline $\mathrm{NCa}_{2}+\mathrm{G}$ & 4,15 & 9,63 & 7,83 & $23,67 a$ & $41,13 a$ & $57,64 a b$ & $24,75 \mathrm{c}$ \\
\hline $\mathrm{NMg}_{\mathrm{I}}$ & 4,55 & 8,60 & 7,40 & $16,53 \mathrm{bcdef}$ & $32,5 b c$ & $50,76 \mathrm{abc}$ & $31,09 \mathrm{abc}$ \\
\hline $\mathrm{NMg}_{2}$ & 4,33 & 8,43 & 8,33 & $17,93 \mathrm{bcde}$ & $34,70 \mathrm{abc}$ & $51,77 \mathrm{abc}$ & $31,70 \mathrm{abc}$ \\
\hline $\mathrm{NMg}_{1}+\mathrm{G}$ & 4,37 & 9,47 & 7.17 & $15,93 \mathrm{cdef}$ & $32,56 \mathrm{bc}$ & $48,88 \mathrm{abc}$ & $31,05 \mathrm{abc}$ \\
\hline $\mathrm{NMg}_{2}+\mathrm{G}$ & 4,44 & 7,17 & 5,33 & $19,33 \mathrm{abc}$ & $31,83 \mathrm{bc}$ & $60,92 a$ & $21,53 \mathrm{c}$ \\
\hline $\mathrm{SA}_{1}$ & 4,26 & 9,13 & 8,10 & $11,30 \mathrm{f}$ & $28,53 \mathrm{~cd}$ & $39,4 \mathrm{lc}$ & $42,28 \mathrm{a}$ \\
\hline $\mathrm{SA}_{2}$ & 4,42 & 8,53 & 6,80 & $16,43 \mathrm{cdef}$ & $31,77 \mathrm{bc}$ & $51,82 \mathrm{abc}$ & $26,20 b c$ \\
\hline $\mathrm{SA}_{1}+\mathrm{G}$ & 4,26 & 10,13 & 7,53 & $16,37 \mathrm{cdef}$ & $34,03 \mathrm{bc}$ & $48,20 \mathrm{abc}$ & $31.53 \mathrm{abc}$ \\
\hline $\mathrm{SA}_{2}+\mathrm{G}$ & 4,66 & 8,07 & 6,83 & $21,77 \mathrm{ab}$ & $36,7 a b$ & $59,27 \mathrm{a}$ & $24,36 \mathrm{c}$ \\
\hline $\mathrm{SN}_{1}$ & 4,27 & 8,73 & 7,83 & $15,37 \mathrm{cdef}$ & $31,93 \mathrm{bc}$ & $48,00 \mathrm{abc}$ & 33,9 labc \\
\hline $\mathrm{SN}_{2}$ & 4,19 & 9,63 & 8,46 & $11,4 \mathrm{f}$ & $29,53 \mathrm{~cd}$ & $39,04 \mathrm{c}$ & $42,31 \mathrm{a}$ \\
\hline $\mathrm{SN}_{1}+\mathrm{G}$ & 4,17 & 9,00 & 8,60 & $12,70 \mathrm{ef}$ & $30,30 \mathrm{bcd}$ & $41,95 b c$ & $40.36 a b$ \\
\hline $\mathrm{SN}_{2}+\mathrm{G}$ & 4,44 & 8,50 & 7,73 & $15,90 \mathrm{cdef}$ & $32,13 b c$ & $49,80 \mathrm{abc}$ & $32,57 \mathrm{abc}$ \\
\hline $\begin{array}{l}\mathrm{F} \\
\mathrm{CV}(\%)\end{array}$ & $\begin{array}{r}\text { n.s. } \\
10,08\end{array}$ & $\begin{array}{c}\text { n.s. } \\
15,26\end{array}$ & $\begin{array}{r}\text { n.s. } \\
17.01\end{array}$ & $\begin{array}{l}11,14^{* *} \\
10,58\end{array}$ & $\begin{array}{l}6,96 * * \\
7,18\end{array}$ & $\begin{array}{c}3,98^{* *} \\
10,34\end{array}$ & $\begin{array}{l}3,92 * * \\
16,13\end{array}$ \\
\hline $\begin{array}{l}\text { CV (\%) } \\
\text { dms }(5 \%)\end{array}$ & $\begin{array}{r}10,08 \\
1,33 \\
\end{array}$ & $\begin{array}{r}15,26 \\
4,06\end{array}$ & $\begin{array}{r}17,01 \\
3,79\end{array}$ & $\begin{array}{r}5,26 \\
5,26\end{array}$ & 7,1 & $\begin{array}{l}15,34 \\
15,98\end{array}$ & $\begin{array}{l}10,13 \\
15,54\end{array}$ \\
\hline
\end{tabular}


Por adicionar cálcio, a aplicação de gesso aumentou o parâmetro soma de bases e CTC até a profundidade de $90 \mathrm{~cm}$ (Tabelas 46, 51 e 56). A saturação em bases foi significativamente aumentada apenas nas profundidades de $30-60$ e 60-90 cm como efeito do gesso. Aumentos na CTC e soma de bases foram observados até $75 \mathrm{~cm}$ de profundidade no trabalho de MORELLI et al. (1987), entretanto no trabalho de REEVE \& SUMNER (1972), a CTC não se alterou porque a adição de cálcio foi similar à perda de $\mathrm{Al}^{3+}$ do solo.

Tabela 51. Médias dos valores de $\mathrm{pH} ; \mathrm{H}^{+} ; \mathrm{Al}^{+3}$; soma de bases (S); capacidade de troca catiônica $(\mathrm{T})$; saturação em bases (V) e saturação em Al, obtidos em amostras de solo retiradas da profundidade $30-60 \mathrm{~cm}$, considerando a aplicação de gesso, independente das doses ou fontes de nitrogênio.

\begin{tabular}{|c|c|c|c|c|c|c|c|}
\hline Tratamentos & $\mathrm{pH}$ & $\overline{\mathrm{H}^{+}}$ & $\mathrm{Al}^{+3}$ & $\mathrm{~S}$ & $\mathrm{~T}$ & $\mathrm{~V}$ & $\overline{\mathrm{m}}$ \\
\hline & ----- & -..-- & $\mathrm{nmol}_{\mathrm{c}} / \mathrm{dr}$ & --.-----. & ---- & \multicolumn{2}{|c|}{ - } \\
\hline sem gesso & 4,24 & 8,81 & 7,60 & $15,36 \mathrm{~b}^{+}$ & $31,77 \mathrm{~b}$ & $48,11 \mathrm{~b}$ & $33,62 a$ \\
\hline com gesso & 4,35 & 8,71 & 7,25 & $17,67 \mathrm{a}$ & $33,64 a$ & $52,28 \mathrm{a}$ & $29,62 b$ \\
\hline $\mathrm{F}$ & n.s. & n.s. & n.s. & $22,55^{* *}$ & $7,67 * *$ & $7,35 * *$ & $7,47^{* *}$ \\
\hline cv (\%) & 10,69 & 15,46 & 17,47 & 10,21 & 7,1 & 10,63 & 16.05 \\
\hline $\mathrm{dms}(5 \%)$ & 0,27 & 0,79 & 0,76 & 0,99 & 1,37 & 3,15 & 2,99 \\
\hline
\end{tabular}

**Valores de $\mathrm{F}$ significativos a $1 \%$ de probabilidade

+ Médias seguidas de mesma letra não diferem estatisticamente entre si (Tukey 5\%)

Tabela 52. Médias dos valores de $\mathrm{pH} ; \mathrm{H}^{+} ; \mathrm{Al}^{+3}$; soma de bases (S); capacidade de troca catiônica (T); saturação em bases (V) e saturação em alumínio (m), obtidos em amostras de solo retiradas da profundidade de $30-60 \mathrm{~cm}$, considerando as fontes de $\mathrm{N}$, independentemente das doses de $\mathrm{N}$ ou da aplicação de gesso.

\begin{tabular}{|c|c|c|c|c|c|c|c|}
\hline Tratam. & $\mathrm{pH}$ & $\mathrm{H}^{+}$ & $\mathrm{Al}^{+3}$ & $\mathrm{~S}$ & $\mathrm{~T}$ & $\mathrm{~V}$ & $\mathrm{~m}$ \\
\hline & \multicolumn{5}{|c|}{ - } & \multicolumn{2}{|c|}{ - $\%$} \\
\hline $\mathrm{NCa}$ & 4,09 & 8,70 & 7,18 & $18,31 \mathrm{a}^{+}$ & $34,19 \mathrm{a}$ & $53,33 a$ & $28,53 a$ \\
\hline $\mathrm{NMg}$ & 4,42 & 8,42 & 7,06 & $17,43 \mathrm{a}$ & $32,91 \mathrm{ab}$ & $53,08 \mathrm{a}$ & $28,84 b$ \\
\hline SA & 4,40 & 8,97 & 7,32 & $16,47 a$ & $32,75 \mathrm{ab}$ & $49,67 \mathrm{ab}$ & $31,93 \mathrm{ab}$ \\
\hline SN & 4,27 & 8,97 & 8,16 & $13,85 b$ & $30,97 b$ & $44,70 \mathrm{~b}$ & $37,29 a$ \\
\hline $\begin{array}{l}F \\
c v \% \\
d m s(5 \%)\end{array}$ & $\begin{array}{r}\text { n.s. } \\
10,69 \\
0,51\end{array}$ & $\begin{array}{r}\text { n.s. } \\
15,46 \\
1,51\end{array}$ & $\begin{array}{r}\text { n.s. } \\
17,47 \\
1,44\end{array}$ & $\begin{array}{c}15,69 * * \\
10,21 \\
1,87\end{array}$ & $\begin{array}{l}3,87 * \\
7,12 \\
2,59\end{array}$ & $\begin{array}{c}6,83 * * \\
10,63 \\
5,93\end{array}$ & $\begin{array}{c}7,78^{* *} \\
16,05 \\
5,64\end{array}$ \\
\hline
\end{tabular}

**Valores de $\mathrm{F}$ significativos a $1 \%$ de probabilidade

* Valores de F significativos a 5\% de probabilidade

+ Médias seguidas de mesma letra não diferem estatisticamente entre si (Tukey 5\%) 
Tabela 53. Médias dos valores de $\mathrm{pH} ; \mathrm{H}^{+} ; \mathrm{Al}^{+3}$; soma de bases (S); capacidade de troca catiônica (T); saturação em bases (V) e saturação em alumínio (m), em amostras de solo retiradas da profundidade de $30-60 \mathrm{~cm}$, considerando as doses de $\mathrm{N}$, independente das fontes de nitrogênio e da aplicação de gesso.

\begin{tabular}{|c|c|c|c|c|c|c|c|}
\hline Tratamento & $\overline{\mathrm{pH}}$ & $\mathrm{H}^{+}$ & $\mathrm{Al}^{+3}$ & $\bar{S}$ & $\bar{T}$ & $\overline{\mathrm{V}}$ & $\mathrm{m}$ \\
\hline & & \multicolumn{4}{|c|}{ - } & \multicolumn{2}{|c|}{ 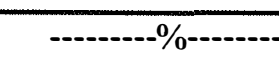 } \\
\hline $60 \mathrm{~kg} \mathrm{~N} \cdot \mathrm{ha}^{-1}$ & 4,22 & 8,87 & 7,58 & $15,28 \mathrm{~b}^{+}$ & $31,73 b$ & $47,98 \mathrm{~b}$ & $33,56 a$ \\
\hline $120 \mathrm{~kg} \mathrm{~N} \cdot \mathrm{ha}^{-1}$ & 4,37 & 8,66 & 7,27 & $17,74 \mathrm{a}$ & $33,68 \mathrm{a}$ & $52,41 \mathrm{a}$ & $29,68 b$ \\
\hline $\begin{array}{l}\mathrm{F} \\
\mathrm{cv}(\%) \\
\mathrm{dms}(5 \%)\end{array}$ & $\begin{array}{c}\text { n.s. } \\
10,69 \\
0,27\end{array}$ & $\begin{array}{l}\text { n.s. } \\
15,46 \\
0,80\end{array}$ & $\begin{array}{c}\text { n.s. } \\
17,47 \\
0,76\end{array}$ & $\begin{array}{c}25,57 * * \\
10,21 \\
0,99\end{array}$ & $\begin{array}{l}8,37 * * \\
7,12 \\
1,37\end{array}$ & $\begin{array}{c}8,30^{* *} \\
10,63 \\
3,15\end{array}$ & $\begin{array}{c}7,03^{*} \\
16,05 \\
2,99\end{array}$ \\
\hline
\end{tabular}

**Valores de $\mathrm{F}$ significativos a $1 \%$ de probabilidade

*Valores de $\mathrm{F}$ significativos a $5 \%$ de probabilidade

+ Médias seguidas de mesma letra não diferem estatisticamente entre si (Tukey 5\%)

Tabela 54. Valores do teste F a 5 ou 1\% de probabilidade para as interações entre gesso, fonte e dose de nitrogênio para os parâmetros: valores de $\mathrm{pH} ; \mathrm{H}^{+} ; \mathrm{Al}^{+3}$; soma de bases (S); capacidade de troca catiônica (T); saturação em bases (V) e saturação em alumínio (m); em amostras de solo retiradas da camada de 30$60 \mathrm{~cm}$ de profundidade.

\begin{tabular}{lccccccc}
\hline Interação & $\mathrm{pH}$ & $\mathrm{H}^{+}$ & $\mathrm{Al}^{+3}$ & $\mathrm{~S}$ & $\mathrm{~T}$ & $\mathrm{~V}$ & $\mathrm{~m}$ \\
\hline Dose N x Fonte N & n.s. & $3,00^{*}$ & n.s. & $5,58^{* *}$ & $\mathrm{n} . \mathrm{s}$. & $3,58^{*}$ & $\mathrm{n} . \mathrm{s}$. \\
Dose N x Gesso & n.s. & n.s. & n.s. & $26,98^{* *}$ & $6,11^{* *}$ & $9,74^{* *}$ & $6,56^{*}$ \\
Fonte N x Gesso & n.s. & n.s. & n.s. & $4,98^{* *}$ & $4,7^{* *}$ & n.s. & n.s. \\
Dose N x Fonte N x Gesso & n.s. & n.s. & n.s. & $6,15^{* *}$ & $6,47^{* *}$ & n.s. & n.s. \\
\hline
\end{tabular}

**Valores de $\mathrm{F}$ significativos a $1 \%$ de probabilidade

*Valores de $\mathrm{F}$ significativos a $5 \%$ de probabilidade 
Tabela 55. Médias dos valores de $\mathrm{pH}, \mathrm{H}^{+}, \mathrm{Al}^{+3}$, soma de bases (S); capacidade de troca catiônica (T), saturação em bases (V) e saturação em alumínio (m) para os diversos tratamentos, em amostras de solo, retiradas da profundidade de 60$90 \mathrm{~cm}$.

\begin{tabular}{|c|c|c|c|c|c|c|c|}
\hline Tratam. & $\overline{\mathrm{pH}}$ & $\overline{\mathrm{H}^{+}}$ & $\mathrm{Al}^{+3}$ & $\mathrm{~S}$ & $\mathrm{~T}$ & $\mathrm{~V}$ & $\mathrm{~m}$ \\
\hline & & \multicolumn{4}{|c|}{ - } & \multicolumn{2}{|c|}{ 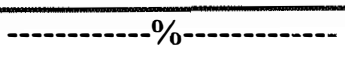 } \\
\hline Test & 4,35 & $5,43 \mathrm{~d}^{+}$ & $8,93 a$ & $10,83 \mathrm{bc}$ & $25,20 \mathrm{~cd}$ & $42,99 \mathrm{abc}$ & $45,19 \mathrm{ab}$ \\
\hline Test $+\mathrm{G}$ & 4,45 & $6,83 \mathrm{bcd}$ & $8,03 \mathrm{ab}$ & $10,10 \mathrm{bc}$ & $24,97 d$ & $40,39 \mathrm{abc}$ & $44,28 \mathrm{ab}$ \\
\hline $\mathrm{NCa}_{1}$ & 4,82 & $6,13 \mathrm{~cd}$ & $6,20 \mathrm{ab}$ & $12,63 \mathrm{ab}$ & $24,97 d$ & $49,63 \mathrm{a}$ & $34,20 b$ \\
\hline $\mathrm{NCa}_{2}$ & 4,49 & $8,73 \mathrm{abc}$ & $8,60 \mathrm{ab}$ & $8,03 c$ & $25,37 \mathrm{~cd}$ & $32,08 \mathrm{c}$ & $51,35 a$ \\
\hline $\mathrm{NCa}_{1}+\mathrm{G}$ & 4,54 & $7,86 \mathrm{abcd}$ & $7,23 \mathrm{ab}$ & $12,57 \mathrm{ab}$ & $27,66 \mathrm{abcd}$ & $45,46 \mathrm{ab}$ & $36,42 \mathrm{ab}$ \\
\hline $\mathrm{NCa}_{2}+\mathrm{G}$ & 4,28 & $8,80 \mathrm{abc}$ & $9,27 \mathrm{a}$ & $12,33 \mathrm{abc}$ & $30,40 \mathrm{abcd}$ & $40,69 \mathrm{abc}$ & $42,89 \mathrm{ab}$ \\
\hline $\mathrm{NMg}_{\mathrm{l}}$ & 4,33 & $8,27 \mathrm{abcd}$ & $8,43 \mathrm{ab}$ & $11,47 \mathrm{abc}$ & $28,17 \mathrm{abcd}$ & $40,73 \mathrm{abc}$ & $42,32 \mathrm{ab}$ \\
\hline $\mathrm{NMg}_{2}$ & 4,38 & $9,70 a b$ & $9,06 \mathrm{a}$ & $10,83 b c$ & $29,60 \mathrm{abcd}$ & $36,61 \mathrm{lbc}$ & $45,56 \mathrm{ab}$ \\
\hline $\mathrm{NMg}_{1}+\mathrm{G}$ & 4,10 & $9,83 \mathrm{ab}$ & $8,73 \mathrm{ab}$ & $12,20 \mathrm{abc}$ & $30,77 \mathrm{abc}$ & $39.63 \mathrm{abc}$ & $41,70 \mathrm{ab}$ \\
\hline $\mathrm{NMg}_{2}+\mathrm{G}$ & 4,53 & $8,37 \mathrm{abcd}$ & 7,33ab & $10,40 \mathrm{bc}$ & $26,10 \mathrm{bcd}$ & $39,88 \mathrm{abc}$ & $41,32 \mathrm{ab}$ \\
\hline $\mathrm{SA}_{1}$ & 4,30 & $8,63 \mathrm{abc}$ & $5,77 \mathrm{ab}$ & $11,73 \mathrm{abc}$ & $26,13 \mathrm{bcd}$ & $44,92 \mathrm{abc}$ & $32,80 \mathrm{~b}$ \\
\hline $\mathrm{SA}_{2}$ & 4,77 & $9,56 \mathrm{ab}$ & $8,60 \mathrm{ab}$ & $12,90 \mathrm{ab}$ & $31,07 \mathrm{ab}$ & $41,52 \mathrm{abc}$ & $39,98 \mathrm{ab}$ \\
\hline $\mathrm{SA}_{1}+\mathrm{G}$ & 4,34 & $9,17 \mathrm{abc}$ & $7,50 \mathrm{ab}$ & $12,03 \mathrm{abc}$ & $28,70 \mathrm{abcd}$ & $41,94 \mathrm{abc}$ & $38,59 a b$ \\
\hline $\mathrm{SA}_{2}+\mathrm{G}$ & 4,97 & $8,66 a b c$ & 7,67ab & $15,73 \mathrm{a}$ & $32,07 a$ & $48,98 a b$ & $32,83 b$ \\
\hline $\mathrm{SN}_{\mathrm{l}}$ & 4,14 & $10,00 \mathrm{a}$ & $8,93 a$ & $9,06 \mathrm{bc}$ & $28,00 \mathrm{abcd}$ & $32,36 \mathrm{c}$ & $49,61 \mathrm{a}$ \\
\hline $\mathrm{SN}_{2}$ & 4,51 & $9,47 \mathrm{ab}$ & $8,27 a b$ & $10,47 b c$ & $28,20 \mathrm{abcd}$ & $37,33 \mathrm{abc}$ & $43,94 a b$ \\
\hline $\mathrm{SN}_{1}+\mathrm{G}$ & 4,14 & $9,13 \mathrm{abc}$ & $8,87 a b$ & $10,23 b c$ & $28,23 \mathrm{abcd}$ & $36,26 b c$ & $46,41 \mathrm{ab}$ \\
\hline $\mathrm{SN}_{2}+\mathrm{G}$ & 4,09 & $8,77 \mathrm{abc}$ & $8,13 \mathrm{ab}$ & $11,57 \mathrm{abc}$ & $28,47 \mathrm{abcd}$ & 40,6 labc & $41,34 \mathrm{ab}$ \\
\hline $\begin{array}{l}\mathrm{F} \\
\mathrm{CV}(\%) \\
\text { dms (5\%) }\end{array}$ & $\begin{array}{c}\text { n.s. } \\
7,57 \\
1,04\end{array}$ & $\begin{array}{c}4,74^{* *} \\
11,74 \\
3,08 \\
\end{array}$ & $\begin{array}{c}2,93^{* *} \\
12,51 \\
3,12 \\
\end{array}$ & $\begin{array}{c}4,18^{* *} \\
12,50 \\
4,39 \\
\end{array}$ & $\begin{array}{l}4,32 * * \\
6,58 \\
5,67 \\
\end{array}$ & $\begin{array}{c}3,39 * * \\
11,89 \\
15,28\end{array}$ & $\begin{array}{l}3,87^{* *} \\
10,32 \\
12,98 \\
\end{array}$ \\
\hline
\end{tabular}

**Valores de $\mathrm{F}$ significativos a $1 \%$ de probabilidade

* Valores de $\mathrm{F}$ significativos a $5 \%$ de probabilidade

+Médias seguidas de mesma letra não diferem estatisticamente entre si (Tukey 5\%) 
As fontes nitrato de cálcio e nitrato de magnésio proporcionaram somas de bases, CTC e saturação de bases maiores na camada de $0-30 \mathrm{~cm}$, com consequente menor saturação em alumínio (Tabela 47). Na camada subsequente (Tabela 52), apenas o sulfnitro promoveu menores médias de soma de bases, CTC e V\% com consequente maior $\mathrm{m} \%$. Na profundidade de $60-90 \mathrm{~cm}$ (Tabela 57 ), verifica-se que os tratamentos com sulfato de amônio apresentaram as maiores médias de $\mathrm{S}, \mathrm{T}$ e $\mathrm{V} \%$ e a menor média de $\mathrm{m} \%$.

$\mathrm{O}$ efeito de doses de $\mathrm{N}$ pode ser verificado nas Tabelas 48 e 53 . A maior dose de $\mathrm{N}$ promoveu maiores médias de $\mathrm{S}, \mathrm{T}, \mathrm{V} \%$ e menor média de $\mathrm{m} \%$ nas profundidades de $0-30$ e $30-60 \mathrm{~cm}$. Na profundidade de 60-90 cm (Tabela 58), não ocorreu efeito significativo de doses de $\mathrm{N}$.

As interações entre os fatores estudados foram significativas em vários casos, conforme mostram as Tabelas 49, 54 e 59, indicando diferenças de fontes com ou sem a aplicação de gesso, ou doses dentro das fontes de N, ou mesmo na interação entre os três fatores. Neste caso, as interpretações ficam dificeis e necessitam de estudos mais detalhados. 
Tabela 56. Médias dos valores de $\mathrm{pH} ; \mathrm{H}^{+} ; \mathrm{Al}^{+3}$; soma de bases $(\mathrm{S})$; capacidade de troca catiônica (T); saturação em bases (V) e saturação em Al, obtidos em amostras de solo retiradas da profundidade $60-90 \mathrm{~cm}$, considerando a aplicação de gesso, independentemente das doses ou fontes de nitrogênio.

\begin{tabular}{|c|c|c|c|c|c|c|c|}
\hline Tratamento & $\mathrm{pH}$ & $\overline{\mathrm{H}^{+}}$ & $\mathrm{Al}^{+3}$ & $\bar{S}$ & $\mathrm{~T}$ & $\bar{V}$ & $\mathrm{~m}$ \\
\hline & & \multicolumn{4}{|c|}{ - } & \multicolumn{2}{|c|}{--- \% --- } \\
\hline sem gesso & 4,46 & 8.81 & 7,98 & $10,89 b^{+}$ & $27,69 b$ & $39.40 \mathrm{~b}$ & 42,47 \\
\hline com gesso & 4,43 & 8,82 & 8,09 & $12,13 a$ & $29,05 a$ & $41,88 \mathrm{a}$ & 40,19 \\
\hline $\begin{array}{l}\mathrm{F} \\
\mathrm{cr}(\%) \\
\mathrm{dms}(5 \%)\end{array}$ & $\begin{array}{l}\text { n.s. } \\
7,85 \\
0.21\end{array}$ & $\begin{array}{c}\text { n.s. } \\
11,70 \\
0.61\end{array}$ & $\begin{array}{r}\text { n.s. } \\
12,87 \\
0,61\end{array}$ & $\begin{array}{c}8.76^{*} \\
12,62 \\
0,86\end{array}$ & $\begin{array}{l}6.56^{*} \\
6.49 \\
1.09\end{array}$ & $\begin{array}{c}4,30^{*} \\
10,24 \\
2,45\end{array}$ & $\begin{array}{r}\text { n.s. } \\
12.31 \\
3,00\end{array}$ \\
\hline
\end{tabular}

* Valores de $\mathrm{F}$ significativos a $5 \%$ de probabilidade

+ Médias seguidas de mesma letra não diferem estatisticamente entre si (Tukey 5\%)

Tabela 57. Médias dos valores de $\mathrm{pH} ; \mathrm{H}^{+} ; \mathrm{Al}^{+3}$; soma de bases $(\mathrm{S})$; capacidade de troca catiônica (T); saturação em bases (V) e saturação em alumínio (m), obtidos em amostras de solo retiradas da profundidade de $60-90 \mathrm{~cm}$, considerando as fontes de $\mathrm{N}$, independente das doses de $\mathrm{N}$ ou da aplicação de gesso.

\begin{tabular}{|c|c|c|c|c|c|c|c|}
\hline Tratam. & $\overline{\mathrm{pH}}$ & $\mathrm{H}^{+}$ & $\mathrm{Al}^{+3}$ & $\bar{S}$ & $\mathrm{~T}$ & $\overline{\mathrm{V}}$ & $\mathrm{m}$ \\
\hline & & \multicolumn{4}{|c|}{ 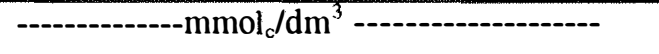 } & \multicolumn{2}{|c|}{------ \% -------- } \\
\hline $\mathrm{NCa}$ & 4,53 & $7,88 \mathrm{~b}$ & $7,82 \mathrm{ab}$ & $11,39 b$ & $27,10 \mathrm{~b}$ & $41,96 a b$ & $41,2 \mathrm{lab}$ \\
\hline NMg & 4,33 & $9,04 a$ & $8,39 \mathrm{ab}$ & $11,22 b$ & $28,66 \mathrm{ab}$ & $39,2 \mathrm{lbc}$ & $42,72 a$ \\
\hline SA & 4,59 & 9,0 lab & $7,38 b$ & $13,10 \mathrm{a}$ & $29,49 a$ & $44,75 a$ & $36,05 b$ \\
\hline SN & 4,34 & $9,34 a$ & $8,55 \mathrm{a}$ & $10,03 b$ & $28,22 \mathrm{ab}$ & $36,64 c$ & $45,33 \mathrm{a}$ \\
\hline $\begin{array}{l}\mathrm{F} \\
\mathrm{cv} \% \\
\mathrm{dms}(5 \%)\end{array}$ & $\begin{array}{c}\text { n.s. } \\
7,85 \\
3,88 \\
\end{array}$ & $\begin{array}{c}4,64^{* *} \\
11,70 \\
1,15 \\
\end{array}$ & $\begin{array}{c}3,22^{*} \\
12,87 \\
1,15 \\
\end{array}$ & $\begin{array}{c}7,59^{* *} \\
12,62 \\
1,61 \\
\end{array}$ & $\begin{array}{l}3,51^{*} \\
6,49 \\
2,05\end{array}$ & $\begin{array}{c}8,48^{* *} \\
10,24 \\
4,62\end{array}$ & $\begin{array}{c}7,08^{* *} \\
12,31 \\
5,65\end{array}$ \\
\hline
\end{tabular}

**Valores de $\mathrm{F}$ significativos a $1 \%$ de probabilidade

* Valores de $\mathrm{F}$ significativos a 5\% de probabilidade

+ Médias seguidas de mesma letra não diferem estatisticamente entre si (Tukey 5\%) 
Tabela 58. Médias dos valores de $\mathrm{pH} ; \mathrm{H}^{+} ; \mathrm{Al}^{+3}$; soma de bases $(\mathrm{S})$; capacidade de troca catiônica (T); saturação em bases (V) e saturação em alumínio (m), em amostras de solo retiradas da profundidade de $60-90 \mathrm{~cm}$, considerando as doses de $N$, independentemente das fontes de nitrogênio e da aplicação de gesso.

\begin{tabular}{|c|c|c|c|c|c|c|c|}
\hline Tratamentos & $\mathrm{pH}$ & $\mathrm{H}^{+}$ & $\overline{\mathrm{Al}^{+3}}$ & $\bar{S}$ & $T$ & $\mathrm{~V}$ & $\mathrm{~m}$ \\
\hline & & \multicolumn{4}{|c|}{ - } & \multicolumn{2}{|c|}{--------\%"------ } \\
\hline $60 \mathrm{~kg} \mathrm{~N} \cdot \mathrm{ha}^{-1}$ & $4,33 \mathrm{~b}^{+}$ & 8,63 & $7,71 \mathrm{~b}$ & 11,49 & 27,83 & 41,57 & 40,26 \\
\hline $120 \mathrm{~kg} \mathrm{~N} \cdot \mathrm{ha}^{-1}$ & $4,57 \mathrm{a}$ & 9,01 & $8,37 \mathrm{a}$ & 11,53 & 28,90 & 39,71 & 42,40 \\
\hline $\begin{array}{l}F \\
\operatorname{cv}(\%) \\
\text { dms }(5 \%)\end{array}$ & $\begin{array}{l}5,73 \\
7,85 \\
0,21\end{array}$ & $\begin{array}{l}\text { n.s. } \\
11,70 \\
0,61\end{array}$ & $\begin{array}{c}4,86^{*} \\
12,87 \\
0,61\end{array}$ & $\begin{array}{l}\text { n.s. } \\
12,62 \\
0,86\end{array}$ & $\begin{array}{l}\text { n.s. } \\
6,49 \\
1,09\end{array}$ & $\begin{array}{l}\text { n.s. } \\
10,24 \\
2,45\end{array}$ & $\begin{array}{l}\text { n.s. } \\
12,31 \\
3,00\end{array}$ \\
\hline
\end{tabular}

Tabela 59. Valores do teste $\mathrm{F}$ a 5 ou $1 \%$ de probabilidade para as interações entre gesso, fonte e dose de nitrogênio para os parâmetros: valores de $\mathrm{pH} ; \mathrm{H}^{+} ; \mathrm{Al}^{+3}$; soma de bases (S); capacidade de troca catiônica (T); saturação em bases (V) e saturação em alumínio $(\mathrm{m})$; em amostras de solo retiradas da camada de 60$90 \mathrm{~cm}$ de profundidade.

\begin{tabular}{lccccccc}
\hline Interação & $\mathrm{pH}$ & $\mathrm{H}^{+}$ & $\mathrm{Al}^{+3}$ & $\mathrm{~S}$ & $\mathrm{~T}$ & $\mathrm{~V}$ & $\mathrm{~m}$ \\
\hline Dose Nx Fonte N & 3,53 & n.s. & $5,67^{* *}$ & $7,1^{* *}$ & $5,21^{* *}$ & $7,92^{* *}$ & $5,89^{* *}$ \\
Dose Nx Gesso & n.s. & $6,00^{* *}$ & $4,62^{*}$ & n.s. & n.s. & $6,94^{*}$ & $5,14^{*}$ \\
Fonte N x Gesso & n.s. & n.s. & n.s. & n.s. & $3,23^{*}$ & n.s. & n.s. \\
Dose Nx Fonte N x Gesso & n.s. & n.s. & n.s. & n.s. & n.s. & n.s. & n.s. \\
\hline
\end{tabular}

**Valores de $\mathrm{F}$ significativos a $1 \%$ de probabilidade

* Valores de $\mathrm{F}$ significativos a $5 \%$ de probabilidade 


\subsection{Eficiência de Utilização do Nitrogênio}

A eficiência de utilização do nitrogênio estimada através do uso do ${ }^{15} \mathrm{~N}$ e de maneira indireta, bem como os dados de nitrogênio na planta proveniente do fertilizante constam da Tabela 60 . As percentagens de nitrogênio na planta provenientes dos fertilizantes (NPPF) praticamente não variaram em função da parte da planta a ser considerada, (folhas + colmos ou grãos) confirmando a grande mobilidade do nitrogênio na planta, fato comprovado e geralmente verificado em trabalhos $\operatorname{com}{ }^{15} \mathrm{~N}$, a exemplo de COELHO et al. (1991) e CABALLERO (1982). Nos tratamentos com gesso (Tabela 61) houve maior teor percentual de NPPF tanto nas folhas + colmos, como nos grãos, entretanto, ao se considerar os acúmulos de NPPF ( $\mathrm{g} / \mathrm{parcela}$ ), as diferenças foram significativas apenas para os grãos e para o total de $\mathrm{N}$ acumulado na planta.

A eficiência de utilização do fertilizante nitrogenado obtida através do uso do ${ }^{15} \mathrm{~N}$ forneceu estimativas mais coerentes do que a eficiência calculada de forma indireta através da diferença com o tratamento sem nitrogênio, como se verifica na Tabela 60. Como o acúmulo de $\mathrm{N}$ no tratamento testemunha + gesso foi consideravelmente elevado, houve provavelmente subestimativas da eficiência calculada de forma indireta para os tratamentos $\mathrm{NCa}+\mathrm{G}$ e $\mathrm{SA}+\mathrm{G}$. Da mesma forma, é possível que superestimativas tenham ocorrido para a eficiência nos tratamentos sem gesso. 
A eficiência de utilização de $\mathrm{N}$ pela planta medida pelo método da diferença é geralmente maior que a obtida pelo método isotópico, conforme observado por JANSON (1971); HAUCK \& BREMNER (1976); NEPTUNE (1977); VILLAS BÔAS (1990) devido ao "efeito priming" onde ocorre um aumento na mineralização do $\mathrm{N}$ em parcelas adubadas. Outra possibilidade é devida ao aumento do sistema radicular em função da adubação.

Comparando as estimativas da eficiência de utilização do fertilizante nitrogenado com a produção relativa (Tabela 4), verifica-se que os aumentos na produção de grãos foram 35,$0 ; 61,8 ; 46,6 ; 49,3 \%$ para os quatro tratamentos respectivamente, o que repete a tendência apresentada pela estimativa da eficiência calculada com o ${ }^{15} \mathrm{~N}$. É bem provável que a eficiência de utilização calculada com ${ }^{15} \mathrm{~N}$ se aproximasse bem mais dos dados de aumentos de produção relativa, se tivessemos levado em conta também o nitrogênio utilizado no sabugo e brácteas das espigas, que neste experimento não foi computado. De acordo com HANWAY (1963), não mais que $8 \%$ de todo o nitrogênio absorvido pelo milho ficam acumulados nessas partes da planta. No caso do cálculo de forma indireta o nitrogênio contido nessas partes (sabugo + palha da espiga) pouco interfere na estimativa, uma vez que não foi considerado tanto no tratamento em questão, como no tratamento testemunha.

Analisando a Tabela 61, verifica-se que a utilização de gesso fez com que a eficiência de utilização do fertilizante nitrogenado fosse superior, passando de $30 \%$ em média para os tratamentos sem gesso, para $43,4 \%$ para os tratamentos com gesso. 
Tabela 60. Médias dos valores de nitrogênio na planta proveniente do fertilizante-NPPF $\left(\%\right.$ e g.parcela $\left.{ }^{-1}\right)$ e eficiência de utilização do fertilizante nitrogenado - EUF (\%), para os tratamentos onde foi aplicado ${ }^{15} \mathrm{~N}$.

\begin{tabular}{|c|c|c|c|c|c|c|c|}
\hline \multirow[t]{3}{*}{ Tratam. } & \multicolumn{5}{|c|}{ NPPF } & \multicolumn{2}{|c|}{ EUF } \\
\hline & \multicolumn{2}{|c|}{ Folhas + Colmos } & \multicolumn{2}{|c|}{ Grãos } & \multirow{2}{*}{$\frac{\text { Total }}{\text { g.parcela }}$} & ${ }^{15} \mathrm{~N}$ & Indireto \\
\hline & $\%$ & g.parcela & $\%$ & g.parcela ${ }^{-1}$ & & 9 & \\
\hline $\mathrm{NCa}$ & $13,27 b^{+}$ & 19,94 & 12,65 & $19,65 b$ & $40,90 \mathrm{~b}$ & $24,43 b$ & 64,90 \\
\hline $\mathrm{NCa}+\mathrm{G}$ & $24,23 a$ & 27,88 & 24,28 & $45,32 \mathrm{a}$ & $73,20 \mathrm{a}$ & $45,18 \mathrm{a}$ & 48,97 \\
\hline $\mathrm{SA}$ & $15,75 b$ & 24,69 & 17,51 & $33,08 \mathrm{ab}$ & $57,77 \mathrm{ab}$ & $35,65 \mathrm{ab}$ & 69,90 \\
\hline $\mathrm{SA}+\mathrm{G}$ & $24,17 \mathrm{a}$ & 28,24 & 24,51 & $39,20 \mathrm{ab}$ & $69,11 \mathrm{a}$ & $41,63 \mathrm{ab}$ & 48,97 \\
\hline $\begin{array}{l}\mathrm{F} \\
\mathrm{CV}(\%) \\
\operatorname{dms}(5 \%)\end{array}$ & $\begin{array}{c}11,48 * * \\
15,05 \\
8,24\end{array}$ & $\begin{array}{c}\text { n.s. } \\
31,76 \\
22,63\end{array}$ & $\begin{array}{c}\text { n.s. } \\
35,60 \\
19,86\end{array}$ & $\begin{array}{c}5,85^{*} \\
22,92 \\
22,25\end{array}$ & $\begin{array}{c}6,43^{*} \\
16,38 \\
27,92\end{array}$ & $\begin{array}{l}5,49^{*} \\
18,29 \\
19,00\end{array}$ & $\begin{array}{c}\text { n.s. } \\
41,15 \\
66,39\end{array}$ \\
\hline
\end{tabular}

Tabela 61. Médias dos valores de nitrogênio na planta proveniente do fertilizante-NPPF $\left(\%\right.$ e g.parcela $\left.{ }^{-1}\right)$ e eficiência de utilização do fertilizante nitrogenado (\%), considerando o efeito do gesso independentemente das fontes de nitrogênio, para os tratamentos onde foi aplicado ${ }^{15} \mathrm{~N}$.

\begin{tabular}{|c|c|c|c|c|c|c|c|}
\hline \multirow[t]{3}{*}{ Tratam. } & \multicolumn{5}{|c|}{ NPPF } & \multicolumn{2}{|c|}{ EUF } \\
\hline & \multicolumn{2}{|c|}{ Folhas + Colmos } & \multicolumn{2}{|c|}{ Grãos } & \multirow{2}{*}{$\frac{\text { Total }}{\text { g.parcela }}$} & ${ }^{15} \mathrm{~N}$ & Indireto \\
\hline & $\%$ & g.parcela & $\%$ & g.parcela ${ }^{-1}$ & & \multicolumn{2}{|c|}{$\%$} \\
\hline sem gesso & $14,51 \mathrm{~b}^{+}$ & $22,31 \mathrm{a}$ & $15,08 \mathrm{~b}$ & $26,36 b$ & $48,68 b$ & $30,04 b$ & 67,90 \\
\hline com gesso & $24,40 \mathrm{a}$ & $28,06 a$ & $24,39 a$ & $42,26 a$ & $70,32 a$ & $43,4 \mathrm{la}$ & 47,57 \\
\hline $\mathrm{F}$ & $33,33^{* *}$ & n.s. & $8,30^{*}$ & $12,26^{*}$ & $11,88^{*}$ & $11,87^{*}$ & n.s. \\
\hline $\begin{array}{l}\mathrm{cv} \\
\mathrm{dms}\end{array}$ & $\begin{array}{r}15,05 \\
411\end{array}$ & $\begin{array}{l}31,76 \\
11,30\end{array}$ & $\begin{array}{r}35,60 \\
881\end{array}$ & 22,92 & $\begin{array}{l}16,38 \\
15,37\end{array}$ & $\begin{array}{l}18,29 \\
0,49\end{array}$ & $\begin{array}{l}41,29 \\
3367\end{array}$ \\
\hline
\end{tabular}

* Significativo a $5 \%$ de probabilidade

** Significativo a $1 \%$ de probabilidade

${ }^{+}$Médias seguidas de mesma letra não diferem estatisticamente entre si (Tukey 5\%) 
Na Tabela 62 apresenta-se os dados de nitrogênio no solo proveniente do fertilizante, e a percentagem do fertilizante aplicado que ainda permanecia no solo ao final do experimento nas três profundidades estudadas. Observa-se que os fertilizantes se distribuiram por todo o perfil, diminuindo sensivelmente com a profundidade. Quantidades expressivas de sulfato de amônio e nitrato de cálcio ainda permaneciam no solo ao final do experimento, sem que as plantas os tivessem utilizado. Vários fatores relativos ao solo e clima como textura ou teor de matéria orgânica, temperatura e baixa precipitação pluvial ou relativos ao próprio fertilizante, como forma ou dosagem do $\mathrm{N}$, são responsáveis pela mobilidade do nitrogênio no solo (TISDALE et al., 1985 e REICHARDT et al., 1979).

$\mathrm{Na}$ Tabela 63 compara-se o efeito do gesso independente das fontes, nas três profundidades estudadas. As parcelas onde o gesso foi aplicado apresentaram ao final do experimento, menores teores residuais de fertilizantes, concordando com a Tabela 61, que mostra um maior aproveitamento dos fertilizantes nitrogenados em função da aplicação de gesso.

A Figura 11 ilustra as percentagens dos fertilizantes nitrato de cálcio e sulfato de amônio que foram utilizadas pelas plantas de milho e que permaneceram no solo ao final do experimento. Por esta metodologia, verifica-se que quantidades substanciais de fertilizantes ficaram no solo e não foram utilizadas pelas plantas de milho. Quantidades entre $30 \%$ e 50\% foram perdidas do sistema analisado. 
Tabela 62. Médias dos valores de nitrogênio no solo proveniente do fertilizante-NSPF (\% e mg.kg solo ${ }^{-1}$ ) e percentagem do fertilizante aplicado que permaneceu nas camadas de $0-30 ; 30-60$ e $60-90 \mathrm{~cm}$ de profundidade, para os tratamentos onde foi aplicado ${ }^{15} \mathrm{~N}$.

\begin{tabular}{|c|c|c|c|c|}
\hline \multirow{2}{*}{$\begin{array}{c}\text { Profundidade } \\
\mathrm{cm}\end{array}$} & & \multicolumn{2}{|c|}{ NSPF } & \multirow{2}{*}{$\begin{array}{c}\begin{array}{c}\text { Fertilizante aplicado } \\
\text { remanescente }\end{array} \\
\%\end{array}$} \\
\hline & & $\%$ & mg.kg solo & \\
\hline & $\mathrm{NCa}$ & 2,07 & 21,93 & $14,79 \mathrm{~b}$ \\
\hline & $\mathrm{NCa}+\mathrm{G}$ & 1,25 & 14,78 & $8,60 c$ \\
\hline \multirow[t]{5}{*}{$0-30$} & SA & 2,07 & 23,25 & $22,20 \mathrm{a}$ \\
\hline & $\mathrm{SA}+\mathrm{G}$ & 1,25 & 15,79 & $14,79 \mathrm{~b}$ \\
\hline & $\mathrm{F}$ & n.s. & n.s. & $19,94^{* *}$ \\
\hline & $\mathrm{cv}$ & 28,99 & 24,99 & 14,81 \\
\hline & $\operatorname{dms}(5 \%)$ & 1,36 & 13,40 & 6,18 \\
\hline \multirow{7}{*}{$30-60$} & $\mathrm{NCa}$ & 0,74 & 6,95 & 5,91 \\
\hline & $\mathrm{NCa}+\mathrm{G}$ & 0,65 & 9,02 & 7,09 \\
\hline & SA & 0,85 & 8,58 & 7,30 \\
\hline & $\mathrm{SA}+\mathrm{G}$ & 0.70 & 7,70 & 6,72 \\
\hline & $\mathrm{F}$ & n.s. & n.s. & n.s. \\
\hline & $\mathrm{cv}$ & 21,43 & 19,67 & 10,42 \\
\hline & $\operatorname{dms}(5 \%)$ & 0,86 & 4,49 & 1,99 \\
\hline \multirow{7}{*}{$60-90$} & $\mathrm{NCa}$ & 0,60 & 5,08 & $3,02 \mathrm{a}$ \\
\hline & $\mathrm{NCa}+\mathrm{G}$ & 0,40 & 3,10 & $2,08 \mathrm{~b}$ \\
\hline & SA & 0.37 & 3,64 & $3,45 \mathrm{a}$ \\
\hline & $\mathrm{SA}+\mathrm{G}$ & 0,41 & 3,80 & $2,87 \mathrm{ab}$ \\
\hline & $\mathrm{F}$ & n.s. & n.s. & $9,49^{* *}$ \\
\hline & $\mathrm{cv}$ & 27,98 & 21,77 & 11,31 \\
\hline & $\operatorname{dms}(5 \%)$ & 0,35 & 2,41 & 0,91 \\
\hline
\end{tabular}

**Significativo a $1 \%$ de probabilidade

'Médias seguidas de mesma letra não diferem estatisticamente entre si (Tukey 5\%) 
Tabela 63. Médias dos valores de nitrogênio no solo proveniente do fertilizante-NSPF $\left(\%\right.$ e mg.kg solo $\left.{ }^{-1}\right)$ e percentagem do fertilizante aplicado que permaneceu nas camadas de 0-30; 30-60 e 60-90 cm de profundidade, considerando o efeito do gesso, independentemente das fontes de nitrogênio, para os tratamentos onde foi aplicado ${ }^{15} \mathrm{~N}$.

\begin{tabular}{|c|c|c|c|c|}
\hline \multirow{2}{*}{$\begin{array}{c}\text { Profundidade } \\
\mathrm{cm}\end{array}$} & & \multicolumn{2}{|c|}{ NSPF } & \multirow{2}{*}{$\begin{array}{c}\begin{array}{c}\text { Fertilizante aplicado } \\
\text { remanescente }\end{array} \\
\%\end{array}$} \\
\hline & & $\%$ & mg.kg solo & \\
\hline \multirow{5}{*}{$0-30$} & sem gesso & $2,07 \mathrm{a}^{+}$ & 19,57 & $17,82 \mathrm{a}$ \\
\hline & com gesso & $1,25 b$ & 18,35 & $11,69 b$ \\
\hline & $\mathrm{F}$ & $8,77 *$ & n.s. & $23,56 * *$ \\
\hline & $\mathrm{cr}$ & 28,99 & 24,99 & 14,80 \\
\hline & $\operatorname{dms}(5 \%)$ & 0,68 & 6,69 & 3,08 \\
\hline \multirow{5}{*}{$30-60$} & sem gesso & 0,79 & 8,14 & 7,01 \\
\hline & com gesso & 0,67 & 7,98 & 6.50 \\
\hline & $\mathrm{F}$ & n.s. & n.s. & n.s. \\
\hline & $\mathrm{cv}$ & 21,43 & 19,67 & 10,44 \\
\hline & $\operatorname{dms}(5 \%)$ & 0,43 & 2,24 & 0,99 \\
\hline \multirow{5}{*}{$60-90$} & sem gesso & 0,48 & $3,72 \mathrm{a}$ & 3,03 \\
\hline & com gesso & 0,39 & $4,09 \mathrm{a}$ & 2,56 \\
\hline & $\mathrm{F}$ & n.s. & n.s. & n.s. \\
\hline & $\mathrm{cv}$ & 27,98 & 21,77 & 13,07 \\
\hline & $\operatorname{dms}(5 \%)$ & 0,17 & 1,20 & 0,52 \\
\hline
\end{tabular}

**Significativo a $1 \%$ de probabilidade * Significativo a $5 \%$ de probabilidade

'Médias seguidas de mesma letra não diferem estatisticamente entre si (Tukey 5\%) 


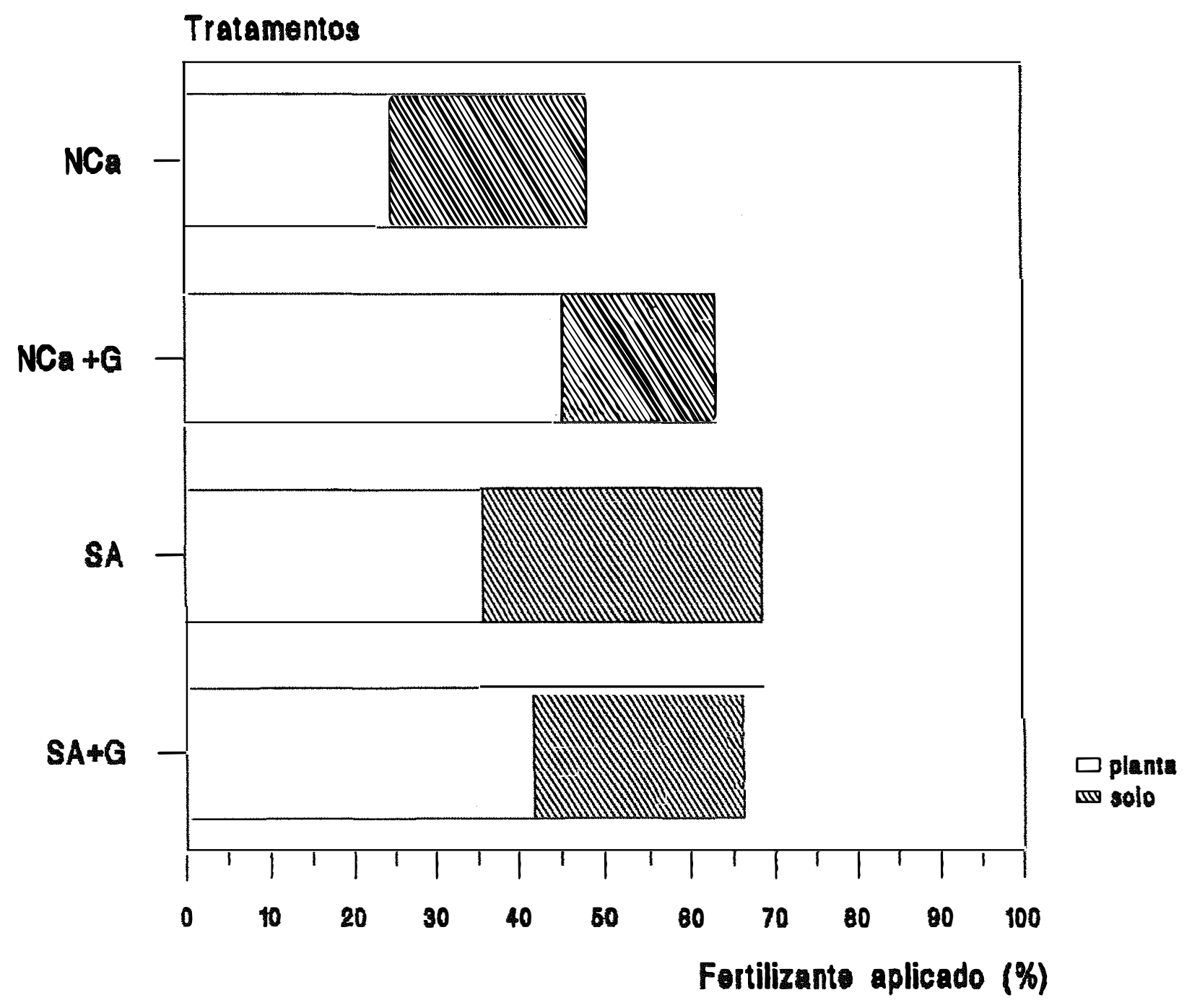

Figura 11. Percentagem dos fertilizantes nitrato de cálcio e sulfato de amônio que foram utilizados pelas plantas de milho e permaneceram no solo ao final do experimento. 


\section{CONCLUSÕES}

Através dos resultados obtidos nas condições deste experimento, pode-se concluir que :

- a adubação nitrogenada e a aplicação de gesso aumentaram a produção de grãos de milho "safrinha". O gesso foi responsável por aumentos de $14 \%$ sendo que, aliado à utilização de fertilizante nitrogenado promoveu aumento de 57\%;

- os fertilizantes nitrato de cálcio e sulfato de amônio foram as fontes nitrogenadas mais eficientes entre as estudadas, no aumento da produção de milho. A dosagem de 120 kg N.ha ${ }^{-1}$ promoveu aumentos de produção de $13,7 \%$ em relação à dose de 60 kgN.ha ${ }^{-1}$;

- a aplicação de gesso, independentemente das fontes nitrogenadas e das doses de $\mathrm{N}$, promoveu maiores acúmulos de $\mathrm{N}, \mathrm{P}, \mathrm{Ca}, \mathrm{Mg}$ e $\mathrm{S}$ nas plantas de milho (folhas+colmos +grãos), da ordem de 15, 24, 17, 19 e 25\%; 
- no solo o gesso aumentou os teores de $\mathrm{Ca} \mathrm{e} \mathrm{SO}_{4}{ }^{-2}$ do solo até $90 \mathrm{~cm}$ de profundidade. Promoveu aporte de $\mathrm{P}$ e K para a camada de 30-60 cm e de $\mathrm{Mg}$ para a camada de 60$90 \mathrm{~cm}$. A soma de bases e a CTC do solo foram aumentadas em todas as profundidades estudadas como resultado do efeito do gesso. A saturação da CTC em bases foi aumentada nas profundidades de 30 a $90 \mathrm{~cm}$;

- o teor de Al não foi alterado, mas a saturação da CTC em alumínio foi diminuída consideralvelmente até $60 \mathrm{~cm}$ de profundidade;

- a aplicação de gesso melhorou a eficiência de utilização dos fertilizantes nitrato de cálcio e sulfato de amônio de 24,4 e 35,6\% (sem aplicação de gesso), para 45 e $41,6 \%$ (com aplicação de gesso), respectivamente. 


\section{LITERATURA CITADA}

ADAMS, F. \& LUND, Z.F. Effect of chemical activity of soil solution aluminum on cotton root penetration of acid subsoils. Soil Science, Baltimore, 101: 193-198, 1966.

ADAMS, F. \& RAWAJFIH,Z. Basalunite and alunite: A possible cause of sulfate retention by acid soils. Soil Science Society American Journal, Madison, 41: 686-92, 1977.

ALCORDO, I.S. \& RECHEIGL, J.E. Phosphogypsum in Agriculture: A Review. Advances in Agronomy, New York, 49: 55-103,1993.

ANJOS, J.T. \& TEDESCO, M.J. Volatilização de amônia proveniente de dois fertilizantes nitrogenados aplicados em solos cultivados. Científica, Jaboticabal, 4(1): 49-55, 1976.

ALVA, A.K.; KERVEN, G.L.; EDWARDS, D.G.; ASHER, C.J. Reduction in toxic aluminum to plants by sulfate complexation. Soil Science, Baltimore, 152(5):351-59, 1991.

ALVA, A.K; SUMNER, M.E.; MILLER, W.P. Reactions of gypsum or phosphogypsum in highly weatheread acid subsoils. Soil Science Society American Journal, Madison, 54 (4): 993-8, 1990.

ALVES, H.M.R. Alterações de características químicas em profundidade pela aplicação superficial de calcário e gesso em um LVA câmbico distrófico textura média fase cerrado. Lavras, 1984, 84p. (Mestrado- Escola Superior de Agricultura de Lavras). 
BARBER, S.A. \& OLSON, R.A. Fertilizer use on corn. In: Nelson, L.B. et al. Changing patterns in fertilizer use. American Society of Agronomy, Madison, 1968. p. 163-88.

BARTL, P.E. \& ALBUQUERQUE, P.C.W. Alternativas para a reciclagem industrial do fosfogesso. In: SEMINÁRIO SOBRE O USO DE GESSO NA AGRICULTURA, 2., Uberaba, 1992. Anais. Brasília, IBRAFÓS, 1992. p.67-81.

BIANCHI, M.A.; CERETTA, C.A.; AITA, C. Alterações em características químicas de um Podzólico Vermelho-Escuro pela aplicação de gesso agrícola. In: CONGRESSO BRASILEIRO DE CIÊNCIA DO SOLO, 23., Porto Alegre, 1991, Anais. Campinas, SBCS, 1991. p. 234.

BLACK, A.S. \& CAMERON, K.C. Effect of leaching on soil properties and growth following lime and gypsum amendments to a soil with an acid subsoil. New Zealand Journal Agricultural Research, Wellington, 27: 195-200, 1984.

BOUYOCOS, G.J. The Hydrometer method for studying soils. Soil Science, Baltimore, 25(5):365-371, 1927.

BREMNER, J.M. Isotope ratio analysis of nitrogen in nitrogen-15, Tracer investigation. In: BLACK,C.A. et al. eds. Methods of soil analysis. Madison, American Society of Agronomy, v.2, p.1256-86, 1965.

CABALlERO, S.S.U. Dinâmica de nitrogênio no sistema solo planta na cultura do feijão (Phaseolus vulgaris,L.) cultivar carioca. Piracicaba, 1982. 154 p. (Doutorado - Escola Superior de Agricultura "Luiz de Queiroz").

CAMARGO, O.A.; MONIZ, A.C.; JORGE, J.A.; VALADARES, J.M.A.S. Métodos de análise química , mineralógica e física de solos. Campinas, IAC, 1986, 94 p. (boletim técnico, 106). 
CAMARGO, O.A. \& RAIJ, B. van. Movimento do gesso em amostras de latossolos com diferentes propriedades eletroquímicas. Revista Brasileira de Ciência do Solo, Campinas, 13:275-80, 1989.

CAMERON, R.S.; RITCHIE, G.S.P. \& ROBSON, A.D. Relative toxicities of inorganic aluminum complexes to barley. Soil Science Society of Agronomy, Baltimore, 50: 1231$36,1986$.

CARVALHO, L.J.C.B.; GOMIDE, R.L.; RODRIGUES, G.C.; SOUZA, D.M.G.; FREITAS, Jr, E. Resposta do milho à aplicação de gesso e déficit hídrico em solo de cerrado. In: SEMINÁRIO SOBRE O USO DE GESSO NA AGRICULTURA, 1., Brasilia, 1985.Anais Brasilia, IBRAFÓS, 1986. p. 61-83.

COELHO, A.M.; FRANÇA, G.E.; BAHIA A.F.C.; GUEDES, G.A.A. Balanço de nitrogênio ${ }^{15} \mathrm{~N}$ em um latossolo Vermelho-escuro, sob vegetação de cerrado, cultivado com milho. Revista Brasileira de Ciência do Solo, Campinas, 15(2): 187-93, 1991.

CRUZ, J.C.; CORREA, L.A.; SANS, L.M.A.; PEREIRA FILHO, I.A.; GUISCEM, J.M. Avaliação de cultivares de milho para "safrinha" na região centro-sul. In: SEMINÁRIO SOBRE A CULTURA DO MILHO "SAFRINHA", 2., Assis, 1994. Anais. Campinas, IAC, 1994. p.35-40.

DURING, C. \& COOPER, M. Sulphate nutrition and movement in a soil with high sulphate sorption characteristics. New Zealand Journal Experimental Agriculture, Wellington, 2:45-51. 1974.

ERNANI, P.R. Alterações em algumas características químicas na camada arável do solo pela aplicação de gesso agrícola sobre a superficie de campos nativos. Revista Brasileira Ciência do Solo, Campinas, 10: 241-5, 1986.

Food and Agriculture Organization-FAO. Maximizing the efficiency of fertilizer use by grain crops. Roma, 1980, 29p. (Fertilizer Bulletin no. 3.). 
FARINA, M.P.W. \& CHANNON, P. Acid-subsoil amelioration. II. Gypsum effects on growth and subsoil chemical properties. Soil Science Society American Journal, Madison, 52:175$80,1988$.

FURLANI, P.R. \& BERTON, R.S. Atividade de cálcio e aluminio e desenvolvimento radicular. In: SEMINÁRIO SOBRE O USO DE GESSO NA AGRICULTURA, 2., Uberaba, 1992. Anais. Brasília, IBRAFÓS, 1992.p.121-38.

HANWAY, J.J. Growth stages of corn Zea mays L. Agronomy Journal, Madison, 55(5):487$92,1963$.

HAUCK, R.D. \& BREMNER, J.M. Use of tracers for soil and fertilizer research. Advances in Agronomy, New York, 28:219-66, 1976.

International Atomic Energy Agency-IAEA - Tracer manual on crops and soil. Vienna, 1976. 277p. (Technical Reports, Series 171).

Instituto Brasileiro de Geografia e Estatística-IBGE. Anuário Estatístico do Brasil-1993. Rio de Janeiro, 1993. p.8-30.

JANSON,S.L. Use of ${ }^{15} \mathrm{~N}$ in studies of soil nitrogen. In: McLAREN,A.D. \& SKUJINS,J. Soil Biochemistry. New York, Marcel Dekker, 1971. v.2., p.129-66.

LARA-CABEZAS, W.A.R.; TRIVELIN, P.C.O.; BOARETTO, A.E.; MORENO, O.G. Volatilização de amônia de fontes nitrogenadas aplicadas em diferentes condições de umidade do solo. In: CONGRESSO BRASILEIRO DE CIÊNCIA DO SOLO,22., Recife, 1989.Anais. Campinas, SBCS, 1989. p.65.

LIANG, B.C. \& MACKENZIE, A.F. Corn yield, nitrogen uptake and nitrogen use efficiency as influenced by nitrogen fertilization. Canadian Journal of Soil Science, Ottawa, 74(2):23540, 1994. 
LIER, Q.J. van Programa para elaboração do balanço hídrico para culturas anuais e perenes. Manual do usuário. Piracicaba, ESALQ-USP, Depto. Agricultura, 58p. 1991.

LINDSAY, W.L.; PEEACH, M.; CLARK, J.S. Determination of Al ion activity in soil extracts. Soil Science Society of America Proceedings, Madison, 23:266-69, 1959.

MARIA, I.C.; ROSSETTO, R.; AMBROSANO, E.J.; CASTRO, O.M. Efeito da adição de diferentes fontes de cálcio no movimento de cátions em colunas de solo. Scientia Agricola, Piracicaba, 50(1):87-98, 1993.

MATHEWS,B.W. \& JOOST,R.E. The effect of leaching surface applied amendments on subsoil aluminum and alfafa growth in a Louisiana Ultisol. Communications in Soil Science and Plant Analysis, New York, 27(7\&8):567-81, 1990.

MORELLI, J.L.; NELLI, E.J.; DEMATTE, J.L.I.; DALBEN, A.E. Efeito do gesso e do calcário nas propriedades químicas de solos arenosos álicos e na produção de cana-de-açúcar. STAB Áçucar, Álcool e Subprodutos, Piracicaba, 6(2):24-31, 1987.

NEPTUNE, A.M.L Efeito de diferentes épocas e modos de aplicação do nitrogênio na produção do milho, na qualidade de proteína, na eficiência do fertilizante e na diagnose foliar, utilizando sulfato de amônio-N" ${ }^{15}$. Anais da Escola Superior de Agricultura "Luiz de Queiroz",Piracicaba, 34(1): 515-39, 1977.

NEPTUNE, A.M.L. \& CAMPANELLI, A. Efeito de épocas e modos de aplicação de sulfato de amônio- ${ }^{15} \mathrm{~N}$ e interação ${ }^{15} \mathrm{~N}$-fósforo- ${ }^{32} \mathrm{P}$, na quantidade e teores de $\mathrm{N}, \mathrm{P}, \mathrm{K}$ na planta e na folha do milho, na produção, na quantidade de proteína e eficiência do nitrogênio fertilizante convertido em proteína. Anais da Escola Superior de Agricultura "Luiz de Queiroz", Piracicaba, 37:1105-43, 1980. 
OATES, K.M. \& CALDWELL, A.G. Use of by-product gypsum to alleviate soil acidity. Soil Science Society of America Journal, Madison, 49: 915-18, 1985.

OLMOS, J.I.L. \& CAMARGO, M.N. Ocorrência de alumínio tóxico nos solos do Brasil, sua caracterização e distribuição. Ciência e Cultura, São Paulo, 28(2):171-80, 1976.

OLSEN, S.R.; CHAMPION, D.F.; PEARSON, C.; GOLUS, H. Corn response to enhanced ammonium supply. In: HUFFMAN, J.R.; Effects of enhanced ammonium diets on growth and yield of wheat and corn., Soil Science Society of America Proceedings, Madison, 54-69, 1991.

OMETTO, J.C. Registros e estimativas dos parâmetros metereológicos da região de Piracicaba,SP. Piracicaba,FEALQ . 1991.76p.

PAOLINELLI, M.T.; OLIVEIRA, P.M.; SANTOS, P.R.R.S.; LEANDRO, V.P.; MORAES, W.V. Aplicação direta do fosfogesso. In: SEMINÁRIO SOBRE O USO DO FOSFOGESSO NA AGRICULTURA, 1., Brasilia, 1985. Anais. Brasília, IBRAFÓS, 1986. p. 197-207.

PAVAN, M.A.; BINGHAM, F.T. Toxicity of aluminum to coffee seedlings grown in nutrient solution. Soil Science Society American Journal, Madison, 46: 993-7, 1982.

PAVAN,M.A. \& VOLKWEISS, S.J. Efeito do gesso nas relações solo-planta: principios . In: SEMINÁRIO SOBRE O USO DE FOSFOGESSO, 1.,Brasilia, 1986. Anais. Brasilia, 1986. p.107-118.

PAVAN, M.A.; BINGHAM, F.T.; PERYEA,F.J. Influence of calcium and magnesium salts on acid soil chemistry and calcium nutrition of apple. Soil Science Society of American Journal, Madison, 51: 1526-30, 1987. 
PAVAN, M.A.; BINGHAM, F.T.; PRATT, P.F. Toxicity of aluminum to coffee in ultisols and oxisols amended with $\mathrm{CaCO}_{3}, \mathrm{MgCO}_{3}$ and $\mathrm{CaSO}_{4} \cdot 2 \mathrm{H}_{2} \mathrm{O}$. Soil Science Society of American Journal, Madison, 46:1201-1207, 1982.

PAVAN, M.A.; BINGHAM, F.T.; PRATT, P.F. Redistribution of exchangeable calcium, magnesium and aluminum following lime or gypsum applications to a Brazilian Oxisol. Soil Science Society of American Journal, Madison, 48:33-38, 1984.

QUAGGIO, J.A. Resposta das culturas de milho e soja à aplicação de calcário, gesso e movimento de íons em solos do estado de São Paulo. In: SEMINÁRIO SOBRE O USO DE GESSO NA AGRICULTURA, 2., Uberaba, 1992. Anais. Brasília, IBRAFÓS, 1992. p.241-62.

QUAGGIO, J.A.; DECHEN, A.R.; RAIJ, B. van. Efeitos da aplicação de calcário e gesso sobre a produção de amendoim e lixiviação de bases no solo. Revista Brasileira de Ciência do Solo, Campinas, 6:189-194, 1982.

RABUFETTI, A. \& KAMPRATH, E.J. Yield, N and S content of corn as affected by $\mathrm{N}$ and S fertilization on Coastal Plain Soils. Agronomy Journal, Madison, 69(5):785-88, 1977.

RAIJ, B. van. Gesso agrícola na melhoria do ambiente radicular no subsolo. São Paulo, ANDA, 1988. 88p.

RAIJ, B. van. Melhoria do ambiente radicular do subsolo. In: SIMPÓSIO AVANÇADO DE SOLOS E NUTRIÇÃO DE PLANTAS, 2., Piracicaba, 1989. Anais. Campinas, Fundação Cargill, 1989. p.117-48.

RAIJ, B. van \& CAMARGO, O.A. Influência de bases trocáveis na lixiviação de potássio em colunas de solo. In: CONGRESSO BRASILEIRO DE CIÊNCIA DO SOLO, 14., Santa Maria, 1973. Anais. Campinas, SBCS, 1973.p.263-69. 
RAIJ,B van \& QUAGGIO,J.A. Métodos de análise de solo para fins de fertilidade. Campinas, IAC,1983, 40p. (IAC.Boletim técnico,81).

RAIJ, B. van; CANTARELLA, H.; FURLANI, P.R. Efeito na reação do solo, da adsorção de amônio e nitrato pelo sorgo, na presença e na ausência de gesso. Revista Brasileira de Ciência do Solo, Campinas, 12:131-136, 1988.

REEVE, N.G. \& SUMNER,M.E. Amelioration of subsoil acidity in Natal oxisols by leaching of surface applied amendments. Agrochemophysica, Pretoria, 4(1): 1-6, 1972.

REICHARDT, K.; LIBARDI, P.L.; VICTORIA, R.L.; VIEGAS, G.P. Dinâmica de N num solo cultivado com milho. Revista Brasileira de Ciência do Solo, Campinas, 3(1): 17-20, 1979.

RITCHEY, K.D.; SOUSA, D.M.G.; LOBATO, E.; CORREA, O. Calcium leaching to increase rooting depth in a Brazilian savannah oxisol. Agronomy Journal, Madison 72(1):40-44, 1980 .

ROSOLEM, C.A. \& MACHADO, J.R. Efeitos da calagem e gessagem na produção de algodão e lixiviação de bases em dois latossolos. Revista Brasileira de Ciência do Solo, Campinas, 8(2):103-109, 1984.

SANTOS, H.L.; VASCONCELLOS, C.A.; BAHIA FILHO, A.F.C.; FRANÇA, G.E.; GARCIA, J.C. Exigências nutricionais e uso de fertilizantes e corretivos na cultura do milho. In: SIMPÓSIO SOBRE A PRODUTIVIDADE DO MILHO,1,,Londrina,1983. Anais. Londrina, IAPAR, 1983. p.81-98.

SARRUGE, J.R. \& HAAG, H.P. Análises químicas em plantas. Piracicaba, ESALQ, Departamento de Química, 1974. 56p. 
SAWAZAKI, E.; DUARTE, A.P.; MARUNO, J.; BORTOLETTO, N.; GALLO, P.B.; GARCIA, L.L.C.; VONTINHO, R.G.; SILVA, J.G.M.; BIANCHIBI, M.T.; SALZEDAS, M.L.V.M.; DONA, S. Avaliação de cultivares de milho "safrinha" no estado de São Paulo. In: SEMINÁRIO SOBRE A CULTURA DO MILHO "SAFRINHA", 2., Assis, 1994. Anais. Campinas, IAC, 1994. p.41-8.

SAYRE, J.D. Mineral accumulation in corn. Plant Phisiology , Lancaster, 23:267-81,1948.

SMYTH, T.J. \& CRAVO, M.S. Aluminum and calcium constrains to continuous crop production in a Brazilian Amazon oxisol. Agronomy Journal, Madison, 84(5):843-850, 1992.

SOUSA, D.M.G. \& RITCHEY, K.D. Correção de acidez sub-superficial: Uso de gesso no solo de cerrado. In: SIMPÓSIO AVANÇADO DE QUÍMICA E FERTILIDADE DO SOLO, 1., Piracicaba, 1986,Anais. Campinas, Fundação Cargill, 1986. p.91-113.

SOUSA, D.M.G. \& RITCHEY, K.D. Uso de gesso no solo de cerrado. In: SEMINÁRIO SOBRE O USO DE GESSO NA AGRICULTURA, 2., Uberaba, 1992. Anais Brasília,IBRAFÓS, 1992. p. 277-306.

SOUSA, D.M.G.; LOBATO, E.; RITCHEY, K.D.; REIN, T.A. Resposta de culturas anuais e leucena a gesso no cerrado. In: SEMINÁRIO SOBRE O USO DE GESSO NA AGRICULTURA, 2., Uberaba, 1992. Anais Brasília,IBRAFÓS, 1992. p.277-306.

SPOSITO,G. \& MATTIGOD, S.W. GEOCHEM: A computer program for the calculation of chemical equilibria in soil solution and other natural water systems. Kearney Foundation of Soil Science, University of Califormia, 1979. 1v.

SUMNER, M.E. Uso atual do gesso no mundo em solos ácidos. In: SEMINÁRIO SOBRE O USO DE GESSO NA AGRICULTURA, 2., Uberaba, 1992. Anais. Brasília,IBRAFÓS, 1992. p.7-40. 
SUMNER, M.E. Aluminum toxicity - A grown limiting factor in some Natal sands. South Africa Sugarcane Technologist Assoc. Proceedings, Pretoria, 44:1-6, 1970.

SUMNER, M.E.; SHAHANDEH, H.; BOUTON, J.; HAMME, L.J. Amelioration of an acid profile through deep liming and surface application of gypsum. Soil Science Society American Journal, Madison, 50:1254-1278, 1986.

TISDALE, S.L.; NELSON, W.L.; BEATON, J.D. Soil fertility and fertilizers, 4 ed., New York, McMillan, 1985.754p.

VILLAS BÔAS, R.L. Alternativas para aumento da recuperação do nitrogênio da uréia pelo milho (Zea mays, L.). Piracicaba, 1990, 78p. (Mestrado - Escola Superior de Agricultura "Luiz de Queiróz").

ZAPATA, F. Isotope techniques in soil fertility and plant nutrition studies. In: HARDARSON, G. ed. Use of nuclear techniques in studies of soil-plant relationships. Vienna, IAEA., 1990. p.61-127. (Training Course Series, 2).

ZONTA, E.P. \& MACHADO, A.A. Sanest- Sistema de análises estatísticas. Instituto de Zootecnia, Nova Odessa, Instituto de Zootecnia, s.d.

ZOTARELLI, E.M.M. Calagem e gessagem em uma areia quartzosa cultivada com cana-deaçúcar. Piracicaba, 1992. 73p. (Mestrado - Escola Superior de Agricultura "Luiz de Queiróz"). 